\title{
Improvements to
}

Technical Specifications

Surveillance Requirements

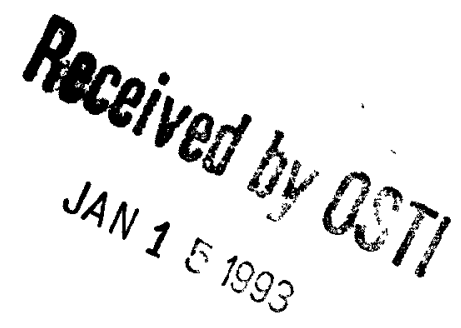

\section{U.S. Nuclear Regulatory Commission}

Office of Nuclear Reactor Regulation

R. Lobel, T. R. Tjader

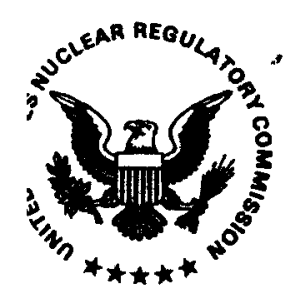




\section{AVAILABILITY NOTICE}

\section{Availability of Reference Materials Cited in NRC Publications}

Most documents cited in NRC publications will be available from one of the following sources:

1. The NRC Public Document Room, 2120 L Street, NW., Lower Level, Washington, DC 20555

2. The Superintendent of Documents, U.S. Government Printing Office, P.O. Box 37082, Washington, DC 20013-7082

3. The National Technical Information Service, Springfield, VA 22161

Although the listing that follows represents the majority of documents cited in NRC publications, it is not intended to be exhaustive.

Referenced documents available for inspection and copying for a fee from the NRC Public Document Room include NRC correspondence and internal NRC memoranda; NRC bulletins, circulars, information notices, inspection and investigation notices; licensee event reports; vendor reports and correspondence; Commission papers; and applicant and licensee documents and correspondence.

The following documents in the NUREG series are available for purchase from the GPO Sales Program: formal NRC staff and contractor reports, NRC-sponsored conference proceedings, international agreement reports, grant publications, and NRC booklets and brochures. Also available are regulatory guides. NRC regulations in the Code of Federal Regulations, and Nuclear Regulatory Commission Issuances.

Documents available from the National Technical Information Service include NUREG-series reports and technical reports prepared by other Federal agencies and reports prepared by the Atomic Energy Commission, forerunner agency to the Nuclear Regulatory Commission.

Documents available from public and special technical libraries include all open literature items, such as books, journal articles, and transactions. Federal Register notices, Federal and State legislation, and congressional reports can usually be obtained from these libraries.

Documents such as theses, dissertations, foreign reports and translations, and non-NRC conference proceedings are available for purchase from the organization sponsoring the publication cited.

Single copies of NRC draft reports are available free, to the extent of supply, upon written request to the Office of Administration, Distribution and Mail Services Section, U.S. Nuclear Regulatory Commission, Washington, DC 20555.

Copies of industry codes and standards used in a substantive manner in the NRC regulatory process are maintained at the NRC Library, 7920 Norfolk Avenue, Bethesda, Maryland, for use by the public. Codes and standards are usually copyrighted and may be purchased from the originating organization or, if they are American National Standards, from the American National Standards institute, 1430 Broadway, New York, NY 10018. 


\section{DISCLAIMER}

This report was prepared as an account of work sponsored by an agency of the United States Government. Neither the United States Government nor any agency Thereof, nor any of their employees, makes any warranty, express or implied, or assumes any legal liability or responsibility for the accuracy, completeness, or usefulness of any information, apparatus, product, or process disclosed, or represents that its use would not infringe privately owned rights. Reference herein to any specific commercial product, process, or service by trade name, trademark, manufacturer, or otherwise does not necessarily constitute or imply its endorsement, recommendation, or favoring by the United States Government or any agency thereof. The views and opinions of authors expressed herein do not necessarily state or reflect those of the United States Government or any agency thereof. 


\section{DISCLAIMER}

Portions of this document may be illegible in electronic image products. Images are produced from the best available original document. 


\section{Improvements to} Technical Specifications Surveillance Requirements

Manuscript Completed: May 1992

Date Published: December 1992

\section{R. Lobel, T. R. Tjader}

Division of Operational Events Assessment Office of Nuclear Reactor Regulation U.S. Nuclear Regulatory Commission Washington, DC 20555
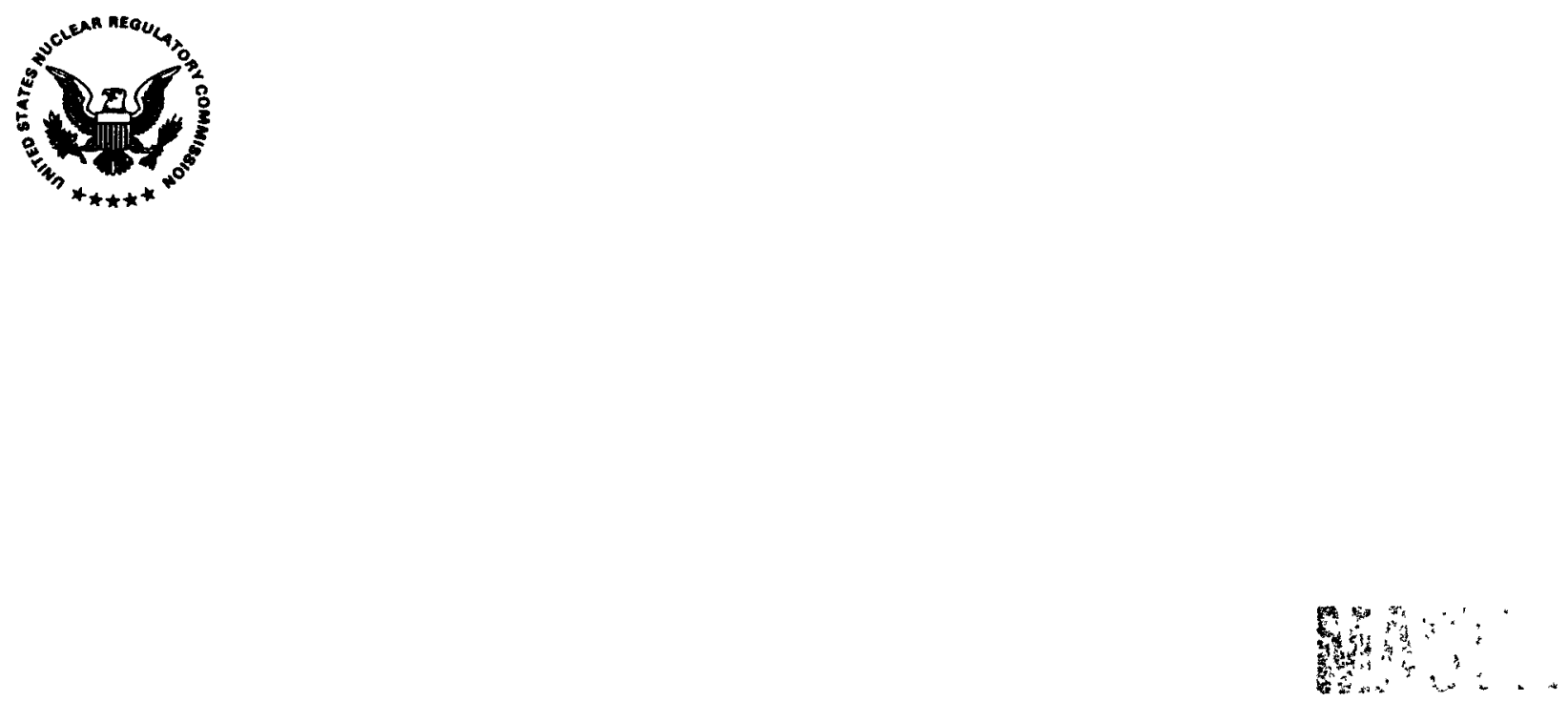



\begin{abstract}
In August 1983 an NRC task group was formed to investigate problems with surveillance testing required by Technical Specifications, and to recommend approaches to effect improvements. NUREG-1024 ("Technical Specifications-Enhancing Safety Impact") resulted, and it contained recommendations to review the basis for test frequencies; to ensure that the tests promote safety and do not degrade equipment; and to review surveillance tests so that they do not unnecessarily burden personnel.

The Technical Specifications Improvement Program

(TSIP) was established in December 1984 to provide the framework for rewriting and improving the Technical Specifications. As an element of the TSIP, all Technical Specifications surveillance requirements were comprehensively examined as recommended in NUREG-1024. The results of that effort are presented in this report. The study found that while some testing at power is essential to verify equipment and system operability, safety can be improved, equipment degradation decreased, and unnecessary personnel burden relaxed by reducing the amount of testing at power.
\end{abstract}





\section{CONTENTS}

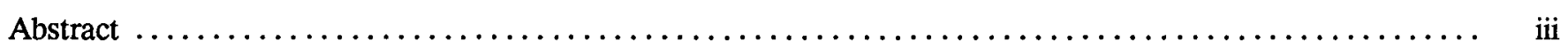

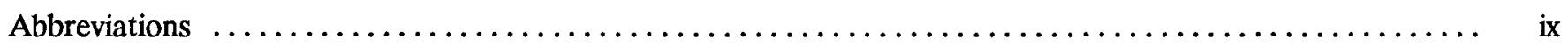

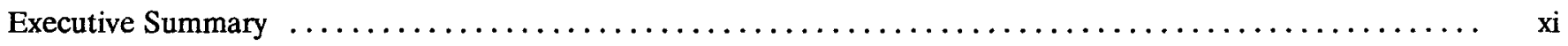

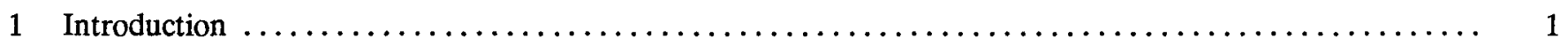

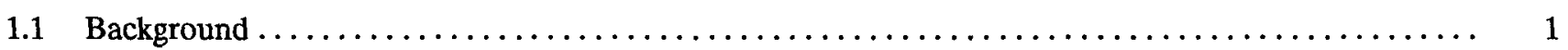

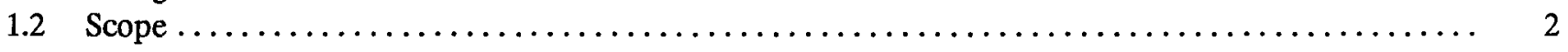

1.3 Qualitative Safety Assessment of Technical Specifications Surveillance Requirements ........... 4

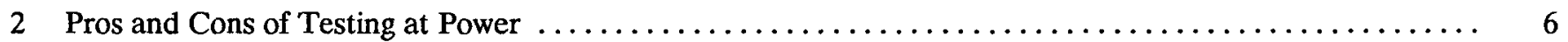

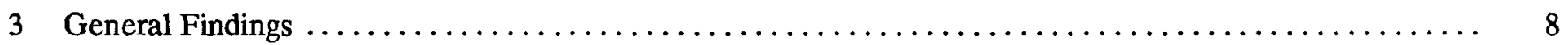

3.1 Magnitude of Surveillance Testing Required by Technical Specifications $\ldots \ldots \ldots \ldots \ldots \ldots \ldots \ldots$

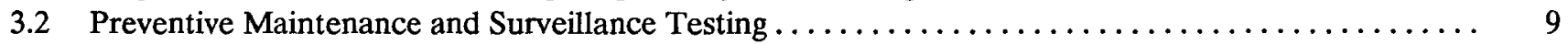

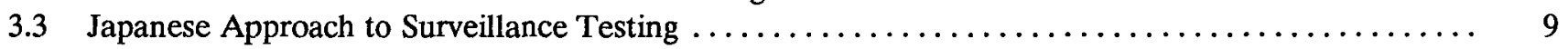

3.4 Technical Specifications and the ASME Code $\ldots \ldots \ldots \ldots \ldots \ldots \ldots \ldots \ldots \ldots \ldots \ldots \ldots \ldots \ldots$

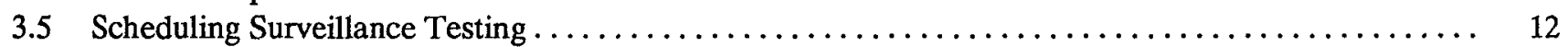

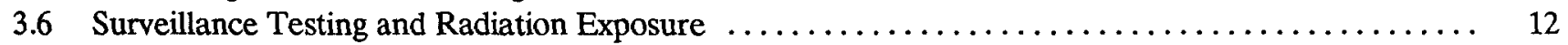

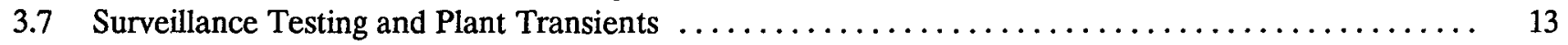

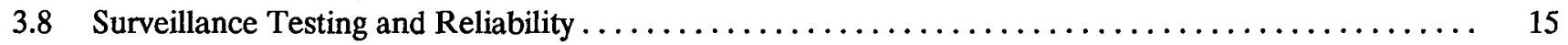

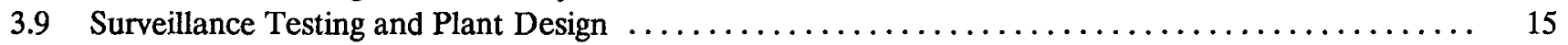

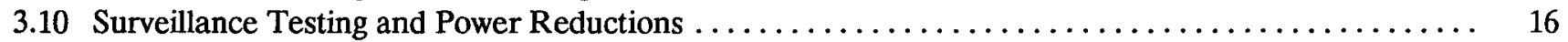

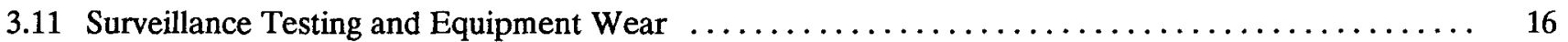

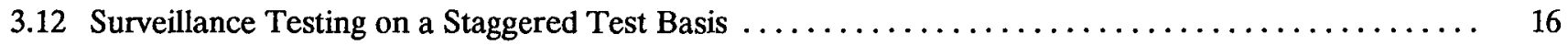

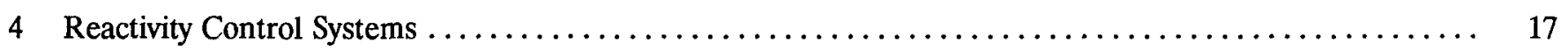

4.1 Moderator Temperature Coefficient Measurement (PWR) $\ldots \ldots \ldots \ldots \ldots \ldots \ldots \ldots \ldots \ldots \ldots \ldots$

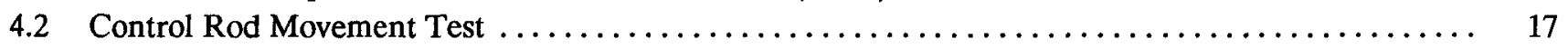

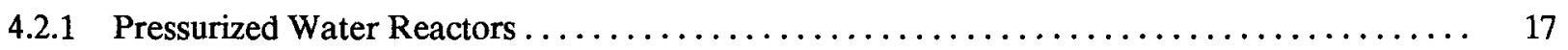

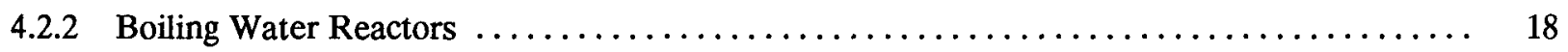

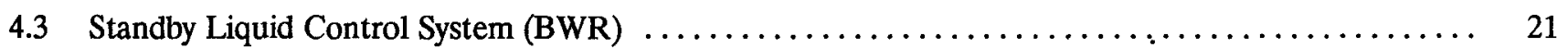

4.4 Closure Time Testing of Scram Discharge Volume Vent and Drain Valves (BWR) .......... 21

4.5 Reactor Scram Testing To Demonstrate Operability of Scram Discharge Volume Vent and

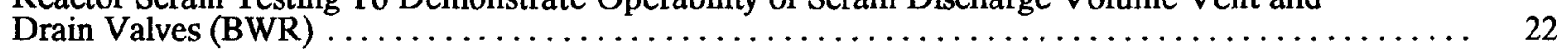

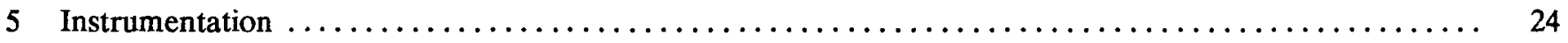

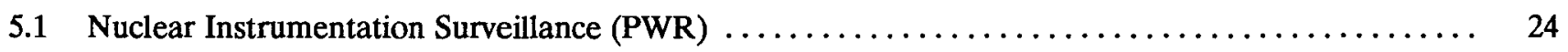

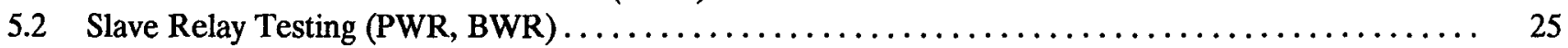

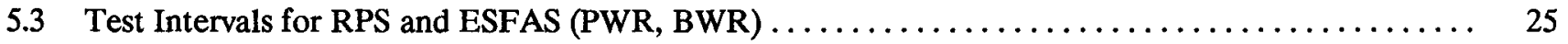

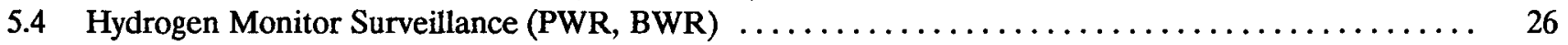

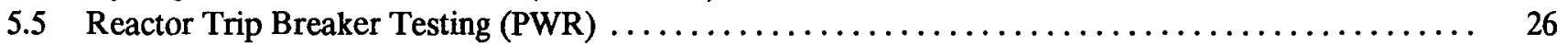

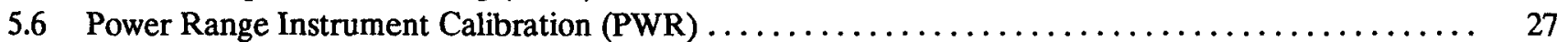

5.7 Control Element Assembly Calculator Surveillance (CE CPC PWR) $\ldots \ldots \ldots \ldots \ldots \ldots \ldots \ldots \ldots \ldots$

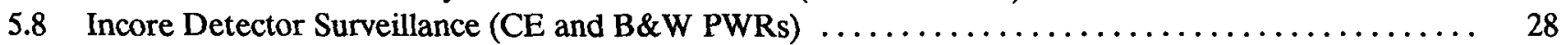

5.9 Response Time Testing of Isolation Actuation Instrumentation (PWR, BWR) $\ldots \ldots \ldots \ldots \ldots \ldots .29$ 
5.10 Source Range Monitor and Intermediate Range Monitor Surveillances (BWR) $\ldots \ldots \ldots \ldots \ldots \ldots . \ldots$

5.11 Calibration of Recirculation Flow Transmitters (BWR) $\ldots \ldots \ldots \ldots \ldots \ldots \ldots \ldots \ldots \ldots \ldots \ldots \ldots$

5.12 Autoclosure Interlocks: Removal of the LCO From the Technical Specifications (PWR, BWR) ... 31

5.13 Turbine Overspeed Protection System Testing (PWR, BWR) $\ldots \ldots \ldots \ldots \ldots \ldots \ldots \ldots \ldots \ldots . \quad 32$

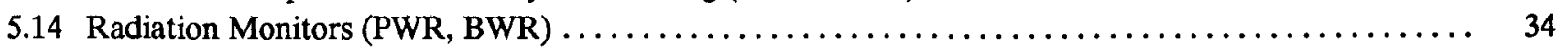

5.15 Radioactive Gas Effluent Monitor Calibration Standard (PWR, BWR) . . . . . . . . . . . 35

5.16 Intermediate Range Monitor and Average Power Range Monitor Channel Functional Tests

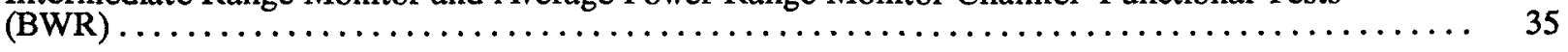

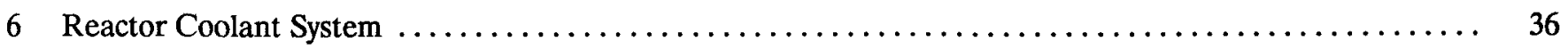

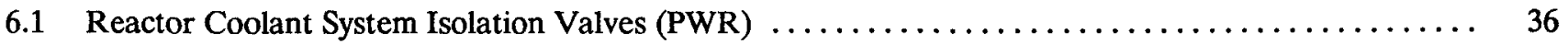

6.2 Power (or Pilot)-Operated Relief Valves and Block Valves (PWR) $\ldots \ldots \ldots \ldots \ldots \ldots \ldots \ldots \ldots \ldots$

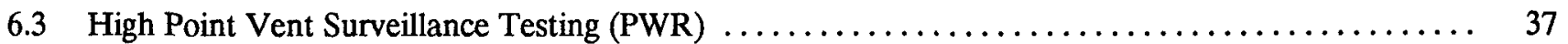

6.4 Low-Temperature Overpressure Protection (PWR) $\ldots \ldots \ldots \ldots \ldots \ldots \ldots \ldots \ldots \ldots \ldots \ldots \ldots$

6.5 Specific Activity of the Reactor Coolant $-100 / \bar{E}$ (PWR, BWR) $\ldots \ldots \ldots \ldots \ldots \ldots \ldots \ldots \ldots \ldots$

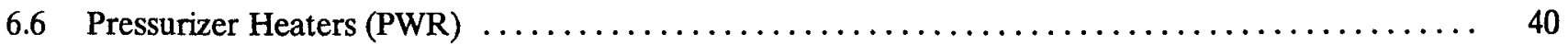

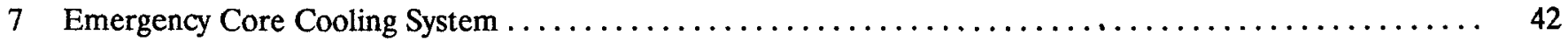

7.1 Surveillance of Boron Concentration in the Accumulator/Safety Injection Tank/Core Flood Tank

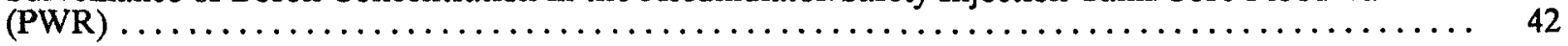

7.2 Verification That ECCS Lines Are Full of Water (Contain No Air) (PWR) .............. 42

7.3 Verification of Proper Valve Lineups of ECCS and Containment Isolation Valves (PWR, BWR) .... 43

7.4 Accumulator Water Level and Pressure Channel Surveillance Requirements (PWR) .......... 43

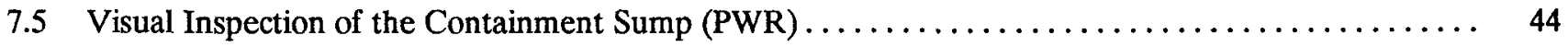

7.6 Verification of Boron Concentration in the Boron Injection Tank (Westinghouse PWR) ........ 44

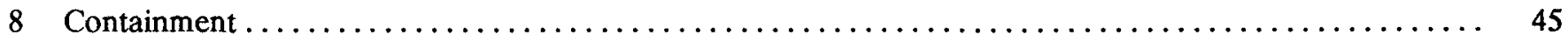

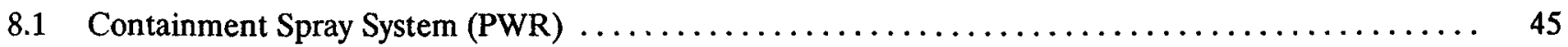

8.2 Containment Purge Supply and Exhaust Isolation Valves (PWR) $\ldots \ldots \ldots \ldots \ldots \ldots \ldots \ldots \ldots \ldots \quad 45$

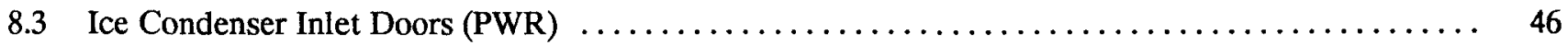

8.4 Testing Suppression Chamber to Drywell Vacuum Breakers (BWR) $\ldots \ldots \ldots \ldots \ldots \ldots \ldots \ldots \ldots .47$

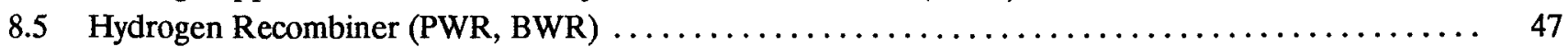

8.6 Sodium Tetraborate Concentration in Ice Condenser Containment Ice $\ldots \ldots \ldots \ldots \ldots \ldots \ldots \ldots .47$

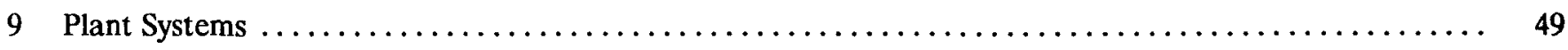

9.1 Auxiliary Feedwater Pump and System Testing (PWR) $\ldots \ldots \ldots \ldots \ldots \ldots \ldots \ldots \ldots \ldots \ldots \ldots$

9.2 Main Steam Line Isolation Valve (MSIV) Surveillance Testing $\ldots \ldots \ldots \ldots \ldots \ldots \ldots \ldots \ldots \ldots \quad 50$

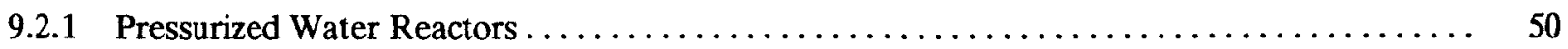

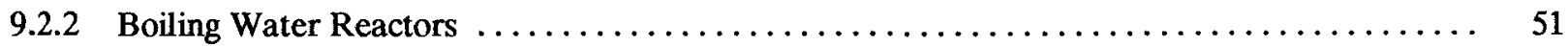

9.3 Control Room Emergency Ventilation System (PWR, BWR) $\ldots \ldots \ldots \ldots \ldots \ldots \ldots \ldots \ldots \ldots \ldots$

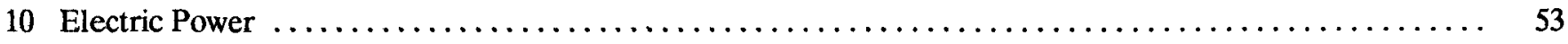

10.1 Emergency Diesel Generator Surveillance Requirements (PWR, BWR) $\ldots \ldots \ldots \ldots \ldots \ldots \ldots \ldots$

10.2 Battery Surveillance Requirements (PWR, BWR) $\ldots \ldots \ldots \ldots \ldots \ldots \ldots \ldots \ldots \ldots \ldots \ldots \ldots \ldots \ldots \ldots \ldots$ 


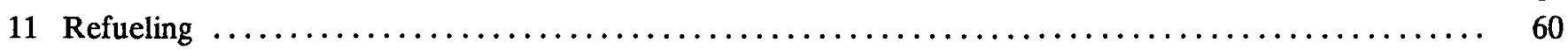

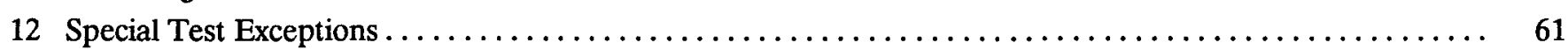

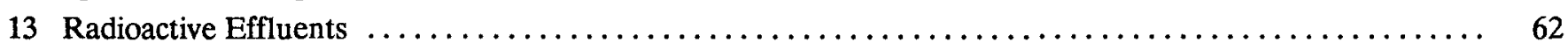

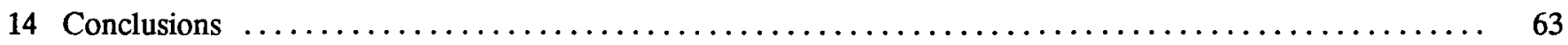

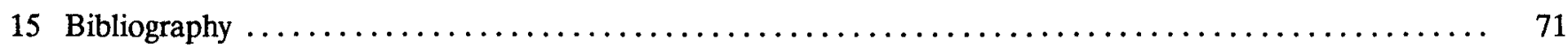

Appendix $\quad$ Routine Inspections (Surveillance Testing) at Japanese Power Plants $\ldots \ldots \ldots \ldots \ldots \ldots \ldots \ldots 77$

\section{Figure}

3.1 PWR trips attributed to surveillance testing, January $1986-$ July $1988 \ldots \ldots \ldots \ldots \ldots \ldots \ldots \ldots \ldots$

\section{Tables}

3.1 Number of surveillance tests required for RPS and ESFAS instrumentation currently, and number proposed in Westinghouse Owners Group topical report $\ldots \ldots \ldots \ldots \ldots \ldots \ldots \ldots \ldots \ldots \ldots \ldots \ldots \ldots \ldots$

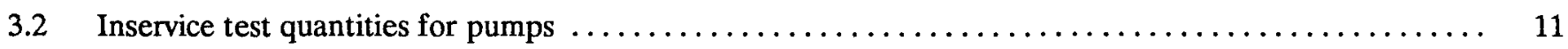

3.3 ASME Code, Section XI requirements for valves $\ldots \ldots \ldots \ldots \ldots \ldots \ldots \ldots \ldots \ldots \ldots \ldots \ldots \ldots \ldots$

3.4 Percentage of annual collective dose at LWRs by work function $\ldots \ldots \ldots \ldots \ldots \ldots \ldots \ldots \ldots \ldots \ldots$

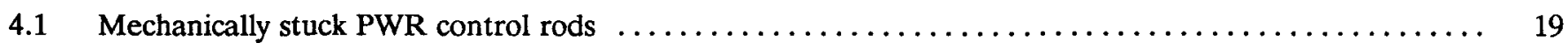

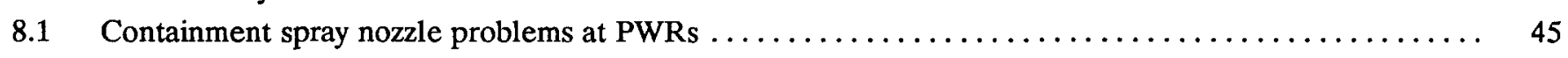

9.1 Inservice testing required by Standard Technical Specifications and ASME Code $\ldots \ldots \ldots \ldots \ldots \ldots$

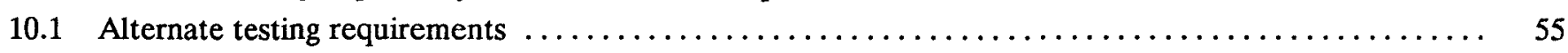

10.2 Comparison of requirements of IEEE Standard 450-1980 with requirements of Westinghouse STS .... 58

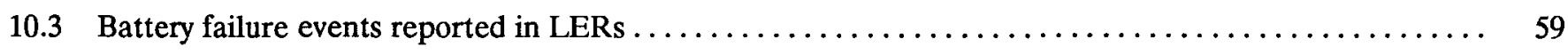

14.1 Summary of recommended changes to surveillance requirements $\ldots \ldots \ldots \ldots \ldots \ldots \ldots \ldots \ldots \ldots .64$ 


\section{ABBREVIATIONS}

\begin{tabular}{|c|c|}
\hline ACI & autoclosure interlock \\
\hline ADS & automatic depressurization system \\
\hline AEOD & Office for Analysis and Evaluation of Operational Data \\
\hline AFW & auxiliary feedwater \\
\hline AIF & Atomic Industrial Forum \\
\hline ALARA & as low as reasonably achievable \\
\hline AOT & allowed outage time \\
\hline AOV & air-operated valve \\
\hline $\begin{array}{l}\text { ASHRAE } \\
\text { ASI }\end{array}$ & $\begin{array}{l}\text { American Society of Heating, Refrigeration and Air Conditioning Engineers } \\
\text { axial shape index }\end{array}$ \\
\hline ASME & American Society of Mechanical Engineers \\
\hline BIT & boron injection tank \\
\hline $\mathrm{B} \& \mathrm{~W}$ & Babcock \& Wilcox \\
\hline BWR & boiling water reactor \\
\hline $\mathrm{CE}$ & Combustion Engineering \\
\hline CEA & control element assembly \\
\hline CEAC & control element assembly calculator \\
\hline CFR & Code of Federal Regulations \\
\hline CIV & containment isolation valve \\
\hline COLSS & core operating limit supervisory system \\
\hline CP & construction permit \\
\hline $\mathrm{CPC}$ & core protection calculator \\
\hline CRD & control rod drive \\
\hline CRDM & control rod drive mechanism \\
\hline CRGR & Committee to Review Generic Requirements \\
\hline DNBR & departure from nucleate boiling ratio \\
\hline ECCS & emergency core cooling system \\
\hline EDG & emergency diesel generator \\
\hline EFPD & effective full-power day \\
\hline EOC & end of the operating cycle \\
\hline EPRI & Electric Power Research Institute \\
\hline ESF & engineered safety feature \\
\hline ESFAS & engineered safety features actuation system \\
\hline FSAR & final safety analysis report \\
\hline $\mathrm{F}_{\mathrm{Q}}$ & ratio of maximum core power to average core power \\
\hline GE & General Electric Co. \\
\hline GI & generic issue \\
\hline GL & generic letter \\
\hline GSER & generic safety evaluation report \\
\hline HPCI & high-pressure coolant injection \\
\hline HPSI & high-pressure safety injection \\
\hline IEEE & Institute of Electrical and Electronics Engineers \\
\hline ILRT & integrated leak rate test \\
\hline INPO & Institute of Nuclear Power Operations \\
\hline IRM & intermediate range monitor \\
\hline IST & inservice testing \\
\hline
\end{tabular}




$\begin{array}{ll}\text { LCO } & \text { limiting condition for operation } \\ \text { LER } & \text { licensee event report } \\ \text { LOCA } & \text { loss-of-coolant accident } \\ \text { LOOP } & \text { loss of offsite power } \\ \text { LPCI } & \text { low-pressure coolant injection } \\ \text { LPD } & \text { local power density } \\ \text { LTOP } & \text { low-temperature overpressure protection } \\ & \\ \text { MOV } & \text { motor-operated valve } \\ \text { MSIV } & \text { main steam line isolation valve } \\ \text { MTC } & \text { moderator temperature coefficient } \\ & \\ \text { NBS } & \text { National Bureau of Standards } \\ \text { NPAR } & \text { Nuclear Plant Aging Research (Program) } \\ \text { NPRDS } & \text { Nuclear Plant Reliability Data System } \\ \text { NRC } & \text { Nuclear Regulatory Commission } \\ \text { NRR } & \text { Office of Nuclear Reactor Regulation } \\ \text { NSAC } & \text { Nuclear Safety Analysis Center } \\ \text { NSSS } & \text { nuclear steam supply system } \\ & \\ \text { PG\&E } & \text { Pacific Gas \& Electric } \\ \text { PNL } & \text { Pacific Northwest Laboratory } \\ \text { PORV } & \text { power (or pilot)-operated relief valve } \\ \text { PPS } & \text { plant protection system } \\ \text { PRA } & \text { probabilistic risk assessment } \\ \text { PWR } & \text { pressurized water reactor } \\ \text { RCC } & \\ \text { RCIC } & \text { rod cluster control } \\ \text { RCM } & \text { reactor core isolation cooling } \\ \text { RCS } & \text { reliability centered maintenance } \\ \text { RES } & \text { reactor coolant system } \\ \text { RG } & \text { Office of Nuclear Regulatory Research } \\ \text { RHR } & \text { regulatory guide } \\ \text { RPS } & \text { residual heat removal } \\ \text { RWCU } & \text { reactor protection system } \\ \text { RWST } & \text { reactor water cleanup } \\ \text { refueling water storage tank }\end{array}$

SAIC Science Applications International Corporation SBLC standby liquid control system

SCSS Sequence Coding and Search System

SDV scram discharge volume

SR surveillance requirement

SRM source range monitor

STI surveillance test interval

STS Standard Technical Specifications

SW service water

TSIP Technical Specifications Improvement Program

UPS uninterruptible power supply

USI unresolved safety issue

VCT volume control tank

VEPCO Virginia Electric \& Power Company 


\section{EXECUTIVE SUMMARY}

The Technical Specifications Improvement Program (TSIP) was established by the Director of the Office of Nuclear Reactor Regulation (NRR) on December 21, 1984 to completely rewrite and streamline the Technical Specifications as well as to make line item improvements to existing Technical Specifications. As a part of this work, many requirements are being relocated from the Technical Specifications to licensee-controlled documents, and owners groups have submitted topical reports proposing changes to surveillance test intervals and allowed outage times on the reactor protection system and engineered safety features actuation system. The Nuclear Regulatory Commission (NRC) staff has reviewed and approved these reports.

To supplement this effort, the NRC staff performed a comprehensive examination of all Technical Specifications surveillance requirements (SRs) in order to identify those that should be improved. The evaluation of the safety benefit of changes to Technical Specifications SRs involves the consideration of the purpose of the SR (how a change affects safety, including the reduction of challenges to plant systems), the effect that the performance of the SR has on personnel (the exposure of personnel to radiation sources and the burden on personnel resources), and the effect that the performance of the SR has on plant equipment (equipment wear or degradation). The results of that work are given in this report. The study recognized that testing is important to periodically verify that systems, structures, and components are available to perform their safety functions. Testing is especially critical to reveal degradation and failures that occur while equipment is in standby mode. The study did find, however, that although testing at power is essential to verify equipment and system operability, safety can be improved by reducing the amount of testing at power. Of the many existing surveillance requirements that were reviewed, only a small fraction, contained herein, are recommended to be performed at longer surveillance intervals.

The staff used four criteria, derived from NUREG-1024 recommendations, to screen the surveillance requirements. The criteria are:

(1) The surveillance could lead to a plant transient.

(2) The surveillance results in unnecessary wear to equipment.

(3) The surveillance results in radiation exposure to plant personnel which is not justified by the safety significance of the surveillance.
(4) The surveillance places an unnecessary burden on plant personnel because the time required is not justified by the safety significance of the surveillance.

In addition to applying these four criteria, the NRC staff performed a qualitative safety assessment on the Technical Specifications surveillance requirements of the Westing-house Standard Technical Specifications, Version 4A, and the Hatch Unit 2 Technical Specifications. The implementation of the recommendations of this report as line- item improvements is consistent with the Commission policy on Technical Specifications improvements. The policy endorses a program of short-term improvements to both the scope and substance of the existing Technical Specifications (Commission's "Interim Policy Statement on Technical Specifications Improvements," dated February 9, 1987: NRC, 1987).

Five reactor sites were visited in 1988 in order to discuss surveillance requirements with the people who plan, manage, and perform these surveillances. The visits were productive and many of the comments received have been incorporated into this study.

In addition, the NRC staff reviewed the dockets of several reactors seeking plant-specific Technical Specifications changes related to surveillance requirements that have generic applicability.

Operational data from licensee event report (LER) searches, Nuclear Plant Reliability Data System (NPRDS) searches, and other sources were relied on heavily to assess the impact of Technical Specifications surveillance requirements on plant operation.

The Nuclear Plant Aging Research Program of the Office of Nuclear Regulatory Research (RES) proved a valuable source of information on component reliability and types of degradation.

It was found that equipment failures and personnel errors during several types of surveillance tests cause a significant number of reactor trips. Reactor protection system testing, turbine valve testing, main steam isolation valve testing, nuclear instrumentation testing, engineered safety features (ESF) logic, and reactor trip breaker testing were all significant contributors to reactor trips. Other TSIP work has decreased the frequency of reactor protection system testing and will relocate the requirement from the Technical Specifications for turbine valve testing so that it can be changed to a more reasonable frequency on a design-specific basis without prior staff approval. However, turbine valve testing is such a significant contributor to reactor trips that this report recommends changing the surveillance interval from weekly and monthly (as presently required) to 
quarterly (if the turbine vendor agrees), rather than waiting for the completion of the new Standard Technical Specifications currently being developed.

In addition to causing reactor trips, testing results in many spurious isolations of the control room, fuel handling building, auxiliary building, and containment ventilation. Inadvertent emergency diesel generator starts are relatively common results of surveillance testing; actuations and isolations of standby safety equipment occasionally occur. It is recognized that difficulties in performing surveillance tests do not always represent a problem with the surveillance requirement, and that some problems can arise from design deficiencies in the plant and its systems. Sometimes designs do not have a built-in capability for performing tests, or do not factor in test optimization and efficiency.

Wear on equipment is also a significant concern; some instrument parts (such as connector pins and plugs) experience wear from the amount of plugging and unplugging required for testing. Auxiliary feedwater pumps were found to be subjected to wear because of the small recirculation lines used during testing.

Emergency diesel generators are subjected to an excessive amount of testing, especially those diesels in plants with older Technical Specifications. A problem with one diesel can result in testing the other(s) every eight hours. A problem with an emergency system other than a diesel generator can result in repeated testing of the diesel generators. A problem with the support system to one diesel generator can mandate that the diesel be declared inoperable and the other diesel or diesels be tested.

The NRC staff recommends that the number of diesel generator tests be greatly curtailed. Only when a valid concern (e.g., potential for common-mode failure) is posed about the availability of the other diesel or diesels when one diesel generator is inoperable, should the operable diesel or diesels be tested--and then, only one.

A significant contributor to the stress put on a diesel generator as a result of testing is the requirement that the diesel generator quickly come up to speed and full load. The requirement for fast starting and loading of a diesel generator comes from the assumptions of the analysis of the large-break loss-of-coolant-accident (LOCA). Newer, more realistic assumptions in the LOCA analysis, supported by experimental data, show that slower diesel generator starting and loading times would be acceptable, since the LOCA criteria would still be met.

Radiation exposure to personnel as a result of surveillance testing can cause up to approximately $20 \%$ of the total dose incurred at a site. The biggest contributor to incurred dose is maintenance, not testing; however, some surveillances do result in significant incurred radiation dose. Tests that require containment entries while the reactor is in operation (e.g., containment purge and exhaust isolation valve leak testing) cause significant doses. Walkdowns of systems to check valve alignments and snubber operability were also found to be significant contributors to radiation dose. Licensees appear to have taken the steps within their power to limit dose from testing.

The report recommends several changes to testing to further reduce exposing personnel to radiation. Included in these recommended changes are reducing the inspections necessary for assuring that there is no loose debris in the containment and reducing the frequency of measuring the contents in the waste gas tanks(s). It appears that, in general, it is not possible to significantly reduce radiation exposure that may result from surveillance testing since a balance must be maintained between the need to perform certain surveillances and the radiation dose incurred.

One utility executive has described the number of surveillance tests required as "overwhelming." The number is large and the utility resources that must be dedicated to surveillance testing are large. In an 18-month cycle, between 15,000 and 20,000 surveillances are typically required (without counting simple channel checks). A comment heard often during plant visits conducted as part of this effort was that equipment was tested which never failed (except, perhaps, because of the testing). Because of the large amount of testing and the fact that it may be greater than necessary on some systems, the application of reliability methods to Technical Specifications surveillance testing would result in a better allocation of utility resources to those systems and components which experience the most problems.

Although this effort concentrated on Technical Specifications surveillance testing, a major conclusion of this work is that preventive maintenance programs must be improved. A review of licensee event reports and other data shows that many of the failures found from testing are due to dirt or impurities in fluid systems, bent or broken parts, loose parts, etc., which should have been corrected before they resulted in failure. Surveillance testing can only identify that a piece of equipment is in an inoperable condition so that the time it is inoperable can be limited; preventive maintenance, however, can limit the number of failures that occur. In this way, preventive maintenance can make a greater contribution to reactor safety than is being made by surveillance testing.

The combination of reliability concepts and preventive maintenance in a reliability-centered maintenance program, together with testing based on reliability characteristics of the system or component, would be an effective method to reduce system/equipment unavailabilities and would represent better use of existing resources. 


\section{INTRODUCTION}

\subsection{Background}

In August 1983, the Deputy Executive Director for Regional Operations and Generic Requirements formed a Nuclear Regulatory Commission (NRC) task group to investigate the scope and nature of problems with surveillance testing required by Technical Specifications and to develop alternative approaches that would provide better assurance that surveillance testing does not adversely affect safety. The staff issued NUREG-1024, "Technical Specifications-Enhancing the Safety Impact," in response to the Deputy Executive Director's request; that report contained five recommendations. The three recommendations concerning surveillance requirements are cited below as stated in NUREG-1024.

\section{Recommendation 1}

The testing frequencies in the Technical Specifications should be reviewed to assure that they are adequately supported on a technical basis and that risk to the public is minimized.

\section{Recommendation 2}

The required surveillance tests should be reviewed to assure that important safety equipment is not degraded as a result of testing and that such tests are conducted in a safe manner and in the appropriate plant operational mode to ensure that risk to the public is minimized.

\section{Recommendation 4}

The surveillance test requirements should be reviewed to assure that they do not consume plant personnel time unnecessarily or result in undue radiation exposure to plant personnel without a commensurate safety benefit in terms of minimizing public risk.

On December 21, 1984, the Director of the NRC Office of Nuclear Reactor Regulation (NRR) established the Technical Specifications Improvement Program (TSIP) to reconsider the entire subject of technical specifications and to make recommendations for improvement. There was close coordination between this project and a similar industry effort sponsored by the Atomic Industrial Forum (AIF). A Commission paper was written (SECY-86-310) and the Commission was briefed on the recommendations of the project. There were two major recommendations.

(1) The NRC should adopt the criteria for defining the scope of the Technical Specifications proposed in the AIF and TSIP reports. The NRC and each of the industry owners groups should then use those crite- ria to completely rewrite and streamline the existing Standard Technical Specifications.

(2) In addition to developing a new set of Standard Technical Specifications as identified in recommendation 1 above, a parallel program of line item improvements (in both scope and substance) to existing Technical Specifications should be initiated.

In accordance with the Commission's "Interim Policy Statement on Technical Specifications Improvement," dated February 9, 1987 (NRC, 1987), each limiting condition for operation (LCO) in each of the existing Standard Technical Specifications (STS) was evaluated by the respective nuclear steam supply system (NSSS) owners group and by the NRC staff for retention in the new STS or for relocation to a licensee-controlled document. As a result of this review, $35 \%$ to $45 \%$ of the LCOs and their associated surveillance requirements were identified for removal from the STS.

Licensees may make changes to these surveillance requirements in accordance with plant-specific needs and evaluations without prior NRC approval, provided the controls applicable to the document they are relocated to are followed (e.g., 10 CFR 50.59 for the requirements relocated to final safety analysis reports [FSARs]). Thus, for a significant number of the surveillance requirements in current Technical Specifications, the licensee will be able to eliminate unnecessary tests or inspections. A letter from Thomas E. Murley (NRC) to the chairperson of each of the owners groups, May 9, 1988 (e.g., a letter from Thomas E. Murley, USNRC to Walter S. Wilgus, Chairman, The B\&W Owners Group) known as the "split report," lists each technical specification which is to be retained and each that may be relocated for each type of reactor, grouped by reactor vendor's design (i.e., Westinghouse PWR, Combustion Engineering PWR, Babcock \& Wilcox PWR, and General Electric BWR).

After deciding which LCOs would remain in the new Standard Technical Specifications, the owners groups commenced to rewrite each of these LCOs along with its associated surveillance requirements in an improved format. This work was completed in early 1990 . Some proposed changes to the new Standard Technical Specifications, including changes to surveillance requirements, were evaluated utilizing risk-based approaches (in SAIC-90/1394) to ensure that the impact of each change on plant core melt frequency or risk is acceptable.

In addition to restructuring the entire Standard Technical Specifications as discussed above, separate, parallel efforts have been taking place on a specification-byspecification (line item) basis to focus on improvements to specific technical requirements. Among other things, 
such parallel efforts deal with changes to both surveillance intervals and allowed outage times.

As a result of probabilistic risk analyses associated with the effort to improve line items, the NRC staff is reviewing, and in some cases has already found acceptable, the increasing of some surveillance intervals for the reactor protection system and engineered safety features actuation systems from monthly to quarterly and, in some cases, to semiannually (GE reports NEDC30851, NEDC-30851 [Supplements 1 and 2], NEDC-30936, and NEDC-31677P-N; CE report CEN-327; Westinghouse report WCAP-10271 and Supplements 1 and 2; and B\&W report BAW-10167 [all approved]. Similarly, increases in allowed outage times have been found acceptable.

In addition to these programs, the Commission issued a staff requirements memorandum on February 25, 1988 (SECY-87-314), requesting the NRC staff to:

... investigate the pros and cons of continuing to require the surveillance and testing of equipment while the plant is at power. The staff should assure that NRC does not require unnecessary tests or inspections that result in equipment disassembly or unnecessary wear. Staff should inform the Commission of the bases of present requirements and any proposed modifications to present Technical Specification requirements.

In response to the Commission's request, the staff initiated an additional short-term effort as part of the TSIP to examine the Technical Specifications requirements which result in testing equipment at power. This effort is the subject of this report and is intended to respond to the Commission and to the recommendations made in NUREG-1024 concerning surveillance requirements.

On June 20, 1988, the Commission was briefed on the status of the TSIP; subsequently, the Commission requested that a paper be prepared on the staff's effort to reduce testing and surveillance requirements during power operation of a nuclear power plant (see Chilk, 1988). The requested paper was to discuss the testing and surveillances which would no longer be required during power operation. The paper, which was based on this report, was issued on October 26, 1988. Neither the Commission paper nor this report provides the exact language for changes proposed to the surveillance requirements of the Technical Specifications. It is expected that others, using the recommendations in this report, will rewrite the surveillance requirements for the Technical Specifications.

The actual implementation of the approved changes will be integrated with the implementation of the TSIP through individual plant conversions to the new Standard Technical Specifications or through individual licensee amendments. A generic letter may be prepared to address those surveillances which are identified as causing a significant number of reactor trips, to allow changes to be made before individual plants convert to the new Standard Technical Specifications. The actual implementation process and schedule for these types of changes will be based on the most cost-effective use of available NRC staff resources recognizing that, although important, they may not have the same safety significance as other proposed changes.

\subsection{Scope}

In this study, the recommendations of NUREG-1024 were incorporated and expanded, the guidance in the "split report" was used, and, with a few exceptions, only those sections of the Standard Technical Specifications that are to be retained in the new STS were evaluated.

This report only addresses the subject of surveillance requirements as found in the Technical Specifications. The NRC staff did not study, and this report does not address such other aspects of the Technical Specifications as allowed outage times or required action when a limiting condition for operation is not met.

This report is structured in a manner that parallels the structure of the Standard Technical Specifications. A section has been included to specifically address the Commission's question about the advantages and disadvantages of testing at power. Next, a section follows on general findings of this study, and then sections corresponding to each of the major sections of the STS appear: Reactivity Control Systems, Instrumentation, Reactor Coolant System, Emergency Core Cooling System, Containment, Plant Systems, Electric Power, Refueling Operations, Special Test Exceptions, and Radioactive Effluents. Each surveillance requirement in the Technical Specifications for which a change is recommended or considered is discussed in its appropriate section. Finally, overall conclusions and references are presented.

The original goal was to study only surveillance testing at power that is required by the Technical Specifications. This was later changed to encompass any surveillance required by the Technical Specifications that met one or more of four criteria selected by this study for screening surveillance requirements to determine which surveillance requirements should be considered for change. These four criteria are:

(1) The surveillance places an unnecessary burden on plant personnel because the time required is not justified by the safety significance of the surveillance. 
(2) The surveillance could lead to a plant transient.

(3) The surveillance results in unnecessary wear to equipment.

(4) The surveillance results in radiation exposure to plant personnel which is not justified by the safety significance of the requirement.

In addition to these criteria, qualitative risk was assessed for the surveillance requirements for the Westinghouse Standard Technical Specifications, Version 4A, as an example of pressurized water reactor (PWR) Technical Specifications, and for the Hatch Unit 2 Technical Specifications as an example of boiling water reactor (BWR) Technical Specifications. This part of the study is discussed in more detail later in this section.

Within the resource and schedule limitations of this study, it was not possible to examine the identified items in sufficient detail to make a recommendation in every case. As a result, some surveillance requirements are identified as needing more study before a conclusion can be reached about whether a change is warranted.

In some cases, the NRC staff recommends that surveillance intervals be extended. In some of these cases, extending a surveillance interval will reduce risk. In other cases, the overall benefits of an extended surveillance interval offsets any negligible effect on safety. Since this is a generic report, the recommendation for an extension could be justified on a generic basis. The basis for each recommendation is given. It may be possible that plantspecific or equipment-specific surveillance test intervals could be even longer. This must be decided separately for each plant.

As part of this study, the NRC staff visited five nuclear power plants to obtain information from reactor operations, maintenance, engineering, chemistry, planning, and testing personnel on which Technical Specifications surveillance requirements meet one or more of the four criteria used for the study. The sites visited were Crystal River Nuclear Plant, Unit 3 (July 7, 1988), San Onofre Nuclear Generating Station, Units 1, 2, and 3 (July 20 and 21, 1988), Catawba Nuclear Station, Units 1 and 2 (August 3, 1988), North Anna Power Station, Units 1 and 2 (August 10,1988), and LaSalle County Station, Units 1 and 2 (August 22 and 23, 1988).

Comments requested and received from the five NRC regions are incorporated in this report.

In another effort to determine which surveillance requirements in the Technical Specifications might meet one or more of the criteria used in the study, the dockets of several PWRs and BWRs were reviewed to study the changes proposed by licensees to determine whether any of these had generic application. The proposed changes to the Technical Specifications of the following PWRs were reviewed: Zion Nuclear Plant, Units 1 and 2; St. Lucie Plant, Units 1 and 2; Prairie Island Nuclear Generating Plant, Units 1 and 2; North Anna Power Station, Units 1 and 2; McGuire Nuclear Station, Units 1 and 2; and Millstone Nuclear Power Station, Unit 2. The following BWR dockets were also reviewed: LaSalle County Station, Units 1 and 2; Hatch Nuclear Plant, Units 1 and 2; and Vermont Yankee Nuclear Power Station.

This study also made use of the work done as part of the NRC Nuclear Plant Aging Research (NPAR) Program (NUREG-1144). The reports on various systems and components prepared under this program gave insight into the rate of failure of specific systems and components and also into the cause of the failures. This information was used to assess whether more testing is being done than could be justified on the basis of the failure rate of equipment.

This effort concentrated on revising surveillance requirements that may be detrimental to reactor safety, personnel safety, or plant operation. It did not attempt to systematically examine possible nonconservative surveillance requirements, although a few such areas were identified and are documented in this report. It also recognizes that the majority of surveillance requirements are essential to verify equipment and system operability and ensure safety. As a consequence, only a small fraction of those surveillance intervals reviewed were recommended to be performed at longer surveillance intervals.

Although every Technical Specifications surveillance requirement for several sets of Technical Specifications was examined for this study, not all are discussed individually in this report. Only those identified from the sources discussed above for which a change was considered are discussed. A change was not recommended in every case, but where the recommendation is made to retain the existing requirement or to study the issue further, the reasons are given.

Technical Specifications are of utmost importance to the operation of a nuclear power plant. They are the NRC's statement establishing the limits within which a nuclear power plant must be operated in order to enhance safety and reduce risk to the public, and as such, they are taken most seriously by both the NRC and the licensees who operate the nuclear power plants. When a "limiting condition for operation" (LCO) is exceeded, the licensee is required to follow the remedial action stipulated in the Technical Specifications (which may involve shutting down the reactor) until the limiting conditions are met.

It is, therefore, extremely important that they state their requirements clearly (as well as the reason for making the requirement), that the requirement is really capable of 
being met, and that the requirement really contributes in a significant way to reactor safety.

Although this study, because of resource and schedule limitations, could not be complete in the sense that it addresses all of the potential weaknesses in Technical Specifications surveillance requirements, it should contribute significantly to the goal of making surveillance requirements in Technical Specifications more relevant and meaningful. Based on the overall assessment, including consideration of the specific factors discussed in each section, it has been determined that the resulting recommendations pose no undue risk and provide significant benefits by achieving a more optimal overall system reliability and availability through a greater balance in the factors involved (and thereby frequently improving safety).

\subsection{Qualitative Safety Assessment of Technical Specifications Surveillance Requirements}

Science Applications International Corporation (SAIC), under contract to the NRC, developed a procedure for this study to evaluate surveillance requirements of Technical Specifications based on a qualitative assessment of safety. SAIC proposed six review criteria for evaluating the surveillance test interval (STI):

(1) direct safety impact

(2) indirect safety impact

(3) reliability

(4) occupational exposure

(5) operator burden

(6) NRC burden

These six criteria were chosen because of their direct impact on decisions associated with frequency of STIs. Each of these criteria represents a specific concern about the frequency of STIs. These criteria address six major concerns, but consideration of these six criteria is not intended to constitute a complete analysis of any STI. In particular, surveillance-specific engineering design concerns are not addressed. For example, these criteria may indicate that a monthly chemical analysis interval can be extended, but engineering considerations, such as chemical depletion at a specific plant, may dictate frequent testing. In any case, engineering considerations, as well as operating experience obtained from several data bases, were used in making the final recommendations.

\section{(1) Direct Safety Impact}

The objective of this criterion is to understand the importance of the component to plant safety. The types of questions asked in considering this criterion are listed below. These include the importance to plant safety of the component to be tested, level of redundancy provided in the plant design for the component under consideration, and whether the function provided by the component can be recovered given component failure. A generally negative response implies that the component is important to plant risk and thus, from the point of view of direct safety impact, should be considered for more frequent testing.

\section{Typical direct safety impact questions*}

(a) Is the component or system providing a relatively unimportant function?

(b) Is there a high level of redundancy?

(c) Can the function affected by equipment be recovered?

\section{(2) Indirect Safety Impact}

The objective of this criterion is to assess the negative impact of frequent testing of components. The types of questions asked in considering this criterion are listed below. These questions are directed toward understanding whether testing performed on the specific component will move the component away from its safe position, and whether the component testing could result in inadvertent plant trip or disabling of another component. Again, a generally negative response implies shortening STIs (more frequent testing) and a generally positive response implies lengthening STIs (less frequent testing).

\section{Typical indirect safety impact questions*}

(a) Does testing require aligning a portion of a safety or support system away from the safe position?

(b) Can testing cause a reactor trip?

(c) Is a safety or support system also partially disabled by the test and trip with no automatic return?

(d) Can testing result in Event $V$ or other loss-of-coolant accident?

\section{(3) Reliability}

The objective of this criterion is to differentiate between the standby, normally operating, or cyclic components, and to determine the dominant cause of the component failure. The types of questions asked in considering this criterion are listed below. In general, if it is determined that a component is normally operating, is cycled, or is continuously monitored, no additional testing is recommended for the component based on this criterion. Some testing may be desirable to detect performance degradation that otherwise would not be detected. The remaining questions on standby components are directed toward

\footnotetext{
*A generally negative response implies shortening test intervals; a generally positive response implies lengthening test intervals.
} 
understanding what dominates the component failure. If equipment wearout and demand stress dominates a component's failure, less frequent testing is recommended. If standby stress is the dominating factor in a component's failure, then more frequent testing would be recommended.

\section{Typical reliability questions*}

(a) Is the component in a normal operational state?

(b) Is the component continuously monitored and alarmed?

(c) Besides demand testing, are there other frequent operability demands on the component?

(d) Is there likely to be test-caused wearout?

(e) Is there likely to be test-caused renewal (i.e., the flushing of a filter or cycling of a battery)?

(f) What type of failure and repair causes dominates?

(g) Is the ratio of repair actions to catastrophic failures high?

(h) If the test aligns a portion of the system away from the safe position with no automatic return, is the test unavailability contribution large when compared to the contribution from standby stress catastrophic failures?

\section{(4) Occupational Exposure}

The objective of this criterion is to understand the potential for exposing plant personnel to radioactivity regularly or accidentally as a result of conducting a specific test. The types of questions asked in considering this criterion are listed below. If the surveillance test under consideration does not result in regular or accidental exposure to plant personnel, no change to STIs would be recommended. If the surveillance test results in any exposure to plant personnel, longer STIs based on this criterion would be considered.

\section{Typical occupational exposure questions*}

(a) Is there regularly a dose to site personnel from testing the component?

\footnotetext{
*A generally negative response implies shortening test intervals; a generally positive response implies lengthening test intervals.
}

(b) Can there be an accidental dose to personnel from testing?

\section{(5) Operator Burden}

The objective of this criterion is to assess the level of burden the test places on the operating staff. The types of questions asked in considering operator burden are listed below. Similar to the occupational exposure criterion, this criterion can either lead to a recommendation of no change in STI if there is no operator burden, or a recommendation to lengthening the STI if there is a burden on the operating staff.

\section{Typical operator burden questions*}

(a) Is the operator burden from testing characterized as high?

(b) Does testing frequently result in a repair action that threatens an allowed outage time (AOT)?

\section{(6) NRC Burden}

The objective of this criterion is to assess the level of burden on the NRC staff. The types of questions asked in considering NRC burden are listed below. Similar to the occupational exposure criterion, this criterion can either lead to a recommendation of no change to an STI if there is no NRC burden, or a recommendation to lengthen the STI if there is burden on the NRC staff.

\section{Typical NRC burden questions*}

(a) Is burden from current Technical Specifications high?

(b) Do Technical Specification testing requirements result in frequent requests for extension?

\section{Application of the Proposed Criteria}

It is important to note that the results of considering the individual criterion must be considered together. The final recommendation is based on the reviewer's judgment which considers the input from all of the criteria.

This procedure was used for studying the surveillance requirements in the Westinghouse Version 4A Standard Technical Specifications and the Hatch Unit 2 Technical Specifications as examples of PWR and BWR Technical Specifications, respectively. 


\section{PROS AND CONS OF TESTING AT POWER}

As is discussed in the introduction (Section 1), the Commission specifically directed the staff to consider the advantages and disadvantages (pros and cons) of continuing to require the surveillance and testing of equipment at power. Surveillance testing is essential to verify that equipment and systems are operable and that they perform their safety functions. In some cases surveillance testing is used to detect equipment and system degradation and thereby determine when maintenance (restoration, repair, or replacement) is to be conducted. Historical records of surveillance test data can be used to determine reliability, to evaluate system design, and thence to formulate system improvements. The mode in which a particular surveillance is conducted should be selected to minimize risk and yet still be able to adequately meet the surveillance requirements. Safety systems are designed with such redundancy that the failure of any single component will not prevent a system from performing its safety function. By choosing components that are highly reliable, the probability is low that two redundant components would be inoperable at the same time due to random failures. Testing is performed to identify failed components and thereby reduce the probability that a system could not perform its safety function because two redundant components have failed during the interval between testing each component. In addition to system redundancy, safety is enhanced by diverse systems that are capable of performing the same safety function. Where reliable and diverse safety systems are provided, the impact on safety of increased surveillance intervals is reduced.

Several safety concerns arise with testing at power. The first is that a reactor at power should have all its safety systems available in case circumstances require their use. If a safety system is being tested, portions (trains, divisions) of the safety system may or may not be available for use, depending on the type of test and the logic built into the system's controls. For example, a standby emergency pump in the recirculating mode would not be available for delivering water to the vessel or steam generator until an operator changed its flowpath. On the other hand, the controls for an emergency diesel generator are designed so that a loss of voltage to an emergency bus will cause the diesel to pick up load, even if it is in the test mode at the time. This feature is required to be tested, typically at every refueling outage. Safety-related instrumentation channels are tested one at a time so that redundancy ensures that the operable channels will perform their function if required. Thus, safety systems may or may not be available immediately to respond to an emergency.

Another concern with testing at power is that sometimes the reactor experiences a transient during testing that may cause a reactor trip. A reactor trip from high power is a significant transient. A reactor is designed for a given number of trips from full power. The number of trips is usually in the range of 200-250. However, a trip requires systems to function so as to stop the nuclear reaction and remove heat to cool the core. A malfunction in one of these systems could turn a routine trip into a more serious event. An error by an operator during a trip when plant conditions are changing rapidly could also turn a routine trip into a more serious event. Even on an ordinary trip from full power, on a pressurized water reactor (PWR), secondary safety valves may lift and there is then some concern that the valves may not reseat. The main feedwater system may or may not still be available. If it is not available, the auxiliary feedwater system must function to provide a continued heat sink. The trip may put a power transient into the electrical grid sufficient to cause a loss of preferred power or the automatic transfer from reactor-generated power to an offsite (preferred) source may not be successful so that the emergency diesel generators must operate. If the trip resulted from or causes a safety injection signal, the containment will be isolated so that important (but not essential) services are lost such as, in a PWR (depending on the design), cooling to the reactor coolant pumps and control rod drive cooling. (The control rods would have already performed their safety function.) Letdown is also isolated. These isolations can be overridden or the containment isolation can be reset if it is spurious.

Besides reactor trips, testing can also cause engineered safety feature actuations which unnecessarily start safetyrelated equipment. Even if such actuation does not trip the reactor, it diverts the operators' attention and can impose wear on the equipment.

Thus, the concern about testing at power is valid and testing at power should be minimized on those systems required at power and those that might cause a plant transient.

It does not, however, appear to be possible or desirable to eliminate all testing at power. The operability of some safety components and systems must be assured during reactor operation. The fundamental question is how can the testing be done so that the potential for causing a plant transient is minimized? The way the test is conducted and the frequency of testing are both important considerations.

A large fraction of the testing that must be done does not lead to a reactor trip. For example, the emergency diesel generators are required to be tested at intervals much shorter than a refueling interval to assure their proper operation. However, this testing should not make the reactor more vulnerable to a trip. There are, however, some systems or components, which are discussed in this 
report, whose testing makes a reactor more vulnerable to a trip.

In deciding whether it is really necessary to test a piece of equipment at power when that testing has the potential for causing a trip, one must consider the importance to safety of that system or component, the failure rate of that system or component, the effectiveness of the test in discovering the failure, and whether the test might be better performed when shut down.

As an example, control rods are important to safety. In a PWR they are required to be tested monthly to assure that they are not stuck so that if a scram signal opens the trip breakers, the rods will drop into the core. However, operating data show that this test has the potential for causing a reactor scram. Operating data also show that the frequency of stuck control rods is very low and that, when a stuck rod has occurred, the condition of the reactor has remained within the bounds of the accident analysis assumption that the single highest worth control rod does not trip. (This assumption is made in every final safety analysis report and in determining reactor shutdown margin.) In addition, a review of the operating data shows that most stuck rods are not found by performing this test, but rather are found at the beginning of a cycle while withdrawing the control rods before making the reactor critical or during low-power physics testing.

Considering these points, it does not seem necessary to perform this test as frequently as is currently required, and the NRC staff recommends that this test be performed less frequently.

On the other hand, the testing frequency of main steam line isolation valves (MSIVs) on PWRs can not be as clearly determined. MSIVs are important to reactor safety. They are required to be tested quarterly. Since completely closing an MSIV would trip the reactor, they are only closed $10 \%$ of the way. However, even this test makes the reactor vulnerable to a trip. MSIVs are complicated devices and operating data show that they do become inoperable. In this case, the test does uncover the inoperable MSIVs. Therefore, the decision of how often to test MSIVs must take into account both that the test makes the reactor vulnerable to a trip and that the test does detect inoperable MSIVs. In this case, the NRC staff recommends that a more careful study be done to determine the correct surveillance test interval.

Reliability and probabilistic risk assessment (PRA) methods have not yet been developed to the point at which they provide definitive guidance on determining specific surveillance test intervals. Approximate methods have been developed and these provide insights. In a recent study using PRA analysis done for the Arkansas Nuclear One, Unit 1 reactor using data from the NRC Interim Reliability Evaluation Program (NUREG/CR-5200), an analysis of surveillance test intervals showed that performing approximately $70 \%$ of the surveillance tests insignificantly decreased risk. The analysis only considered the benefit from testing and not the risk due to the test. If the risk of testing (such as potential plant trips or equipment degradation) were included, the percentage of surveillance tests which insignificantly decreased risk would be even larger.

Thus, even though a precise number has not been determined, the evidence from this study indicates that more testing takes place than is necessary to reduce plant risk of core melt.

The data, however, do show that some testing is important to reducing risk and must be done during operation of the reactor.

This report, by the use of operating data, discussions with plant personnel who perform the surveillance tests, engineering judgment, and a qualitative assessment of the risk impact, has attempted to determine which tests are important to safety and which are not.

Reviewing data on equipment failure from licensee event reports leads to the conclusion that many of the failures could have been prevented by better maintenance practices. Industry reports on equipment performance have also reached this conclusion. If the frequency of inoperable equipment were reduced, testing could also be reduced. As long as surveillance testing at power finds failed equipment, it must be continued. The recommendations included in this report are based upon balancing the benefits for identifying potential component failures by frequent testing and the benefits of reduced testing because of the potential for challenges to safety systems, equipment wear, removal of equipment from service for testing, personnel radiation exposure, and diversion of personnel resources from other safety-related activities. For each recommendation for an increase in a surveillance interval, the conclusion is that this action will provide a net benefit to plant safety.

The answer to the Commission's question is, therefore, that some testing at power is necessary. Indications also exist that too much testing at power is currently being done. The Technical Specifications Improvement Program is reducing the amount of required testing. However, testing will remain necessary for finding inoperable equipment. 


\section{GENERAL FINDINGS}

This section addresses certain general topics related to surveillance testing required in Technical Specifications to give the reader a broader perspective before the individual surveillance requirements are discussed. The following subjects are included in this section:

- Magnitude of Surveillance Testing Required by Technical Specifications

- Preventive Maintenance and Surveillance Testing

- Japanese Approach to Surveillance Testing

- Technical Specifications and the ASME Code

- Scheduling Surveillance Testing

- Surveillance Testing and Radiation Exposure

- Surveillance Testing and Plant Transients

- Surveillance Testing and Reliability

- Surveillance Testing and Plant Design

- Surveillance Testing and Power Reductions

- Surveillance Testing and Equipment Wear

- Surveillance Testing on a Staggered Test Basis

\subsection{Magnitude of Surveillance Testing Required by Technical Specifications}

In August 1981, the NRC staff published a report (NUREG-0839) on the results of a survey taken by senior NRC managers to obtain the views of plant operators on the safety impact of regulatory activities. Surveillance testing was one of the areas examined. Some of the comments recorded in that report are similar to comments received during plant visits conducted for this study. The comments received during the August 1981 study were summarized as follows: "The number of surveillances is overpowering according to licensees. A large percentage of incidents occur as the direct result of surveillances. A frequent comment was that equipment is wearing out. One group of licensees observed that some of the requirements for testing do not make sense when compared with others."

The number of surveillance requirements is indeed large. As part of the preparation of the split report, the NRC staff counted the number of surveillance tests required in the Technical Specifications that would be relocated as a result of relocating Technical Specifications identified in the split report. A boiling water reactor (Limerick) was chosen. It was estimated that, during an 18-month cycle, 36,620 individual surveillance tests would be relocated by eliminating approximately $42 \%$ of the limiting conditions for operation (LCOs) that did not meet the split report criteria for retention in the Technical Specifications. Of the surveillance tests that would be eliminated, 20,280 surveillances are required to be done while the plant is shut down.

That count did not consider those LCOs that were to remain in the Technical Specifications. (It would not be correct to extrapolate the total number of surveillances from this estimate because most of the safety-related mechanical, electrical, and instrumentation equipment was not included.) As part of this study (using the Technical Specifications of a new Westinghouse reactor), the NRC staff counted the number of surveillances required for just the reactor protection system (RPS) and engineered safety features actuation system (ESFAS) instrumentation assuming an 18-month cycle with three shutdowns and startups during the cycle.

The results are given in Table 3.1. Also shown in the table is the estimated number of surveillances required after the approval and implementation of the owners group topical reports which propose to extend the surveillance test interval for this instrumentation.

Excluding channel checks, just over 5000 functional tests and calibrations of the RPS and ESFAS are presently required. This number will be reduced to approximately 2300 , or a reduction of approximately $54 \%$, when the recommendations in the owners group topical reports are implemented.

The magnitude of testing can also be measured in terms of personnel time required for testing. Licensees gave several indications of this during this study. These are

Table 3.1 Number of surveillance tests required for RPS and ESFAS instrumentation currently, and number proposed in Westinghouse Owners Group topical report

\begin{tabular}{lcccr}
\hline & \multicolumn{2}{c}{ RPS } & \multicolumn{2}{c}{ ESFAS } \\
Surveillances & Current & Proposed & Current & Proposed \\
\hline $\begin{array}{l}\text { Total surveillances } \\
\text { excluding channel checks }\end{array}$ & 2,000 & 900 & 3,000 & 1,500 \\
$\begin{array}{l}\text { Percent reduction in } \\
\text { surveillances }\end{array}$ & & $56 \%$ & & $51 \%$ \\
\hline
\end{tabular}


given in the sections that follow on individual Technical Specifications. As one example, functional tests of instrumentation account for a large amount of monthly testing. Approximately 900 staff-hours per unit are expended each month for these tests on more than 300 instrument channels at one multi-unit site. This does not include administrative staff-hours for supervision and paperwork processing.

In terms of numbers of procedures, which is not necessarily an accurate measure of the number of tests performed, one utility provided the following statistics. The utility uses approximately 300 procedures for surveillance testing which contain approximately 1100 requirements. Of these 300 procedures, only 65 do not contain Technical Specifications requirements. Some of these do, however, contain surveillance requirements from such documents as regulatory guides and bulletins.

The licensee for Limerick provided the following information on the total number of surveillances done on an annual basis. For 1986 (with no refueling) 14,888 surveillances were performed. For 1987 (with a refueling outage) 17,540 surveillances were performed. Approximately $98 \%$ of these were required by Technical Specifications, the other $2 \%$ were required by other agreements made between the licensee and NRC. This includes instrumentation (RPS, ESFAS, radiation monitors, security, etc.), pump and valve testing, and testing of electrical equipment. It includes tests done both during operation and at refueling outages. At this particular reactor, all channel checks for a day are counted as one test, so channel checks contribute only 365 tests per year to this total.*

These numbers, although not presenting a complete picture of the magnitude of the utilities' effort necessary to perform surveillance requirements, do give an indication that a large effort is required.

\subsection{Preventive Maintenance and Surveillance Testing}

Surveillance requirements in the Technical Specifications for a nuclear power plant are written, in general, to ensure the level of operability of systems and components required to meet the assumptions of the plant's safety analyses. They are not designed to track degradation of equipment by monitoring or trending performance and, therefore, the surveillance requirements do not necessarily predict the adequacy of future operability of the com-

\footnotetext{
"The staff count of surveillances for Limerick discussed on the previous page counted each channel check as a separate test. When the staff count is adjusted by counting all channel checks done on one day as one test, as is done by the Limerick licensee, the counts are more consistent.
}

ponent or system. This may be particularly true if the surveillance test stresses the equipment severely.

Safety systems spend most of their time in a standby mode. A majority of the operational time of some safety systems comes from testing. The combination of long times in standby and short test run times may be very hard on some equipment. This is true, for example, of pumps, if the pump must operate on recirculation on a different portion of the head-capacity curve than the point at which it was designed to operate, and of emergency diesel generators, which are subjected to thermal stresses during fast startup and loading.

To illustrate the stress of testing standby equipment, one licensee compared the wear of a continuously operating centrifugal circulating water pump with the wear of a low-head safety injection pump which is in standby service. The circulating water pumps are typically $10 \%$ degraded after approximately 10 years of operation; the low-head safety injection pumps may be $8 \%$ degraded in the same time even though the actual running time was much less. If a surveillance test only discovers that a component or system is inoperable, it performs the function of limiting the time after failure that the piece of equipment is relied on. If, on the other hand, a test identifies degradation in the performance of a component or system which may lead to failure, and if the degradation is corrected, then the test can limit the number of failures as well as the time between failures. Thus, preventive maintenance that identifies degradation combined with operability testing is more useful in maximizing the availability of safety equipment than are operability tests alone.

There is a definite relationship between surveillance testing and preventive maintenance. The Technical Specifications, as stated earlier, require testing only to determine operability. However, equipment that is frequently inoperable is a symptom of a preventive maintenance program that is too lax. Some of the most important safety systems, e.g., emergency diesel generators, batteries, and reactor trip breakers, require a high-quality preventive maintenance program to prevent inoperability.

From another viewpoint, an effective preventive maintenance program will prevent the frequency of equipment failures from increasing as the equipment ages. Thus, if a preventive maintenance program is effective, needs for testing will not increase; instead, an overly conservative testing requirement established previously will become a candidate for test reduction.

\subsection{Japanese Approach to Surveillance Testing}

Studies comparing the Japanese and American approaches to managing and regulating commercial nuclear 
power (e.g., NUREG/CR-3883) examine the differences in testing between the utilities of the two nations.

The performance of the Japanese utilities seems to be excellent. In 1984, a year for which data were available, Japan had 28 nuclear reactors in operation. These reactors had an average capacity factor of $73.9 \%$ and the frequency of unplanned shutdowns was 0.1 time/reactor/ year (4 trips for 28 units).

Such good performance is due, in large part, to the rigorous, extensive preventive maintenance program which is performed at all Japanese nuclear power plants.

An annual inspection is mandated, and the governing regulation specifies the systems and components that must be inspected. A voluntary supplemental inspection is performed at the same time, as well as corrective actions, backfits, and corrective maintenance. The effort includes systems which, in the United States, are considered both nuclear steam supply and balance-of-plant. This rigorous program does affect the capacity factor. Note that even with a very small number of unplanned shutdowns, the capacity factor is good but not great.

In addition, in Japan routine inspections (surveillance testing) are carried out during operation. The Appendix, taken from NUREG/CR-3883, provides a partial list of surveillance tests done during normal operation for a Japanese PWR and BWR. In general, the test intervals and the equipment tested are not significantly different from those in U.S. plants. In some cases, certain equipment is tested more often in Japan than here. Some of the tests identified during this study as causing a significant number of trips are performed even more often in Japan, according to NUREG/CR-3883, for example, PWR control rod movement tests and BWR MSIV partial closure tests.

Several factors seem to account for the difference in both countries in the rate of incidents while performing these tests.

The Japanese, in general, minimize the performance of tests that have the potential for tripping the reactor. Relay actuations are not done at power. RPS logic is tested, but the equipment is designed so that it is not necessary to enter cabinets; test switches are provided. Other equipment, such as MSIVs, is designed to be tested easily, lessening the likelihood of a mishap.

In general, according to NUREG/CR-3883, surveillance testing at power appears to be targeted at discovering passive failures in components rather than at ensuring their operability. Verification of operability appears to be relegated to the shutdown inspection process.

Another factor to be considered comes from an industry observation: "Any test involving an RPS channel trip receives close supervisory attention which helps to raise the operator's awareness of the effects of an error."

In summary, it appears that the Japanese success with avoiding incidents while testing at power is due to:

(1) avoidance of testing that may cause a trip, if possible

(2) meticulous care and vigilant supervision in conducting tests

(3) equipment designed for testing to avoid "juryrigging" to do tests at power

(4) preventive maintenance that keeps the equipment operable (A significant number of trips in this country appear to come from equipment failures while the equipment is being exercised during surveillance testing.)

\subsection{Technical Specifications and the ASME Code}

10 CFR $50.55 \mathrm{a}(\mathrm{g})$ requires that safety-related pumps and valves be tested according to the requirements of Section XI of the American Society of Mechanical Engineers (ASME) Boiler and Pressure Vessel Code (ASME Code) and addenda. The requirements for the tests of pumps and valves are summarized in Tables 3.2 and 3.3 of this report. Section 4.0.5 of the Standard Technical Specifications refers to these requirements. 10 CFR $50.55 \mathrm{a}(\mathrm{g})(4)$ requires that the inservice inspection program for a facility must be revised at 120 -month intervals and the program for testing pumps and valves must also be revised every 120 months. Moreover, these programs must use, to the extent practicable, the requirements in the latest editions and addenda in the ASME Code that are incorporated by reference in 10 CFR $50.55 \mathrm{~d}$ (b) 12 months prior to the start of the 120 -month interval.

The wording of Section 4.0.5 is general enough to accommodate these changes to the program without requiring changing the Technical Specifications with each program change.

The testing requirements of the ASME Code only test certain aspects of the operation of a pump or a valve and do not require the verification of whether a whole system will perform its safety function. In this respect, the testing 
Table 3.2 Inservice test quantities for pumps

\begin{tabular}{lll}
\hline Quantity & Measure & Observe \\
\hline Speed, N (if variable speed) & $\checkmark$ & \\
Inlet pressure, P & $\vee^{*}$ & \\
Differential pressure, $\Delta \mathrm{P}$ & $\checkmark$ & $\checkmark$ \\
Flow rate, $\mathrm{Q}$ & $\sqrt{ }$ & \\
Vibration amplitude, $\mathrm{V}$ & $\checkmark$ & \\
Proper lubricant level or pressure & & \\
Bearing temperature, $\mathrm{T}$ & $\sqrt{ }$ \\
\hline
\end{tabular}

"Measure before pump startup and during test.

Table 3.3 ASME Code, Section XI requirements for valves

\begin{tabular}{lllll}
\hline $\begin{array}{l}\text { Exercise } \\
\text { quarterly }\end{array}$ & $\begin{array}{l}\text { Exercise and } \\
\text { stroke time } \\
\text { quarterly }\end{array}$ & $\begin{array}{l}\text { Leak rate test } \\
\text { not to exceed } \\
\text { 2 years }\end{array}$ & $\begin{array}{l}\text { Fail-safe } \\
\text { test } \\
\text { quarterly }\end{array}$ & $\begin{array}{l}\text { Setpoint press- } \\
\text { ure verification } \\
\text { 5 years }\end{array}$ \\
\hline Check valves & MOVs and AOVs & Check valves & $\begin{array}{l}\text { MOVs and } \\
\text { AOVs }\end{array}$ & $\begin{array}{l}\text { Safety/relief } \\
\text { valves }\end{array}$ \\
$\begin{array}{l}\text { Certain manual } \\
\text { valves }\end{array}$ & $\begin{array}{l}\text { Certain manual } \\
\text { and locked- } \\
\text { closed valves }\end{array}$ & & \\
& $\begin{array}{l}\text { MOVs and AOVs, } \\
\text { e.g., containment } \\
\text { isolation valves }\end{array}$ & & \\
\hline
\end{tabular}

will perform its safety function. In this respect, the testingrequired by the Technical Specifications goes beyond that required by the ASME Code. For example, in testing pumps, the ASME Code requires the information in Table 3.2 to be obtained. For the auxiliary feedwater pumps, the Technical Specifications typically require that the flowpath to each steam generator be verified following each cold shutdown of more than 30 days, that each automatic valve in the flowpath actuates to its correct position, and that each AFW pump automatically actuates on receipt of the proper signal. For emergency core cooling system (ECCS) pumps, the proper flow distribution to each cold leg (assumed in the safety analysis) is verified as well as the automatic actuation of the pumps on the appropriate signals.
Monthly testing of Class 2 and 3 pumps was required by Section XI of the ASME Code before the winter 1979 version was issued; this requirement was incorporated into the Technical Specifications. Therefore, some utilities are still testing their pumps monthly, rather than quarterly as is required by the newer versions of the ASME Code and Standard Technical Specifications.

Some utilities have sought relief from the ASME Code Section XI monthly testing requirements on the basis that the newer versions of the ASME Code only require quarterly testing. These requests have routinely been approved.

BWR standby liquid control system pumps and PWR auxiliary feedwater pumps are required by the Technical 
Specifications to be tested monthly, even for those plants at which other pumps are required by the Technical Specifications to be tested quarterly. These requirements are discussed in Sections 4.3 and 9.1, respectively, of this report.

This report recommends that safety-related pump testing that is done more often (e.g., monthly) than required in the current versions of the ASME Code be performed quarterly.

A study performed for the Electric Power Research Institute (EPRI) examined the testing of emergency pumps that are on standby to determine if the testing contributed to the failure rate of these pumps (NP-4264, Vol. 1). Both PWR and BWR emergency pumps were included in this study. The study found that the highest pump failure rates were associated with PWR auxiliary feedwater (AFW) pumps and BWR residual heat removal pumps and residual heat removal service water pumps. However, the report concluded: "Except for the possibility that some plants may be testing at too low of a flow, none of the AFW LERs [licensee event reports] appear to be caused by any aspect of the surveillance test." (This is discussed in more detail in Section 9 of this report.)

For the BWR systems, the EPRI report concluded: "None of the RHR [residual heat removal] and SW [service water] LERs appear to be caused by any aspect of the surveillance test."

Thus, except for one problem with AFW pump testing," pump testing does not appear to have any adverse effect on emergency pumps.

\subsection{Scheduling Surveillance Testing}

Since the amount of testing required by Technical Specifications is large, the licensee should be given as much freedom as possible to schedule testing so that tests on the same system can be done at the same time to minimize personnel resources and maximize the availability of the equipment.

Standard Technical Specifications contain a surveillance requirement (4.0.5) which clarifies the application of the inservice inspection and testing requirements of the ASME Code to surveillance testing requirements in Technical Specifications. Some versions of 4.0.5 allow the frequency of these tests to be extended by stating that Section 4.0.2 is applicable; other versions state that Section 4.0.2 is not applicable. Section 4.0.2 allows an extension of the surveillance interval by $25 \%$. Previously, the combined time interval for any three consecutive inter-

\footnotetext{
The problem is testing on recirculation with recirculation lines which restrict flow to less than design flow. Other safety-related pumps may also have this problem on a plant-specific basis.
}

vals was not to exceed 3.25 times the specific surveillance interval.

This inconsistency in the application of Section 4.0.2 was remedied by Generic Letter 89-14. This allows utilities more flexibility in planning surveillance tests so that testing required by the ASME Code and testing required by the Technical Specifications can be better coordinated (by deleting the 3.25 requirement).

Appendix $\mathrm{J}$ to $10 \mathrm{CFR}$ Part 50 requires the containment to be tested for leaks. Three types of tests are discussed. The type A test is an integrated leak rate test, the type $B$ test is a test for leakage across penetrations, and the type $\mathrm{C}$ test measures leakage across isolation valves. Type A tests are required by Appendix J to be performed "at approximately equal intervals during each 10 -year service period." Because of this wording, which allows flexibility, the provisions of 4.0.2 apply to type A testing. Type B and $C$ tests must be performed "in no case at intervals greater than 2 years." Because of this wording, 4.0.2 is not applicable to type $B$ and $C$ testing.

This can present scheduling problems if the plant has been shut down during the cycle for a long time, then starts up, and must now perform type B or C leakage tests to comply with the time limit of Appendix J. Some of these tests can only be done when the plant is shut down. This is also true of other surveillance tests (e.g., ECCS flow distribution tests in a PWR, or some emergency diesel generator surveillances which are required at 18-month intervals).

It has been the position of the NRC staff that the inservice surveillance testing interval should not be extended by either storage under controlled conditions or by the system remaining dormant or shut down for long periods of time. The NRC staff reconsidered this guidance as part of this program and still considers it to be reasonable since equipment could continue to degrade even if the plant is in a long-term outage condition (e.g., lubricant hardening or resilient seal degradation).

The Technical Specifications Improvement Program has eliminated the Section 4.0.2 requirement that the total maximum combined interval time for any three consecutive surveillance intervals should not exceed 3.25 times the specified surveillance interval. This does not alter the existing $25 \%$ extension limit on each surveillance test interval. This is presented by Generic Letter 89-14. This . will be helpful for those intervals controlled by Technical Specifications and not by the regulations.

\subsection{Surveillance Testing and Radiation Exposure}

One of the criteria used for this study, as discussed in Section 1 , is that the radiation dose received by personnel 
performing the surveillance should be commensurate with the importance of the surveillance. Before examining individual surveillance tests, it is useful to put the radiation dose received during surveillance testing into perspective with the radiation dose received performing other plant activities.

Table 3.4, taken from NUREG-0713, Vol. 7 shows that surveillance and inservice testing accounted for from $13.8 \%$ to $21.4 \%$ of the annual collective dose at LWRs over the time period from 1975 through 1985. Routine and special maintenance accounted for the largest percentage of the incurred dose (from $67.1 \%$ to $76.6 \%$ ).

Even though surveillance testing is not the largest contributor to dose, it is significant and should be reduced where possible by reducing the frequency of testing in those areas that have significant radiation. Some utilities have acted to reduce radiation dose during surveillance testing (along with other routine activities) by performing walkthroughs of the tests in order to minimize time in high radiation areas as part of their ALARA (as low as reasonably achievable) programs.

In some cases, a conflict exists between the concern for incurred dose during testing and the need to test. An example of this, discussed in Section 8, is the testing of containment purge and exhaust isolation valves with resilient seals.

Containment purge and exhaust isolation valve tests require personnel to enter the containment. A general concern exists about containment entries at power. Is the risk from the problem requiring the containment entry at power a greater risk than the risk from the potential loss of containment integrity due to the entry? Containment airlocks are troublesome and airlock door interlocks are not especially reliable. Also, is the radiation dose received by the workers who enter the containment justified? The NRC should study this issue.

It appears that the occupational radiation exposure tends to increase as a plant ages. This appears to be due to additional maintenance and inspections required as the reactors age (NUREG/CR-5158). This trend, however, is probably independent of Technical Specifications requirements since they would not increase exposure as a function of plant age.

\subsection{Surveillance Testing and Plant Transients}

A study was made to determine which surveillance tests resulted in the most reactor trips and other types of plant transients.

This portion of the study was done by reviewing 10 CFR 50.72 reports of reactor trips over the period from January 1986 through July 1988 and by reviewing LERs on reportable test-caused transients occurring between 1984 and 1988. Those LERs were retrieved using the Sequence Coding and Search System (SCSS).

The LER review provided insight into the frequency and severity of test-caused events, but the analysis was bounded by (1) time and resource constraints, (2) detail provided in the LER abstracts and in 10 CFR 50.72 reports, and (3) the LER collection itself. The SCSS data were neither reviewed nor cross-checked, nor was additional sampling performed to ensure that all relevant LERs were reviewed. In addition, not all tests that produced transients are tests that are required by the Technical Specifications.

Table 3.4 Percentages of annual collective dose at LWRs by work function

\begin{tabular}{lrrrrrrrrrrrr}
\hline & \multicolumn{10}{c}{ Percentage of collective dose each year } \\
\cline { 2 - 12 } Work function & $\mathbf{1 9 7 5}$ & $\mathbf{1 9 7 6}$ & $\mathbf{1 9 7 7}$ & $\mathbf{1 9 7 8}$ & $\mathbf{1 9 7 9}$ & $\mathbf{1 9 8 0}$ & $\mathbf{1 9 8 1}$ & $\mathbf{1 9 8 2}$ & $\mathbf{1 9 8 3}$ & $\mathbf{1 9 8 4}$ & $\mathbf{1 9 8 5}$ \\
\hline Reactor operations & & & & & & & & & & & \\
and surveillance & 10.8 & 10.2 & 10.5 & 13.3 & 12.2 & 9.5 & 8.9 & 9.4 & 10.1 & 11.4 & 12.8 \\
Routine maintenance & 52.6 & 31.0 & 28.1 & 31.5 & 29.2 & 35.5 & 36.1 & 27.9 & 29.7 & 26.9 & 34.6 \\
Inservice inspection & 3.0 & 6.0 & 6.4 & 7.7 & 9.0 & 5.5 & 5.3 & 6.5 & 7.6 & 6.3 & 8.6 \\
Special maintenance & 19.0 & 40.0 & 42.5 & 35.9 & 39.4 & 40.6 & 40.5 & 46.8 & 43.9 & 45.4 & 32.5 \\
Waste processing & 6.9 & 5.0 & 5.8 & 5.0 & 3.6 & 3.0 & 4.2 & 5.0 & 4.6 & 3.6 & 5.1 \\
Refueling & 7.7 & 7.9 & 6.7 & 6.6 & 6.6 & 6.1 & 5.0 & 4.4 & 4.1 & 6.4 & 6.5 \\
\hline
\end{tabular}

Source: NUREG-0713, Vol. 7. 
For PWRs, reactor protection system (RPS) surveillances gave the most trips. Turbine valve testing caused the next highest number.

The next categories had approximately the same number of trips: engineered safety feature (ESF) logic testing, reactor trip breaker testing, and nuclear instrumentation testing. Monthly exercising of control rods also contributed to the reactor trips during the time period examined for this study. Figure 3.1 shows the frequency of trips due to various types of testing for PWRs.

The large number of reportable events (more than 2000 LER abstracts were examined) reflects the number and complexity of tests done at nuclear power plants. The number of events occurring during shutdown was similar to the number occurring at power. The increased testing and maintenance activity while the plant is shut down appears to offset the fact that plants spend more time critical than shut down. Overall, plants typically submit 5 to 10 LERs related to testing each year. These events fall into several general categories:

- trips

- partial emergency system actuations

- conditions that could jeopardize the safe shutdown

The review of the LER abstracts (for both PWRs and BWRs) showed that the reactor trip events were dominated by events caused during RPS instrument and control testing and turbine and turbine control testing. This is consistent with the results of the 10 CFR 50.72 report review. RPS-caused trips occurred most frequently during regularly scheduled tests during steady-state operation. The most prevalent causes were human errors such as mishandling of electrical leads, omitted procedural steps, and wrong train/wrong channel events.

Examples of these types of human errors are given below for one BWR.

- Poor communication and inattention caused the wrong equipment to be tested and resulted in a recirculating pump trip.

- Grounding of a jumper during removal for test restoration caused an unnoticed blown fuse. A reactor scram occurred during subsequent testing of another channel.

- Grounding of a jumper during installation caused trip of an RPS bus.

- Valving errors during functional test caused draining of a reactor vessel level reference leg and spiking of other instruments on the same reference leg. This caused a major plant transient and an eventual trip.

The most common cause of trips from power found in the LER review (which covered a longer period of time than the 10 CFR 50.72 review) is turbine-related tests at power. Examples include trips due to malfunctioning of control valves, bypass valves, governors, and stop valves.

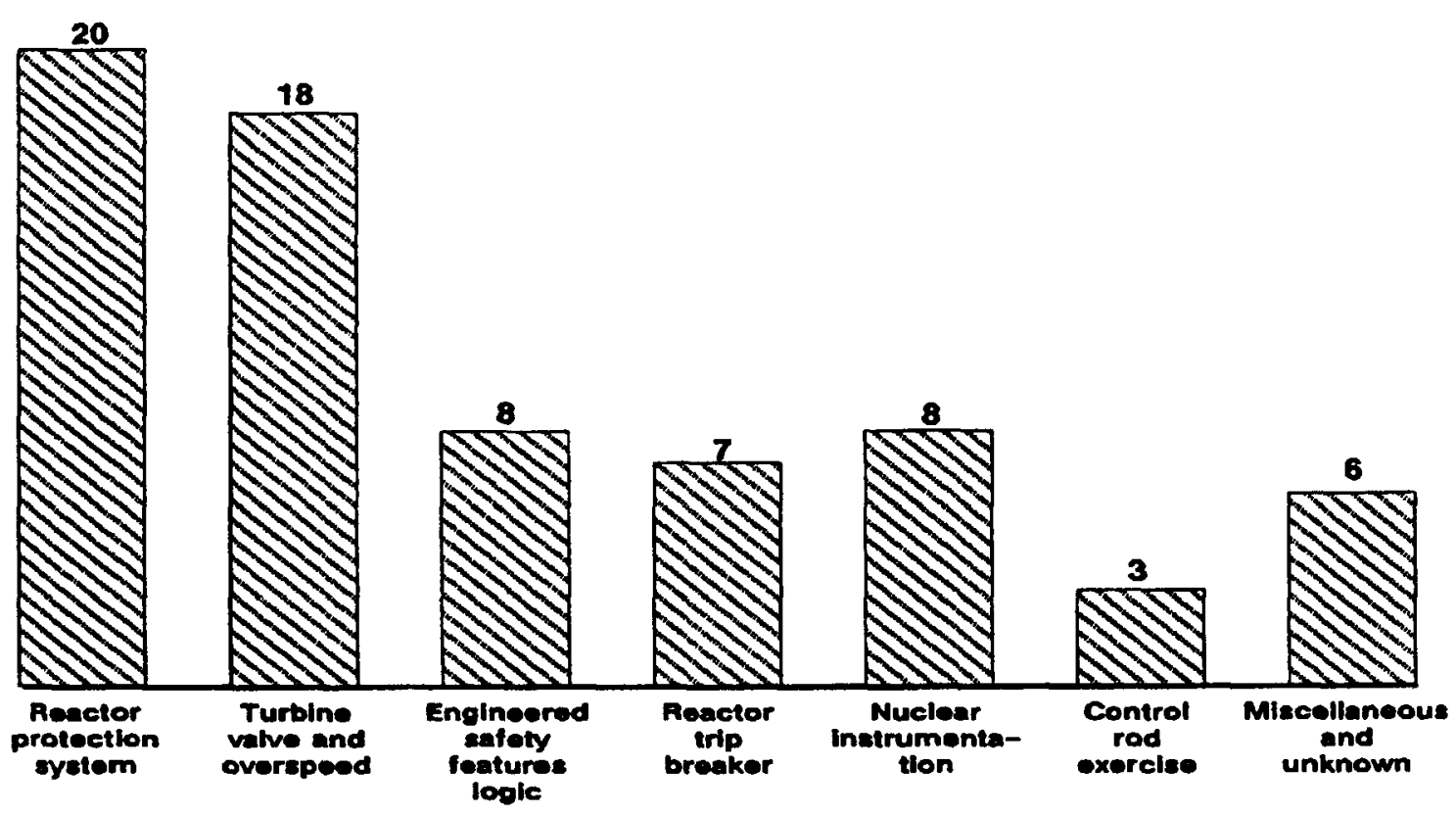

Figure 3.1 PWR trips attributed to surveillance testing, January 1986-July 1988 
Many of the turbine trips occurred at less than full power because the tests are required during reactor startup or the initial test conditions required lowered reactor power. Turbine trips were caused by electrical and mechanical problems, and, like most events, were also caused by human errors in writing procedures or following them. The remaining trips found in the LER data were generally caused by steam-system, feed-system, and electricalsystem testing. The steam- and feed-system trips were caused by stroking and partial stroking of MSIVs, and other assorted condensate and feed-system valves. These tests, like turbine tests, can cause spurious trip signals, or cause steam flow, steam pressure, steam generator level, and power fluctuations that can lead to trips. The total test-induced trip frequency is estimated (roughly) to be 0.6 per year. Note that this is about $10 \%$ of the total trip frequency.

The largest number of events reviewed were attributed to partial emergency system actuations. Most of these events have little safety significance, but they burden and distract plant operators. Most of these events involve ventilation (control room, turbine building, auxiliary building, etc.) shifting to the emergency mode. Reactor water cleanup (RWCU) initiations and partial containment isolations are also common. Inadvertent equipment starts include some emergency diesel generator and auxiliary feedwater actuations. These are not common but can lead to excessive equipment wear. Like reactor trips, nearly all events can be attributed to human error; less than $10 \%$ can be attributed to component failures.

Overall, reportable events caused by surveillance tests occur frequently, but are not generally severe. The testcaused trip frequency is not negligible, but relaxing surveillance test intervals cannot be expected to significantly reduce the overall trip frequency. Test-caused trips most frequently occur because of errors made when personnel follow specifically written procedures or when operators mishandle electronic test equipment and leads during regularly scheduled surveillances.

Reduced testing at power will reduce the number of human actions that could cause trips, but less-frequent testing may proportionately increase the number of procedural and other human errors. A specific concern noted in the review is that many surveillance test procedures require operators to lift leads or attach jumpers or probes to complicated circuits and test panels. These tests are difficult to perform in an error-free manner, and as operators and technicians perform the tests less frequently and are, therefore, less familiar with the tests, error rates may increase.

Thus there is a balance between reducing the test frequency to avoid human errors and keeping the tests frequent enough that the human error does not increase because operators are unfamiliar with the procedures.

\subsection{Surveillance Testing and Reliability}

The comment was made several times during the site visits that there is a lot of testing of equipment that rarely fails but that must be tested anyway; that is, a lot of unnecessary testing takes place.

The best way to approach the problem of too frequent or unnecessary testing is in terms of reliability-based Technical Specifications which would give credit for good performance. If a component failed infrequently, the surveillance interval could be increased (if the failures were predominantly due to standby stresses as opposed to demand stresses); likewise, if a component failed often, the surveillance interval would be decreased to some minimum value.

However, degradation of the equipment caused by testing too frequently must be kept in mind. If a component is failing too frequently, better preventive maintenance, a design change, or some other solution is preferable to more testing.

An NRC/industry working group has been established to investigate the feasibility of risk-based Technical Specifications in conjunction with reliability-centered maintenance (RCM). A lead plant has been selected to be used in a pilot study of this approach.

The Canadians currently use reliability-based Technical Specifications which state a reliability goal to be met by certain systems.

As discussed in Section 10 of this report, personnel involved in Generic Issue (GI) B-56 have been studying how to implement these reliability goals. Thus, work is beginning in the area of reliability- based Technical Specifications.

\subsection{Surveillance Testing and Plant Design}

Difficulties in performing surveillance tests or inspections are sometimes not inherent in the requirement but in the design of the plant and its various systems.

Instrumentation systems may be designed so that testing requires lifting of leads, use of jumpers, and other expedients to bypass channels for testing.

Access to valves or other equipment that must be operated in order to perform a surveillance is sometimes difficult, putting an unnecessary burden on personnel or exposing them to more radiation than would be necessary with a design that took better account of the need for testing. For example, at one PWR, in order to verify that the ECCS piping is filled and vented (to ensure that a 
water hammer could not occur), operators and health physicists who must climb ladders to the top of a tank farm must be dressed in protective clothing because the tank farm is a radiation area.

At another PWR, the surveillance on the containment area high radiation monitor requires that a heavy (because of shielding) high-level source be lowered to the monitor.

The current industry effort on advanced reactor designs should include a study of how all required surveillance testing will be performed in order to (1) minimize the possibility of a transient caused by testing, (2) minimize the burden on plant personnel who will have to perform these tests, and (3) minimize the radiation exposure received by people in performing the required testing.

\subsection{Surveillance Testing and Power Reductions}

Some surveillance tests in both PWRs and BWRs require power reductions in order to prevent a transient that can trip the reactor. In a PWR, a power reduction is necessary for stroking turbine valves. In a BWR, there are three tests that typically require a reduction in power: MSIV testing, control rod movement testing, and turbine valve stroking. Therefore, another incentive for eliminating unnecessary testing is the increase in capacity factor if such testing were done at a reduced frequency.

\subsection{Surveillance Testing and Equipment Wear}

Equipment is sometimes operated in a different way for surveillance testing than the way it would be used performing its design function. A simple example is an injection pump which, when tested, recirculates water back to a tank through a line that is smaller in diameter than the normal injection line, thus making the pump operate off its best efficiency point which degrades the pump. This is discussed in more detail later.

Electrical and electronic equipment wears or breaks from unplugging and removing equipment from cabinets for testing or from lifting leads and using jumpers.

The use of valves for isolation or flowpath change causes leaks around the valve packing and other valve or valve actuator problems.

The testing of an emergency diesel generator in its emergency mode induces thermal stresses and causes other problems which are discussed later in this report.

Thus, the importance of the test must be balanced against considerations of wear on equipment as well as on other considerations.

\subsection{Surveillance Testing on a Staggered Test Basis}

Staggered testing is the scheduling of tests for the subsystems or trains of a system in which the surveillance test interval is divided into a subinterval for each subsystem or train.

The advantage to testing on a staggered test basis is that the chances of a common-mode failure and equipment unavailability are reduced. A staggered test basis can have disadvantages.

One resident inspector stated that, at his plant, this type of testing requires additional licensed operators and overtime for operators. It also requires more individual entries into protection cabinets which causes scheduling problems for licensees and may increase the chance of a reactor trip. It can also extend the time required to perform surveillance tests by requiring initial setup time for test equipment to be repeated for each test rather than setting up just once. 


\section{REACTIVITY CONTROL SYSTEMS}

\subsection{Moderator Temperature Coefficient Measurement (PWR)}

All Standard Technical Specifications for PWRs contain a requirement to monitor the value of the moderator temperature coefficient (MTC), both the beginning-of-cycle value (which is typically positive but is always the least negative) and the end-of-cycle value (which is the most negative value). The least negative value is important for predicting plant behavior in events in which the reactor coolant is heated and the most negative value is important for predicting plant behavior when the reactor coolant is cooled (the most limiting event is the postulated main steam line break accident).

The current surveillance requirement in the Standard Technical Specifications for end-of-life MTC states that the MTC must be measured within 7 effective full-power days (EFPDs) after boron concentration in the reactor coolant decreases to $300 \mathrm{ppm}$. If this measured MTC is more negative than a specified value, then measurements of MTC must continue every 14 EFPDs until the end of cycle.

In a letter to NRC dated January 3, 1986 (Stewart, 1986), Virginia Electric \& Power Company proposed for North Anna Power Station, Units 1 and 2, adding a footnote to the technical specification which states that once the equilibrium boron concentration is $60 \mathrm{ppm}$ or less, further measurement of the MTC may be suspended provided that the measured MTC at an equilibrium boron concentration of $60 \mathrm{ppm}$ or less is less negative than the predicted value at $60 \mathrm{ppm}$.

This was supported by calculations which showed that the maximum possible change in MTC from $60 \mathrm{ppm}$ to the end of the operating cycle (EOC) is less than the difference in values of MTC from $60 \mathrm{ppm}$ to EOC specified in this technical specification.

This change to MTC surveillance requirements is important from an operational viewpoint since once the equilibrium boron concentration falls below $60 \mathrm{ppm}$, dilution operations take an extended amount of time because such a large volume of dilution water is required.

The VEPCO letter of January 3, 1986 (Stewart, 1986) states that, as an example, dilution of the reactor coolant system (RCS) from $50 \mathrm{ppm}$ to $40 \mathrm{ppm}$ requires charging of approximately 17,000 gallons of primary grade water and requires over 2 hours. Extended dilution times make reliable MTC measurements difficult to obtain because of fluctuations on system conditions that may take place over this time interval.
The NRC staff approved this proposed change to the MTC end-of-cycle surveillance requirement in a letter dated September 8, 1986 (Engle, 1986). The concept has generic applicability but requires plant-specific analyses.

\section{Findings}

- Technical Specifications require determination of moderator temperature coefficient at $300 \mathrm{ppm}$ boron concentration.

- If measured moderator temperature coefficient is more negative (less conservative than the technical specification value), the licensee must measure the moderator temperature coefficient every 14 EFPDs until the end of the cycle.

- Measuring the moderator temperature coefficient at low boron concentrations is difficult.

- VEPCO proposed a method for eliminating this requirement below $60 \mathrm{ppm}$.

- Method is plant specific.

Recommendation

Other licensees may wish to use the VEPCO approach.

\subsection{Control Rod Movement Test}

\subsubsection{Pressurized Water Reactors}

A test that seems to be of concern to reactor operators is the determination, every 31 days, that each control rod, not fully inserted, is capable of movement of a specified amount in either direction.

This test is performed to determine if the control rods are immovable. The control rods may be immovable either because of an electrical problem in the control rod drive circuitry or because the control rod is mechanically stuck. Following discovery, the licensee must determine whether the control rod is capable of being tripped, since the action requirements differ depending on that determination. As long as a control rod can be tripped, shutdown margin is not as great a concern; however, requirements for rod misalignment and rod insertion limits must still be followed with an immovable control rod.

The concern with this test is that it causes reactor trips or dropped rods. At first this may seem strange since control rods are designed to be moved and this test does not involve moving the control rods in any way that differs from the way the rods would be moved when controlling power or power distribution. However, rod drive 
mechanisms and control rod drive control systems are complex and their mecharrical movements and timing requirements are exacting. Most PWRs, except for these tests, operate with both the regulating rods and the shutdown rods withdrawn during normal operation.

Electrical problems with the control rod drive system, in general, do not prevent insertion of a control rod into the core when the reactor trip breakers are opened.

Mechanical problems are much less common. Table 4.1 lists cases in which the control rods were mechanically stuck or, at least, behaved as though they were. For these cases, a reactor trip signal would not have resulted in these rods inserting fully into the core.

Two observations can be made about the events listed in Table 4.1 in which a control rod was found mechanically immovable. First, not all of these stuck control rods were found during the control rod movement surveillance tests. Most were discovered during control rod drop timing tests performed during startup physics testing or when the rods were withdrawn from the core during plant startup.

Second, accident analyses assume that the single highest worth control rod is stuck and will not insert. In only one of these events was a second rod involved (Point Beach Nuclear Plant, May 1985) and in this case both of the rods were partially inserted.

A review of plant trip data from 1986 through July 1988 found three reactor trips that occurred during fuel rod motion testing.

In view of the successful operational record demonstrated by the control rod movement tests during power operation, the NRC staff recommends that the surveillance interval for control rod testing be changed from every 31 days to quarterly.

\section{Findings}

- The purpose of PWR control rod movement tests is to detect rods that cannot move.

- Most stuck rods are discovered during plant startup during initial pulling of the rods or during rod drop testing.

- This test causes reactor trips, dropped rods, and unnecessary challenges to safety systems.

\section{Recommendation}

Change frequency of the PWR control rod movement tests to quarterly.

\subsubsection{Boiling Water Reactors}

All control rods in a BWR are required to be tested by moving the control rod at least one notch every 7 days. The purpose of this test, as with PWR control rod movement tests, is to verify that the control rods are movable in response to a scram signal.

At any time during the operating cycle of a BWR, some control rods may be fully out while others are in an intermediate position. In the control cell core operating strategy which is used on most BWRs, most rods are fully withdrawn. It is the testing of the control rods at intermediate positions between fully in and fully out that presents operational problems for BWRs since flux peaks above the rod tips require a power reduction in order to reduce the stress on the fuel during rod movement. This power reduction must be scheduled around other plant activities, especially fuel preconditioning ramps. If control rods are exercised during a preconditioning ramp, power reductions of 50 to 100 MWe may typically be required.

If a control rod drive double-notches past the original position, local power changes of 1.5 to $2 \mathrm{~kW} / \mathrm{ft}$ can result. This is significant in terms of stress on the fuel. Testing fully withdrawn rods does not require a load reduction. The use of barrier fuel (or other fuel designs that eliminate high local cladding stress) should alleviate this problem.

Also, to prevent a missed surveillance, there is a strong desire to perform this surveillance on the same day each week. This, coupled with the load reduction requirements, makes scheduling very difficult.

Problems detected during this surveillance include hydraulic control unit directional control valves sticking in the open position and failures of the rod manual control system electronics. However, these failures are not related to the scram capability of the control rod.

A search using the Nuclear Plant Reliability Data System (NPRDS) found 212 cases of control rod drive failures between 1980 and the end of March 1988. Of these, only 8 were found during testing and of these 8 no failures were found that would have affected ability to scram.

The NRC staff has had discussions with General Electric Co. (GE) concerning the extension of the surveillance test interval. GE is concerned that if this surveillance interval were extended stagnant water in the seal area would not be sufficiently flushed. Without flushing of this stagnant water, the seals might degrade. GE stated that more study and perhaps a test would be necessary. 
Table 4.1 Mechanically stuck PWR control rods

\begin{tabular}{|c|c|c|c|c|c|}
\hline Plant & Date & Reference & Power level & $\begin{array}{l}\text { Discovered by } \\
\text { TS rod motion } \\
\text { surveillance }\end{array}$ & Description \\
\hline Haddam Neck & $08 / 69$ & See Note 1 & - & No & $\begin{array}{l}\text { Radial vane of spider, to which } 2 \text { rodlets were attached } \\
\text { had broken. Found during startup. }\end{array}$ \\
\hline Pt. Beach 1 & $10 / 70$ & See Note 1 & $\begin{array}{l}\text { Before } \\
\text { criticality }\end{array}$ & No & $\begin{array}{l}\text { During rod drop testing, several shutdown criticality } \\
\text { bank A rods stuck intermittently. More than } 20 \text { milling } \\
\text { chips were found in upper internals. One chip was found } \\
\text { lodged between the guide tube assembly and one control } \\
\text { rod spider arm. }\end{array}$ \\
\hline Robinson & $11 / 70$ & See Note 1 & Trip & No & Piece of foreign material was found in guide tube. \\
\hline Indian Pt. 2 & $\begin{array}{l}04 / 72- \\
05 / 72\end{array}$ & See Note 1 & $\begin{array}{l}\text { Before power } \\
\text { escalation } \\
\text { testing }\end{array}$ & No & $\begin{array}{l}\text { Malfunction of movement of } 4 \text { CRDs. Two were caused } \\
\text { by foreign matter. Two were caused by locally reduced } \\
\text { section of guide tube in dash pot area. }\end{array}$ \\
\hline Yankee Rowe & $\begin{array}{l}05 / 72- \\
08 / 72\end{array}$ & See Note 1 & - & No & $\begin{array}{l}\text { Rod } 18 \text { could withdraw but would not drop properly. } \\
\text { Failed to drop completely during an October scram. } \\
\text { Loose fasteners suspected of causing difficulties. }\end{array}$ \\
\hline Davis-Besse & $06 / 81$ & LER 81-038 & - & No & $\begin{array}{l}\text { Control rod 5-8 was not withdrawing with the rest of its } \\
\text { group. Leaf spring anti-rotational device of the lead screw } \\
\text { nut assembly had fractured into several pieces preventing } \\
\text { lead screw from rising. }\end{array}$ \\
\hline San Onofre 1 & $12 / 81$ & LER 82-003 & - & No & $\begin{array}{l}\text { Rod cluster control (RCC) assembly stuck. Freed after } \\
\text { repeated manipulation. Probable cause: failure of weld } \\
\text { attaching a vane supporting two rodlets to the } R C C \text { hub. }\end{array}$ \\
\hline Calvert Cliffs 2 & $02 / 82$ & $\begin{array}{l}\text { LER } 82-10 \text {, } \\
\text { Rev. } 1\end{array}$ & Shutdown & No & $\begin{array}{l}\text { CEA-19 stuck following trip at } 8 \text { inches withdrawn. Seven } \\
\text { days later CEA-19 was "freed" and tested satisfactorily. } \\
\text { Inspection at following refueling failed to find a cause. }\end{array}$ \\
\hline
\end{tabular}


Table 4.1 (Continued)

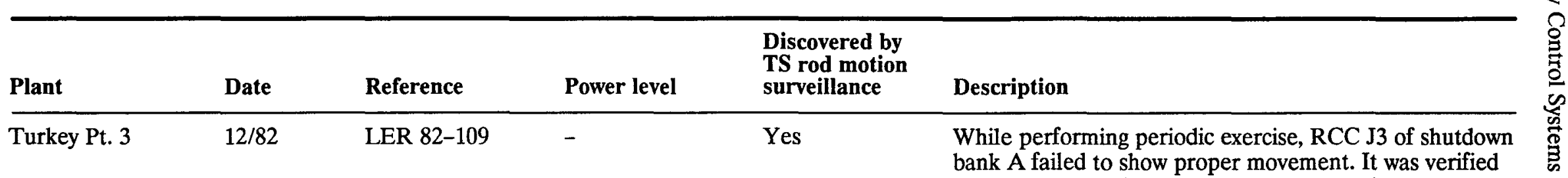

\begin{tabular}{|c|c|c|}
\hline Surry & $06 / 84$ & LER 84 \\
\hline
\end{tabular}

that $\mathrm{J} 3$ stayed in fully within position. 12/28/82 unrelated

trip occurred. J3 remained withdrawn. Root cause not determined. On 12/31/82, RCC J3 began to move normally.

$\begin{array}{lllll}\text { Surry } 1 & 06 / 84 & \text { LER } 84-017 & 29 \% & \text { Yes }\end{array}$

Control rod B- 6 became stuck. One of two holddown spring clamps had separated from the top of a fuel assembly and had become lodged between two RCC assembly rodlets.

$\begin{array}{lllll}\text { McGuire } 2 \text { LER 84-032 } & \text { 12/84 }\end{array}$

Duke notified by Westinghouse that a Korean reactor control rod drive mechanism (CRDM) guide screw rotated out of position, fell, and became lodged on top of CRDM latch assembly. Loose guide screws could cause bending and prevent driveline motion. 5 out of 53 guide screws on McGuire 2 did not meet acceptance criteria and were replaced. 14 drive rods replaced on Catawba 1.

$\begin{array}{lcccc}\text { Davis-Besse } & 03 / 85 & \text { LER 85-006 } & 0 \% & \text { No } \\ \text { Pt. Beach } 1 & 05 / 85 & \text { See Note 1 } & - & \text { No } \\ \text { McGuire 2 } & 06 / 86 & \text { LER 86-008 } & 0 \% & \text { No } \\ \text { Palo Verde 1 } & 01 / 88 & \text { See Note 2 } & - & \text { No }\end{array}$

Set screw frequently jammed inside CRDM, preventing disengagement of the latching assembly during control rod drop testing.

Control rod stuck at mid-height during rod drop testing. Second rod stuck at 90 inches out.

Control rod L-3 stuck and unable to drop into core. On $6 / 21 / 86$ while inserting all control rods into core, control rod L-3 inserted with other rods. Sticking attributed to small particle of debris.

CEA-56 did not drop during rod drop testing. Bearings from multi-stud tensioner machine lodged in guide tube.

1. Nuclear Power Experience, Volume PWR-2; Book-1, “Experiences”; IV-“Control Rods and Drives”; Section A-“Control Rods,” pp. 1-14 (January 1973-July 1988); S. M. Stoller Corp.,

2. Letter from E. E. Van Brunt, Jr. (Arizona Nuclear Power Project), to J. B. Martin, Region V Administrator (NRC), February $25,1988$. 
The NRC staff therefore recommends that the BWR Owners Group study the feasibility of extending the test interval for the BWR control rod movement test. If it is concluded that the extension of this interval is feasible from an engineering design viewpoint, the NRC staff should analyze the study findings and allow the extension, if found acceptable.

Another technical specification for BWR control rods states that if one control rod is immovable because of friction or mechanical interference, the other control rods must be exercised once every 24 hours. This requirement is very resource intensive. In view of the successful experience noted during the control rod movement tests, the NRC staff recommends that the requirement be changed to "within 24 hours of discovery of an inoperable control rod and every 7 days thereafter."

\section{Findings}

- BWR control rod movement tests take significant time to do.

- A search using NPRDS failed to find a single situation in which an immovable control rod was discovered as a result of this test.

- If a control rod is found immovable, all other control rods are required to be tested every 24 hours. This is very resource intensive.

\section{Recommendations}

- The BWR Owners Group should study the feasibility from an engineering viewpoint of extending the surveillance test interval for the control rod movement test from the present requirement of every 7 days. If the BWR Owners Group decides that it is feasible from an engineering viewpoint, the NRC staff should examine the study findings and allow the extension if found acceptable.

- The Technical Specifications should be changed to require that, if a control rod is immovable because of friction or mechanical interference, the other control rods should be tested within 24 hours and every 7 days thereafter.

\subsection{Standby Liquid Control System (BWR)}

The standby liquid control (SBLC) system injects concentrated boric acid into the reactor vessel of a BWR as an emergency measure to maintain shutdown margin. This is done by opening an explosive valve and starting a pump. Technical Specifications require testing the explosive charge every 18 months. The Boiler and Pressure Vessel Code of the American Society of Mechanical Engineers
(ASME Code) requires that at least $20 \%$ of the charges in explosively actuated valves shall be removed, fired, and replaced every 2 years with charges from a fresh batch. A sample charge from the fresh batch must be tested satisfactorily. Charges must not be older than 10 years. If a charge fails to fire, all charges with the same batch number must be removed, destroyed, and replaced with charges from a fresh batch from which a sample charge has been tested satisfactorily. Because these valves must function during a reactivity control emergency, the staff considers the 18-month surveillance of the explosive valves in the SBLC system to be reasonable. For those plants considering a 24-month cycle, testing the explosive charges once each refueling interval would be acceptable. However, for plants that operate on a 24-month fuel cycle, the bounding surveillance interval could be as long as 30 months. In this case, $25 \%$ of the charges should be tested each refueling interval so that the Code requirement that all charges must not be older than 10 years will continue to be met.

The Technical Specifications also require testing the SBLC system pumps every 31 days. The ASME Code requires that this test be performed quarterly. The NRC staff recommends that the interval in this surveillance requirement to test the pumps be changed to quarterly.

\section{Finding}

Testing of the explosive valves and pump in the standby liquid control system is required more frequently by the Technical Specifications than by the ASME Code.

\section{Recommendations}

- Explosive valves should be tested once each refueling interval for fuel cycles up to 24 months' duration.

- The SBLC system pump test should be required by Technical Specifications quarterly, in agreement with the ASME Code.

\subsection{Closure Time Testing of Scram Discharge Volume Vent and Drain Valves (BWR)}

The Standard Technical Specifications require that at least once every 18 months each scram discharge volume (SDV) vent and drain valve be tested to assure that it will close within 30 seconds after receipt of a signal for control rods to scram and will open when the scram is reset.

The 30-second criterion for vent and drain valve closure was proposed as Criterion 1 of the generic safety evaluation report for the BWR scram discharge system (GSER, 1980). However, many BWR closure tests produce closure times that are very close to 30 seconds, leaving very little margin. 
Georgia Power Co., the licensee for Hatch Nuclear Plant, Units 1 and 2, proposed to increase the required closure time.

General Electric Co. provided an analysis (MDE 103 1184) that took into account the following factors and made assumptions about the value of each factor:

(1) scram time

(2) displacement volume of water per individual control rod drive

(3) average expected post-scram leakage flow per individual control rod drive

(4) SDV drain flow prior to isolation

(5) minimum scram discharge volume

The analysis considered (1) overfilling of the scram discharge volume (which would produce a radiological concern because of spillage of primary water outside the primary containment) and (2) the temperature increase in the SDV (if the temperature were greater than saturation, there could be flashing of the water to steam and possible hydrodynamic loads).

The analysis showed that the SDV would not overfill with a longer closure time. Hence there was no radiological concern. The analysis (based on GE data) also showed that there would be no flashing of water to steam and, therefore, no hydrodynamic loads.

This analysis is dependent on specific plant values for the five factors listed above. Thus, in the case of Hatch, the licensee was able to justify a closure time of 60 seconds for Unit 2 but only 45 seconds for Unit 1 (Crocker, 1987).

Hence, the NRC staff recommends that licensees who experience difficulty with the 30-second closure time of Criterion 1 of the Generic Safety Evaluation Report dated December 1, 1980 (GSER, 1980) and the Standard Technical Specifications do a plant-specific analysis using the approved methods of MDE 1031184 to derive a new vent and drain valve closure time for their plant(s).

\section{Findings}

- Some BWR SDV vent and drain valves close in times very close to the 30 -second criterion in the Technical Specifications.

- Georgia Power Co. and GE derived a method of assuring safe operation with longer vent and drain valve closing times. This method is plant specific.

\section{Recommendation}

Other BWR licensees may wish to use the Georgia Power Co./GE method on a plant-specific basis to extend the SDV vent and drain valve closure time requirement.

\subsection{Reactor Scram Testing To Demonstrate Operability of Scram Discharge Volume Vent and Drain Valves (BWR)}

A Generic Safety Evaluation Report was issued December 1, 1980 (GSER, 1980) for the BWR scram discharge system. The report considered the Browns Ferry Nuclear Power Station, Unit 3 partial scram failure event of June 28,1980 and subsequent investigations, tests, and analyses, and failures of scram level instruments at other plants. The GSER provided an acceptable basis for continued BWR plant operation along with criteria for design and/or modification of the scram discharge system. This also included surveillance criteria to be included in Technical Specifications.

One of the surveillance tests required by the GSER is a verification that the scram discharge volume vent and drain valves are operable when the control rods are scram tested from a normal control rod configuration of $50 \%$ or less rod density. The vent and drain valves must close within 30 seconds* after the signal for control rod scram is received and must open after the scram signal is reset. This test is required at least once every 18 months.

While reviewing a proposed technical specification change for the SDV at Susquehanna Steam Electric Station, Units 1 and 2, to eliminate this test requirement, Region I personnel noted that a large variation exists for SDV surveillance requirements between plants (Kane, 1987).

NRC Region I staff compiled information regarding SDV vent and drain valve surveillance requirements for all NRC Region I BWR facilities. This compilation showed that:

... in [NRC] Region I, 5 facilities have surveillance requirements for testing the SDV vent and drain valves from less than or equal to $50 \%$ control rod density; 4 facilities require the test to be done from a shutdown condition; one facility requires the test to be done from both conditions; and 4 facilities have no requirement for this type of testing. In addition, review of Technical Specification surveillance requirements for recently licensed facilities in other

\footnotetext{
-See Section 4.4 in this report on closure time testing of the SDV vent and drain valves.
} 
regions revealed that River Bend 1, Perry 1, Clinton 1 and Fermi 2 each have the requirements for conducting the testing from a shutdown condition.

The GSER technical basis for including a scram is that:

[A] total integrated system test [IST] will demonstrate that the system retains its capability to monitor the accumulation of water in the SDV and to scram the plant when required. The IST will allow operators to check for the proper operation of system components and instrumentation under operating conditions normal to a scram operation.

The Standard Technical Specifications require the integrated system test to be performed at least once every 18 months.

Pennsylvania Power and Light Company, the licensee for the Susquehanna Steam Electric Station, justified the technical specification change deleting this test requirement on the basis that: (1) deletion will eliminate the possibility of subjecting Susquehanna Units 1 and 2 to additional plant scrams solely for the purpose of meeting this requirement and (2) operability of the SDV vent and drain valves can be adequately demonstrated during a scram initiated from shutdown conditions, as occurs during the 18-month reactor mode switch shutdown position functional check.

Thus, there are inconsistencies in the application of this requirement to different BWRs. There also does not appear to be a strong technical basis for this requirement since testing of the SDV vent and drain valves can be conducted at shutdown conditions without subjecting the reactor to unnecessary scrams.
NRC Region I staff recommended that: "the Technical Specifications be revised to include a requirement to evaluate SDV system response after each scram to verify no abnormalities exist prior to plant restart," and further stated that: "this requirement along with system testing during a scram from shutdown conditions and periodic valve operability checks fully meets the intent of the Generic Safety Evaluation Report for BWR Scram Discharge System."

It is concluded that the Region I recommendations are reasonable and should be applied to all BWRs.

The NRC staff therefore recommends that this requirement be deleted from the Technical Specifications.

\section{Findings}

- A scram test at $50 \%$ rod density or less to assure vent and drain valve operability is required.

- Other tests are done to assure SDV vent and drain valve operability.

\section{Recommendations}

- Remove the requirement for a scram check of SDV vent and drain valve operability at a $50 \%$ rod density or less.

- Require an evaluation of SDV system response after each scram to verify that no abnormalities exist prior to plant restart.

- Require vent and drain valve operability testing during a scram from shutdown conditions. 


\section{INSTRUMENTATION}

\subsection{Nuclear Instrumentation Surveillance (PWR)}

The excore neutron monitoring system for pressurized water reactors (PWRs) is typically designed to sense leakage neutron levels from neutron source strength (0.001 $\mathrm{n} / \mathrm{cm}^{2} / \mathrm{sec}$ ) to a level greater than the neutron flux corresponding to $100 \%$ power (typically $125 \%$ to $200 \%$ power). In order to accurately cover this region, the excore system is divided into three ranges: the source range, the intermediate range, and the power range. The source range covers shutdown and subpower neutron levels. The intermediate range provides coverage of the subpower operating levels as well as covering the entire power range. The power range yields information of core neutron level when the reactor is critical and is supplying heat to the reactor coolant system. The three ranges of neutron indication are successively overlapped by at least one decade to prevent a loss of indication when one range is operating at the high end of its scale and the next range is operating at the low end of its scale.

These instruments typically perform safety, monitoring, and control functions.

There are typically four channels of power range nuclear instrumentation. A channel functional test is presently required monthly. The testing involves simulating a trip signal in one channel. This type of testing results in reactor trips when a human error or an electrical disturbance causes a second channel to trip. As is discussed in the introduction (Section 1) of this report, nuclear instrumentation testing is a frequent cause of reactor trips from testing.

The safeguards built into the design of the neutron flux measuring instrumentation vary from plant to plant but typically, four power range nuclear instrumentation channels are provided for overpower protection. An additional auctioneered high signal is derived by auctioneering the four channels for automatic rod control. If any channel fails in such a way as to produce a low output, that channel is incapable of proper overpower protection but does not cause control rod movement because of the auctioneer. Two out of four overpower trip logic ensures an overpower trip if needed, even with an independent failure in another channel.

In addition, channel deviation signals in the control system give an alarm if any significant power range channel deviation occurs. Finally, an overpower signal from any nuclear power range channel blocks manual and automatic rod withdrawal. The set point for this rod stop is below the reactor trip set point.

Operating data on the nuclear instruments were reviewed to assess nuclear instrument failure and how to detect such failure. Many of the problems with nuclear instrumentation appear to be found by operators doing routine channel checks or observations of the instrument readouts.

Relatively few failures of the nuclear instrumentation appear to have been found during regularly scheduled surveillance testing. Power supply failures occur fairly often and they are found immediately by alarms or by deviations from expected values. Other frequent causes of failure of the nuclear instrumentation systems are amplifier failures, or cabling failures (e.g., failures caused by radiation or water). The detectors themselves also fail, but not as often as the electronic instrumentation associated with the detectors.

Some failures of the nuclear instrumentation system cause reactor trips, especially when the plant is already in shutdown and being monitored by intermediate range instrumentation (which is a one-out-of-two to trip). Turbine runbacks are also caused by faulty nuclear instrumentation: (For a turbine runback, only one channel need fail.)

It appears from a review of operating experience that nuclear instrumentation experiences significant set point drift. Therefore, before the calibration requirements are modified, the set point drift of nuclear instrumentation should be more completely examined. However, there seems to be no reason, based on a review of the operating data, why the analog channel operational test could not be performed quarterly rather than monthly. (This has already been proposed by the vendor owners group and in some cases has already been approved by NRC.)

\section{Findings}

- Nuclear instrumentation systems consist of source range, intermediate range, and power range detectors and supporting electronic instrumentation and power supplies.

- Testing of nuclear instrumentation is a significant cause of trips.

- Most failures of the nuclear instrumentation system are found from plant behavior (trips, turbine runbacks, or from operator channel checks, or response to alarms). 


\section{Recommendation}

Change surveillance interval of analog channel functional tests of nuclear instrumentation to quarterly.

\subsection{Slave Relay Testing (PWR, BWR)}

Each instrumentation channel and interlock of the engineered safety features actuation system (ESFAS), as well as the actuation logic and relays, are required by the Technical Specifications to be demonstrated operable. The actuation logic test and master relay test are to be performed monthly on a staggered test basis. Slave relay testing is to be performed quarterly. The actuation logic tests and the master relay tests do not appear to be a problem; the slave relay tests, however, involve the actuation of a large number of components (valves and pumps). A great deal of coordination is therefore necessary between the test technicians and the control room operators.

These tests lead to inadvertent actuations of safety equipment and reactor trips.

NUREG/CR-4715 examined the failure modes of relays of various types (undervoltage, control, timing, and protective) and concluded that although the failure data showed age-related failure trends for relays, the data available to date do not indicate a high failure rate. The normalized licensee event report (LER) and Nuclear Plant Reliability Data System (NPRDS) data indicate an average failure rate of fewer than two reportable relay failures per year per plant, which is small by comparison to the number of relays in the plant.

The reliability of slave relays is a reasonable basis for relaxing the testing requirements.

The NRC staff recommends that the scope of each quarterly test be reduced so that a different sample is tested each quarter. This approach has been applied to at least one plant that could not test some slave relays at power. Depending on the sample size, some slave relays could be tested at power and others could be tested when the plant is shut down.

With this alternative, one could be assured that those slave relays that offer the greatest potential for plant upsets would be deferred to that group that is tested during a plant shutdown. This would further the goal of reducing the potential of challenges to safety systems due to testing during power operation. By testing a portion of the slave relays during each quarter, there is a reasonable time limit in which common-mode failure could be detected. Common-mode failure is generally a greater threat to safety than are single-component failures.
Findings

- Relay reliability is generally good.

- Relay testing at power contributes to the frequency of inadvertent equipment starts and reactor trips.

\section{Recommendation}

Perform relay testing on a staggered test basis over a cycle and leave the tests carrying highest risk to a refueling outage or other cold shutdown.

\subsection{Test Intervals for RPS and ESFAS (PWR, BWR)}

During discussions with one of the utilities, the staff noted that although there wasn't opposition to the requirement for staggered testing, a strict application of staggered test requirements caused problems because it results in a different test schedule for three- and four-channel systems. The NRC is reviewing or has approved the owners groups topical reports for extending the channel functional test of reactor trip system channels from monthly to quarterly. For testing on a quarterly basis (every 92 days), the interval between tests of different channels for a staggered test basis for three-channel systems is every 31 days, but every 23 days for a four-channel system ( $92 / 3 \mathrm{vs.}$ 92/4). The effect is that each cabinet, containing one channel, is involved in a test twice each quarter. The preferred solution would be a relaxation of the staggered test cycle for three-channel systems to coincide with the test cycle for four-channel systems. The net effect is that instead of two different testing cycles with the concomitant increase in the required access to instrument cabinets, there would be one four-channel testing interval in which a three-channel test would not be performed.

The NRC staff recommends that this change be implemented with the approval of the owners groups topical reports and allow its application before then if a utility so chooses.

\section{Findings}

- Some RPS and ESFAS functions have three channels; others have four.

- $\quad$ Staggered test basis testing would require more frequent access to instrument cabinets when applied to three- and four-channel functions.

\section{Recommendation}

Test three-channel systems on the four-channel schedule. Do not test one of the three channels during a fourchannel test interval. Thus, the sequence of testing would be: 
Three channel

$\begin{array}{ll}\text { A } & \text { A } \\ \text { B } & \text { B } \\ \text { C } & \text { C } \\ - & \text { D } \\ \text { A } & \text { A }\end{array}$

This could be implemented now for those three- and four-channel functions requiring staggered test basis testing.

\subsection{Hydrogen Monitor Surveillance (PWR, BWR)}

Hydrogen (or combustible gas) monitors are to monitor hydrogen concentration in containment following a lossof-coolant accident (LOCA) and are designed to be consistent with Regulatory Guide 1.2, "Control of Combustible Gas Concentrations in Containment Following a LOCA." These monitors are used only after a LOCA to tell the operator when to initiate the hydrogen recombiners. The hydrogen recombiners are not required for a period of hours to days after a large-break LOCA.

The Technical Specifications require a channel check (at least once every 12 hours), an analog channel operational test (at least once every 31 days), and at least once every 92 days, on a staggered test basis, a channel calibration using two gas samples, one containing $1 \%$ hydrogen, the other containing $4 \%$ hydrogen.

The monthly tests check only the electronics. The quarterly test checks calibration.

Typical staff hours required for these tests are given in the table that follows:

\begin{tabular}{lll}
\hline Test & $\begin{array}{l}\text { Personnel } \\
\text { required }\end{array}$ & Time \\
\hline $\begin{array}{l}\text { Analog channel } \\
\text { operational test }\end{array}$ & 2 technicians & 4 hours \\
$\begin{array}{l}\text { Calibration with } \\
\text { two gas samples }\end{array}$ & 2 technicians & 32 hours \\
\hline
\end{tabular}

Typically, the hydrogen monitors have alarms to indicate electronic system or power failures. In addition, daily channel checks are done.

In order to perform the analog channel operational test and calibration, the containment isolation valves which are normally closed must be opened for those plants with the sensor inside the containment. The Technical Specifications allow these valves to be "opened on an intermittent basis under administrative control." There are four containment isolation valves for two monitors. "Administrative control" means that measures are taken to assure that the control room operators are aware of the position of these valves so that the appropriate action will be taken to close them, if required.

There are other operability checks of the system. There are alarms to indicate electronic system and power failures. In addition, operations personnel monitor the indication daily and note any changes in indication. In view of this, the NRC staff recommends that the surveillance test interval for hydrogen monitors be extended to a refueling interval, and analog channel operational test to quarterly.

\section{Findings}

- Hydrogen monitors serve only an indicating function and are only required after an accident in which the core is damaged.

- Calibration requires opening containment isolation valves for a system with sensor inside the containment.

- Calibration is time consuming.

\section{Recommendation}

Change frequency of calibration to once each refueling interval and analog channel operational test to quarterly.

\subsection{Reactor Trip Breaker Testing (PWR)}

The Standard Technical Specifications require reactor trip breakers and reactor trip bypass breakers to be tested every 31 days. The Standard Technical Specifications further allow a channel to be bypassed for surveillance testing for up to 2 hours.

A search of operating data was undertaken to attempt to determine the cause of reactor trip breaker failures. In particular, the NRC staff attempted to determine if testing might be contributing to the failure of reactor trip breakers.

NUREG/CR-4715, prepared for the Nuclear Plant Aging Research (NPAR) Program, notes that most of the failures of reactor trip circuit breakers were age related, that is, related to service duration and the number of operating cycles, and that, among the primary mechanically induced stress mechanisms is routine opening 
and closing operations. It therefore seems that testing is a contributor to breaker failure. However, adjustment and lubrication problems were also significant, as were broken parts. Therefore, although testing may be too frequent, it seems that preventive maintenance could be improved.

In order to assess, based on today's testing and preventive maintenance practices, whether less frequent testing might contribute to better reactor trip breaker reliability, a more detailed study is necessary. For this present study, the answer was inconclusive. It is relevant to note that since diverse trip features were incorporated in reactor trip breakers (shunt trip feature) there has been no relaxation of the test interval, although those changes resulted in a significant improvement in reliability.

However, it is clear that reactor trip breaker testing has caused reactor trips. The reason for trips is usually human error while conducting the testing. In order to attempt to reduce this error rate, the NRC staff recommends that the allowed outage time for one channel be increased to allow plant personnel to do the testing without being rushed.

\section{Findings}

- Testing reactor trip breakers has caused reactor trips.

- Most of these trips are related to human error.

- Aging of reactor trip breakers is a function of the number of cycles of operation. Reactor trip breakers are most often operated for testing.

- Reactor trip breakers require good preventive maintenance.

\section{Recommendation}

The vendor owner groups should consider whether more recent operating experience would justify a change in the test interval for reactor trip and bypass breakers. Licensees should pursue implementing an increase in the allowable outage time for testing reactor trip and bypass breakers as addressed in the vendor topical reports for extending surveillance intervals.

\subsection{Power Range Instrument Calibration (PWR)}

Technical Specifications require that above $15 \%$ power the calorimetric power be compared with the excore power indication. If the absolute difference is greater than $2 \%$, the excore channel gains must be adjusted to be consistent with the calorimetric power. During the plant visits conducted for this study, it was suggested that the $2 \%$ limit be retained for steady-state operation, but that a $5 \%$ limit be permitted for such transient operation as might occur during power changes at startup or load changes, because a less restrictive allowable deviation during transient operation would greatly lessen the probability of reactor trip due to error while this calibration is performed. This was considered justified because of the temporary nature of the situation.

This proposal was made on the basis of the fact that many of the adjustments that are made at low power or following transients may not ensure the same accuracy at full power. Thus, many of these adjustments made at these conditions may not have a significant effect on the accuracy at which high power trips would occur. Also, the plant computer provides almost continuous thermal power calculations which are used to ensure that the $100 \%$ power rating is not exceeded and, therefore, the errors in indicated nuclear power are not significant from the standpoint of exceeding the licensed power level.

However, reactor safety analyses are done assuming a $2 \%$ error in power and the safety analyses assume that the accident being analyzed can start from any condition of normal operation. Therefore, to increase this uncertainty to $5 \%$ would be inconsistent with the accident analyses assumptions on power variation. At least one reactor vendor, however, already takes into account a transient uncertainty as well as a steady-state uncertainty in calculating core power distribution limits.

The staff suggests that the owners groups consider this issue, and if it is judged to be of sufficient importance, the owners groups should present a proposal which will help prevent reactor trips and be consistent with the safety analysis and Technical Specifications power distribution requirements.

\section{Findings}

- At greater than $15 \%$ thermal power, the nuclear power must agree with the calorimetric power within $2 \%$. If it does not, the gain of nuclear instruments must be adjusted.

- A recommendation was made that the uncertainty should be increased to $5 \%$ to help avoid reactor trips during the calibration when the plant was in a transient operating mode.

- Safety analyses assume a $2 \%$ uncertainty on power. This must include unsteady power operation unless a specific allowance is made separately for unsteady power. 


\section{Recommendation}

The owners groups should consider this issue, and if it is judged to be of sufficient importance, the owners groups should present a proposal which will help prevent reactor trips and be consistent with the safety analyses and Technical Specifications power distribution requirements.

\subsection{Control Element Assembly Calculator Surveillance (CE CPC PWR)}

Newer Combustion Engineering (CE) reactors utilize a computer system as part of the plant protection system (PPS). This system is the core protection calculator (CPC) and is used to generate two reactor trips (there are several other reactor trips included in the system design, for example, each of the San Onofre Nuclear Generating Station Units 2 and 3 has 15 total trips). The two computer-generated trips are the low departure from nucleate boiling ratio (DNBR) and the high local power density (LPD) trips.

The control element assembly calculator (CEAC) provides the CPC with information about individual CEA position deviations. The CEAC "looks" at the four CEAs in a subgroup and sends penalty factors to the CPCs if the positions of rods in a subgroup deviate from each other by more than a deadband value.

The CEAC also provides a CEA withdrawal prohibit signal via the CPCs on a CEA misalignment.

The monthly channel functional test is required to include the injection of simulated process signals as close to the sensors as practicable to verify the operability, including the alarm and trip functions. To perform this test requires two technicians to work about 4 hours per CEAC. It involves an administrative burden in scheduling surveillance, since testing is not allowed by the licensee during PPS testing or during "hands-off" periods of high system load demand. Because of this, the technicians must work quickly, according to the San Onofre licensee, increasing the risk of an inadvertent plant trip.

With one CEAC out of service for this testing, a failure of the other CEAC will cause a plant trip. Human error could also lead to a trip, since the CEACs are one-of-two to trip.

The licensee for San Onofre stated that during the tests the CEAC is powered off and powered on, which represents a stress over time on the computers. The cabinet doors remain open during this test, causing both the CEAC and its associated CPC to overheat because the normal air cooling flow patterns are disrupted. The testing involves mechanical cycling of cables and connectors and may result in premature failures of these components.

The CEACs do not generate a penalty on inward single CEA deviations and are not required to protect against multiple inward deviations. The CEAC is not credited for protection against CEA ejection events. Its only purpose currently is to protect against single CEA withdrawals from deep group insertions at high power. This combination of conditions is uncommon. The "withdrawal prohibit" signals generated by either CEAC protect against many withdrawal events. The CEA drive mechanism control system is designed to be single-failure-proof so that the probability of core damage due to events normally covered by CEAC operation is low.

The CEACs perform self-checking routines during normal operation and the operators check the CEAC operation at least twice each day as required by the Technical Specifications. Sudden major failures would result in annunciation. A slow drift would be discovered by the channel checks.

This surveillance requirement, therefore, appears to meet several of the staff's criteria. Its one-out-of-two trip logic means that the plant is placed in a vulnerable position. The people performing the surveillance are under some stress to work quickly on a sensitive task and there is some wear on the equipment. In addition, the equipment is self-checking and reliable. The NRC staff, therefore, recommends extending the surveillance interval to quarterly for the channel functional test. A further extension might be possible on a plant-specific basis.

\section{Findings}

- The CEAC channel functional test places the plant in a vulnerable position.

- The test puts some stress on personnel and the equipment.

- The CEAC is self-checking. In addition, channel checks are required by Technical Specifications.

\section{Recommendation}

Extend the surveillance interval from monthly to quarterly.

\subsection{Incore Detector Surveillance (CE and B\&W PWRs)}

Incore detectors in $\mathrm{CE}$ and $\mathrm{B} \& \mathrm{~W}$ reactors are used to monitor core power distribution parameters such as azimuthal (quadrant) tilt and axial shape index (CE) or axial power imbalance (B\&W). In $\mathrm{CE}$ reactors, incore detectors are used to monitor the linear heat generation 
rate and in $\mathrm{B} \& W$ reactors, to measure $\mathrm{FQ}$ (ratio of maximum core power to average core power).

In $\mathrm{CE}$ reactors in which the core protection calculator is part of the plant protection system, the incore detectors provide input to COLSS (core operating limit supervisory system).

COLSS is a continuous online monitoring system whose program is located in the plant computer. Its inputs to the plant computer are control grade (not safety grade). Thus, COLSS is not part of the plant protection system and does not trip the plant. It monitors LCOs on thermal margin (DNBR), linear heat rate, azimuthal tilt, and axial shape index. It also assists the operator in maintaining total core power equal to or below the reactor's licensed power. COLSS will alarm to warn the operator if any of these LCOs are violated.

In $\mathrm{CE}$ reactors, the surveillance requirements for the incore detectors state that a channel check is required within 24 hours before its use for monitoring or calibrating and at least once every 7 days thereafter. Thus, a channel check is required weekly, independent of the requirement to assure operability by performing a channel check before use in monitoring or calibrating. B\&W reactors do not have this requirement. $B \& W$ Technical Specifications require a channel check only within 7 days before use.

The channel check requires about 1 hour each for San Onofre 2 and San Onofre 3 . This would be increased to 3 hours a week per unit if a combination of new and old detectors was used in the core. The Technical Specifications require that the detectors be monitored before using them with COLSS on reactor startups. This results in critical path impact since the reactor must be above $15 \%$ power to generate sufficient neutron flux and must remain below $20 \%$ power until the surveillance is done.

There are nominally 280 incore detectors in the core. The Technical Specifications allow operation with $25 \%$ of the detectors out of service. Thus, more than 70 detectors would have to be failed to fall outside the Technical Specifications limit. On average, there is less than one detector failure per 100 effective full power days (EFPDs) of operation (according to the San Onofre licensee). Therefore, the probability of a single failure during the 1-week interval is extremely small. A detector failure normally causes COLSS calculations to become more conservative. The incore detector signals are verified on a monthly basis anyway as a part of performing the monthly core parameters surveillance. COLSS checks the incore signals internally and will reject one that is obviously failed. It will also alarm in the control room if more than $25 \%$ of the detectors are failed, thus helping to ensure compliance with the Technical Specifications. Since the incore detectors are a purely passive system, a simple failure of a detector cannot result in core damage. The detector must fail in conjunction with some other initiating event. Since there is no limitation on specific detectors that may be failed, operation with a newly failed detector is not materially different from operation with a detector whose failure has been recognized.

COLSS checks the incore detector signals for validity and monitors compliance with the Technical Specifications limits on failed detectors. COLSS also calculates axial shape index (ASI) and azimuthal tilt which would show a sudden change in value if a detector failed seriously. COLSS ASI is compared to CPC ASI on each shift and any deviation would be identified at that time.

The NRC staff recommends that the surveillance requirement for CE Technical Specifications be changed to be consistent with the B\&W Technical Specifications; that is, the surveillance of the incore detectors would be required within 7 days before they are used for power distribution measurements.

It should be noted that this change does not change any operability requirements for incore detectors, just the surveillance requirements.

\section{Finding}

Incore detectors are monitored within 24 hours before use and weekly in CE reactors and 7 days before use for power distribution measurements in $\mathrm{B} \& \mathrm{~W}$ reactors.

\section{Recommendation}

The B\&W surveillance requirement for incore detectors should be used for CE plants.

\subsection{Response Time Testing of Isolation Actuation Instrumentation (PWR, BWR)}

In order to limit the consequences of line breaks, BWRs are designed with the capability to isolate portions of systems to retain vessel inventory. A typical list of these isolations follows for a BWR:*

\section{(1) PRIMARY CONTAINMENT ISOLATION}

(a) Reactor Vessel Water Level

1. Low, Level 3

2. Low Low, Level 2

3. Low Low Low, Level 1

(b) Drywell Pressure - High

(c) Main Steam Line

1. Radiation - High

2. Pressure - Low

3. Flow - High

"This list is for illustration only and is not complete 


\section{(2) SECONDARY CONTAINMENT ISOLATION}

(a) Drywell Pressure - High

(b) Reactor Vessel Water Level - Low Low, Level 2

(3) REACTOR WATER CLEANUP SYSTEM ISOLATION

(a) $\Delta$ Flow - High

(b) Heat Exchanger Area Temperature - High

(c) Heat Exchanger Area Ventilation $\Delta \mathrm{T}$ - High

(d) Reactor Vessel Water Level - Low Low, Level 2

(4) REACTOR CORE ISOLATION COOLING SYSTEM ISOLATION

(a) RCIC Steam Line Flow - High

(b) RCIC Steam Supply Pressure - Low

(c) Drywell Pressure - High

(d) RCIC Equipment Room $\Delta$ Temperature High

(5) RHR SYSTEM SHUTDOWN COOLING MODE ISOLATION

(a) Reactor Vessel Water Level - Low, Level 3

(b) Reactor Vessel (RHR Cut-in Permissive) Pressure - High

Safety analyses assume that instrument channel actuation for non-MSIV channels occurs simultaneously with diesel start. The Technical Specifications, therefore, give required response times which include both the instrument response time (typically measured in fractions of a second), the response times of the actuation logic circuits (typically less than a second), and the diesel generator start time (10 to 13 seconds, typically).

Therefore, the chance is remote that a channel's response time would degrade to the point where it exceeds the 13-second diesel start time without a failure that would be noticeable in other ways. The Technical Specifications "Bases" section states that the only purpose for checking these response times is "to enhance overall system reliability and to monitor instrument channel response time trends."

At LaSalle, approximately 230 staff-hours/unit/refueling interval are expended satisfying the non-MSIV isolation system response time testing requirements. Five days, around the clock, are required to perform these surveillances.

It appears this staff time could be better spent on other work.
Another negative aspect of the response time testing besides the burden on personnel time is the increased risk of plant trips and equipment damage. While these risks are present during any testing, response time tests are particularly at risk for the following reasons:

First of all, a large number of lifted leads, jumpers, and pulled fuses are required to simulate the necessary system conditions. This creates the potential for errors. Some examples from experience at LaSalle are given below:

- Lead of temperature compensation resistor was broken during post-test restoration of lifted leads. (1985)

- Fuse blew when reinstalled, but condition was not noticed. When another fuse was removed for testing in another channel, a reactor scram occurred. (1987)

- Jumper that was grounded during removal for test restoration caused unnoticed blown fuse. Reactor scram occurred during subsequent testing of another channel. (1987)

- Jumper that was grounded during installation caused an RPS bus trip. (1988)

In addition, most response time tests are performed during refueling outages when the configurations (i.e., jumpers, lifted leads, etc.) of associated systems are more likely to be different from those covered by the test procedure.

And finally, the test equipment used to simulate hydraulic ramp inputs to sensors is complex, difficult to use, and unfamiliar to technicians (due to its infrequent use).

Failures and degradation which could affect response time in these systems are normally detected through other tests of the same or higher frequency (such as monthly functional tests and logic functional tests). Two examples of such situations noted during a review done by the LaSalle licensee included the following.

- Torn diaphragm in RCIC exhaust diaphragm high pressure isolation switch. (Found during a monthly functional test.)

- Torn diaphragm in RCIC high steam flow isolation $\mathrm{dP}$ switch. (Found during a monthly functional test.)

PWR Technical Specifications have a similar table and the difficulties are similar to BWRs.

The NRC staff therefore recommends eliminating response time testing of isolation actuation instrumentation where the required response time corresponds to the diesel start time.

As part of the Technical Specifications Improvement Program, the NRC staff is currently considering extensions in 
the surveillance test intervals and allowed outage times for isolation actuation instrumentation common to the reactor protection system and/or the ECCS.

\section{Findings}

- Non-MSIV isolation response time testing is difficult, time consuming, and has a risk of tripping the reactor.

- The test criteria are not meaningful compared to measured isolation response time.

\section{Recommendation}

Delete requirement from both BWR and PWR Technical Specifications to perform response time testing where the required response time corresponds to the diesel start time.

\subsection{Source Range Monitor and Intermediate Range Monitor Surveillances (BWR)}

Present calibration interval for the source range monitors (SRMs) and intermediate range monitors (IRMs) is quarterly for surveillances required for the control rod withdrawal block instrumentation. Another Technical Secifications surveillance requirement for reactor protection system instrumentation specifies a refueling interval calibration for the IRMs.

A review of set point trend data for the IRMs done by the LaSalle licensee shows very little drift in equipment calibration. These data, supported by the refueling interval frequency already incorporated in the technical specification for reactor protection system instrumentation surveillances, provides a justification for extending the calibration interval for the SRMs and IRMs.

The NRC staff recommends that the interval be changed to once each refueling interval for calibration of the source range and intermediate range monitors in the control rod withdrawal block instrumentation surveillance requirements.

\section{Findings}

- There are two different calibration requirements for BWR SRMs and IRMs.

- These instruments show little set point drift.

\section{Recommendation}

The calibration interval for the BWR SRMs and IRMs should be changed to once each refueling interval.

\subsection{Calibration of Recirculation Flow Transmitters (BWR)}

The control rod withdrawal block instrumentation surveillance requirements include a requirement to calibrate recirculation flow (pressure difference) transmitters quarterly. In BWRs these are typically Rosemount units. The normal frequency of calibration in other applications using the same type of transmitter is refueling; for example, this is the case for low reactor water level isolation functions. Recent failures of Rosemount units, which upon failures have displayed symptoms that can be detected during calibration (slow drift, lack of response over transmitter's full range, increase in transmitter's time response, deviation from normal signal fluctuations, decrease in detectable noise level, deviation between signals, "one-sided" signal noise, and poor response to transients), dictate that the calibration requirement remain at a quarterly interval.

\section{Finding}

BWR pressure difference instrumentation has different calibration requirements in different sections of the Technical Specifications. Calibrations are required quarterly and at refueling. Rosemount units have been recently failing and, in doing so, exhibiting symptoms that are detectable by calibration.

\section{Recommendation}

Retain surveillance interval at its current quarterly frequency.

\subsection{Autoclosure Interlocks: Removal of the LCO From the Technical Specifications (PWR, BWR)}

The normally closed residual heat removal (RHR) system isolation valves are opened only for RHR after system pressure and temperature have been reduced to the set points for system operation which are below the design temperature and pressure limits of the RHR system. An interlock prevents the valves from being opened when the RCS pressure or the RHR pump pressure is above the RHR system design pressure. A second interlock, the autoclosure interlock (ACI), is provided to automatically close the valve if the RCS pressure increases above a set pressure.

By letter dated August 4, 1987 (Shiffer, 1987a), Pacific Gas \& Electric Company (PG\&E) requested staff concurrence with its 10 CFR 50.59 evaluation which determined that removal of the RHR autoclosure interlock function does not constitute an unreviewed safety question or require modification of Technical Specifications. The NRC staff focused its review of this issue on the 
effect that the proposed change has on the Event V (intersystem LOCA outside of the containment) sequence.

The staff reviewed the probabilistic risk assessment (PRA) submitted by the Diablo Canyon licensee to support this proposal and also explored alternatives to total removal of the ACI circuitry.

The proposal, as agreed to by the NRC staff, will consist of hardware and procedure modifications.

PG\&E proposes to remove the autoclosure interlock function from the RHR system suction valves. The open permissive interlock will remain intact. An alarm will be added to each valve which will actuate if the valve is open and if RCS pressure is above a value set between 390 psig and 450 psig , which is above the RHR valve open permissive set point. In addition, the status lights on the operator's panel, which indicate that these valves are open or closed, will remain functional after power has been removed from these valves.

The licensee also developed improved operating procedures to assure closure of these valves.

The main reasons for removing the $\mathrm{ACI}$ are given in a report from the Office for Analysis and Evaluation of Operational Data (AEOD) concerning decay heat removal problems at U.S. pressurized water reactors (AEOD/C503). This report points out that, of the 130 loss-of-RHR events that were documented at U.S. PWRs between 1976 and 1983, 37 were caused by the automatic closure of the suction/isolation valves. The AEOD report also quotes a study prepared by Sandia Laboratory for the NRC (NUREG/CR-4335) which evaluated the competing risks associated with RHR suction/isolation valve closures and Event V. Sandia concluded that:

The lowest core melt frequency due to the combination of loss of RHR suction during cold shutdown and V-LOCAs is obtained when there are no autoclosure interlocks on the RHR suction valves...removing the overpressure interlocks from the RHR suction valves gives the best RHR suction arrangement for PWRs based upon this analysis....when interlocks are present, loss of RHR suction is the largest contributor to core melt frequency. However, when the interlocks are not present, the core melt frequency due to loss of RHR suction is comparable to or less than the $\mathrm{V}$ LOCA core melt frequency for the best estimate cases.

The AEOD report concluded that, even though it was most likely a good idea to remove the $\mathrm{ACl}$, the effects of ACI removal upon plant safety must be evaluated on a plant-by-plant basis because of numerous plant-specific differences. The PG\&E submittal (Shiffer, 1987a) contains such a plant-specific analyses.

The Westinghouse Owners Group, however, submitted, and the NRC staff approved, a generic proposal for the deletion of the ACI (WCAP-11736-A).

Resolution of GI-99, "Loss of RHR Capability in PWRs," recommends (but does not require) that the $\mathrm{ACI}$ be removed.

Other licensees should review their safety bases for the autoclosure interlock of RHR isolation valves to determine if removal of the ACI results in a lower core melt frequency and, if it does, should propose removing this requirement from their Technical Specifications.

\section{Findings}

- Analyses show that removal of the autoclosure interlock decreases the core melt probability.

- The Westinghouse Owners Group submitted a generic proposal to remove the ACI and it was approved by the NRC staff.

- Resolution of GI-99, "Loss of RHR Capability in PWRs," recommends (but does not require) that the ACI be removed.

\section{Recommendation}

Other owners groups besides Westinghouse should determine if the core melt risk is higher or lower with the ACI deleted.

\subsection{Turbine Overspeed Protection System Testing (PWR, BWR)}

The present Technical Specifications for a PWR require a turbine overspeed protection system to be operable in Mode 1. The system must also be operable in Modes 2 and 3 if all steam paths to the turbine are not isolated.

The Technical Specifications for the turbine overspeed protection system in a BWR are equivalent; they require the system to be operable in Operating Condition 1 and, if the MISIVs are open, in Operating Condition 2.

The Technical Specifications "split report" has designated this technical specification as one that may be relocated from the Technical Specifications. However, it has become apparent in performing this study that, because of the problems caused by the turbine valve testing, faster action is called for. There are several reasons for this:

First, this surveillance has caused a significant number of reactor trips. 
Second, the surveillance results in some wear to the valves and stress to the steam system.

Third, while the test is being done, in order to avoid a reactor trip, the steam flow to the turbine must be reduced. This is done by either reducing reactor power, which results in a reduction of capacity factor, or by dumping steam to the condenser, which could be detrimental to the condenser because of the damage done by vibration of the condenser tubes when large amounts of steam bypass the turbine and enter the condenser.

In addition, because power must be lowered to perform this test, the test becomes very difficult to do at the end of cycle when there may not be enough dilution capability (in a PWR) or rod worth (in a BWR) to override xenon.

The surveillance testing requires moving each of the turbine valves through one cycle (from the valve position prior to the test, to fully closed, and returning to the original position). The test is typically performed by a control room operator with an observer at the valve. The test verifies freedom of movement of the valve components; that is, it verifies that nothing inhibits the valve from closing. Westinghouse has stated (WCAP-11525) that " $t$ ]his type of testing is beneficial for (1) detecting non- or sluggish operation of the valves, and (2) identification of gross outward appearance of valve condition."

The surveillance requirements for valve operability ensure that all the turbine steam inlet valves are capable of closing to protect the turbine from excessive overspeed. Protection from excessive turbine overspeed is required since excessive overspeed of the turbine could generate potentially damaging missiles that could hit and damage safety-related components or structures.

Thus, the test is beneficial in some ways and serves a safety function.

The issue here is not whether the test should be done, but rather how often it should be done.

As discussed earlier (see Section 3) turbine overspeed protection system testing is a major source of reactor trips that occur during or as a result of surveillance testing. In addition, licensees have stated that this test is hard on the steam system, causing relief valves to lift and adding thermal and mechanical stresses to the piping.

Personnel at the San Onofre site estimate that performing the weekly test takes a crew of technicians approximately 3 hours (per unit). The monthly surveillance requires approximately 6 hours per unit.
The concern in this case, however, is not burden on the licensee but the number of inadvertent trips and wear on the equipment.

Turbine overspeed protection is typically redundant and diverse. If a turbine accelerates from its normal speed (e.g., due to a change in load) the normal turbine control system positions the control (or governor) valves to rapidly return the speed to the proper set point.

In addition to this, there is typically both mechanical and electrical overspeed protection. These systems are described in Section 10.2 of each plant's final safety analysis report.

Mechanical overspeed protection, which is independent of the electrohydraulic controller (EHC), is provided by the mechanical overspeed trip mechanism that is set to activate at (typically) $110 \%$ of rated speed.

Electrical overspeed protection, which is set at (typically) $111.5 \%$ of rated speed, is provided as a backup to the mechanical overspeed trip device. The electrical trip solenoid valves are deenergized to trip the turbine upon receiving an open contact from the EHC, which represents an overspeed condition.

In addition, each steam line to the turbines typically has two valves in series so that a failure of a single valve cannot cause the turbine to overspeed.

The present requirements for the test frequency are based on recommendations from the turbine vendor (Trammel, 1987). This test interval was developed for fossil units and carried over to nuclear units due to the similarity in design. Fossil units produced steam with much greater particulate (impurities) content than is permitted in nuclear units. These impurities required more frequent valve surveillance to ensure reliable operation. Also, fossil units and early PWR units utilized phosphate chemistry in their condensate. The phosphate-based chemistry control contributed to valve inoperability. For example, Turkey Point Plant, Unit 3 had stuck-open turbine stop valves which were found during shutdown. The cause was phosphate deposits between the shafts and bushings of the valves (NPE-2).

A review of the operating history of turbine valves (NPE-2) shows that failures of these valves do occur and that, unlike some other Technical Specifications tests which do not find failures, these failures are found during the turbine overspeed testing. However, the number of trips attributable to this testing is significant.

The NRC has granted increases in the testing interval for turbine overspeed protection testing. For example, in a letter dated April 16, 1984 (Engle, 1984), the staff approved changing the requirement for cycling each of the 


\section{Instrumentation}

turbine valves from every 7 days to every 31 days for North Anna Power Station, Unit 1.

Another factor in this case is the turbine manufacturers' recommendations about the testing frequency of these valves. In some cases, these frequencies are comparable to the existing Technical Specifications.

The NRC staff recommends that, where the turbine manufacturer agrees, the testing interval for turbine valves as part of the turbine overspeed protection system surveillances be extended from weekly and monthly tests to one test done quarterly, in which a direct visual observation will be made of the movement of each of the turbine valves currently required by Technical Specifications to be tested.

A quarterly test corresponds to the most stringent valve testing requirement of the ASME Code.

\section{Findings}

- Turbine overspeed testing requires a reduction in power and is a main cause of reactor trips during testing.

- Testing of the turbine valves is necessary and the manufacturers' recommendations should be followed.

\section{Recommendation}

Where the turbine manufacturer agrees, the turbine valve testing frequency should be changed to quarterly.

\subsection{Radiation Monitors (PWR, BWR)}

The Technical Specifications contain three categories of radiation monitors: those used for gaseous and liquid effluent monitoring, those used for monitoring an area and indicating the radiation level, and those that are part of the reactor protection system and engineered safety features actuation systems. The only radiation monitors with a reactor trip function are the main steamline radiation monitors on BWR main steam lines. The engineered safety features actuations are basically isolation functions and air cleanup functions. Many radiation instruments perform a monitoring function; these instruments monitor for reactor coolant leakage, accident conditions in containment, and the release of gaseous and liquid effluents.

As with other instrumentation, radiation monitors are required to undergo three types of surveillances: a channel check, a channel functional test, and a calibration. In addition, a source check is performed.
The capability to source check provides an integral verification of the response of the detector. This is generally required monthly or before using a system that would release potentially radioactive fluid.

The testing of radiation monitors produces a significant number of isolations of the control room, fuel handling building, auxiliary buildings, and various process lines. In addition, the testing requires significant licensee staff. Licensees also stated that the frequent testing tends to degrade the equipment. The instrumentation must be removed from cabinets and reinserted. A majority of the instrumentation is self-checking so that most failures will be found in this way or by channel checks.

The San Onofre licensee proposed that the surveillance test intervals for radiation monitors be extended. Detailed information on failure history was provided for some monitors. In addition, the San Onofre licensee made the following points in support of the extension of the surveillance test interval: The radiation monitors at San Onofre have had a minimal failure history. The failures are normally of remote meter indication which would not impact the safety function. In addition, channel checks and failure alarms would detect failures that require corrective action.

The extent to which these points are generic has not been determined as part of this study. It is, therefore, difficult to take the San Onofre experience and design and to extrapolate it to other reactor sites. This appears to be a situation in which reliability-based Technical Specifications surveillance requirements could be utilized to decrease the frequency of surveillance testing on reliable radiation monitoring systems while requiring more frequent testing on radiation monitors that are not as reliable.

It does seem reasonable to give relief on the frequency of channel functional tests since these tests do not involve the sensor (radiation monitor) itself, Therefore, in order to decrease the licensee burden and increase the availability of the radiation monitoring systems, the NRC staff recommends that channel functional tests on radiation monitoring equipment be performed quarterly. For some radiation monitoring equipment, this surveillance is already done quarterly. Channel checks, source checks, and calibrations would be done at their existing surveillance test intervals.

The NRC staff also recommends that the vendor owners groups study the reliability, set point drift, failure modes, and alarm capabilities of radiation monitors (with industry participation) to determine if further decreases in testing and calibrations are possible. 


\section{Findings}

- Radiation monitor testing appears to require a large amount of resources.

- Most failures of radiation monitors can be found from channel checks, source checks or alarms.

- There is a large variation in the type and reliability of radiation monitoring equipment among utilities.

\section{Recommendations}

- In order to decrease licensee burden and increase the availability of radiation monitors, change the monthly channel functional test to quarterly.

- The vendor owners groups should study whether further reductions in radiation monitor surveillance testing are possible.

\subsection{Radioactive Gas Effluent Monitor Calibration Standard (PWR, BWR)}

BWRs and PWRs are required by their Technical Specifications to calibrate noble gas activity monitors at refueling. Some of these BWR Technical Specifications have the following note attached to this requirement.

The initial channel calibration shall be performed using one or more of the reference radioactive standards certified by the National Bureau of Standards (NBS) or using standards that have been obtained from suppliers that participate in measurement assurance activities with NBS. These standards shall permit calibrating the system over its intended range of energy and measurement range. For subsequent channel calibration, the initial reference radioactive standards or radioactive sources that have been related to the initial calibration shall be used.

This requirement is viewed by some in the industry as excessive since the equipment vendors supply information or kits for calibrating monitors. The requirement for an NBS standard makes instrument calibration more expensive. A search of plant Technical Specifications shows that the NRC staff has not been requiring an NBS standard for calibration consistently, but there appears to be a reasonable basis for the requirement.

First, there is a great variability between radiation detectors at different sites and the calibration standards and procedures of these detectors. Thus, while an NBS stan- dard may be excessive for one vendor's detectors, this cannot be the generic conclusion.

Secondly, the NRC depends on the accuracy of the licensees' reporting of releases of effluents from the site. In order to have confidence in these releases, a reliable calibration standard is necessary.

Individual licensees may be able to justify a program for effluent monitoring instrumentation which does not include this requirement but, on a generic basis, this requirement appears to be necessary.

\section{Finding}

NBS calibration standards are necessary for effluent monitoring instrumentation because of the variety of instruments used and the need for accurate measurements of effluent radioactivity.

\section{Recommendation}

Retain this requirement.

\subsection{Intermediate Range Monitor and Average Power Range Monitor Channel Functional Tests (BWR)}

IRM and APRM channel functional tests are performed every 7 days, while all other RPS channel functional tests are performed once every 31 days.

In the time available, the NRC staff could not determine the reason for this difference. The NRC staff should discuss this difference with the BWR Owners Group to determine whether there is a valid basis for this difference. If justified, the surveillance interval for the IRM and APRM channel functional tests should be changed to every 31 days.

\section{Findings}

- IRM and APRM channel functional tests are performed every 7 days while all other RPS channel functional tests are performed every 31 days.

- The reason for this difference was not determined as part of this effort because of time restraints.

\section{Recommendation}

The BWR Owners Group should determine if the 7-day requirement for channel functional tests on IRMs and APRMs can be extended. 


\section{REACTOR COOLANT SYSTEM}

\subsection{Reactor Coolant System Isolation Valves (PWR)}

The Standard Technical Specifications (STS) require that reactor coolant system isolation valves be tested "prior to entering Mode 2 whenever the plant has been in cold shutdown for 72 hours or more and if leakage testing has not been performed in the previous 9 months."

The qualitative risk analysis and discussions with licensees of pressurized water reactors (PWRs) indicate that the surveillance requirements are burdensome and can result in occupational exposure; equipment reliability characteristics suggest longer surveillance test intervals (STIs). In addition, this STS requirement causes plant personnel to rush to recover from short forced outages. Thus, longer surveillance test intervals are recommended.

In the judgment of the NRC staff, making the conduct of this surveillance contingent upon being shut down 72 hours or more has a potential for causing problems resulting from a hurried recovery. It is very likely that a plant could have been operating satisfactorily for more than 9 months without difficulty, and yet must delay restart after a short shutdown in order to satisfy this surveillance requirement. In addition, extending the STI associated with this surveillance does not significantly alter the associated risk.

The NRC staff recommends that the 72-hour time for remaining in cold shutdown without testing the RCS isolation valves for leaks be increased to 7 days. This will help utilities perform repairs under less stress, but will make an insignificant difference in risk.

\section{Finding}

RCS isolation valves are to be tested for leaks if the reactor is in cold shutdown for more than 72 hours and the valves have not been so tested in the last 9 months.

\section{Recommendation}

Increase the 72-hour time for remaining in cold shutdown without leak testing the RCS isolation valves to 7 days.

\subsection{Power (or Pilot)-Operated Relief Valves and Block Valves (PWR)}

NRC report NUREG/CR-4692 discusses a survey of the operating history of power (or pilot)-operated relief valves (PORVs) and block valves. The survey included 230 failures occurring between 1971 and mid-1986 in- cluding PORVs, block valves, and their control systems. Mechanical failure or degradation accounted for 101 of the events; of these, 91 were attributed to the PORV controls. Of the 101 events, 32 involved block valve failures of which 4 involved block valve controls. Since PORVs and block valves were not considered safety related, their failures were not always reported (especially before 1979). Therefore, this may not be a complete accounting of failures.

The breakdown of failures between types of PORVs is not uniform. Babcock \& Wilcox (B\&W) plants with Dresser/ Crosby PORVs accounted for $45 \%$ of the PORV mechanical failures. Also, more than $70 \%$ of the reported failures or degradation of PORV controls concerned problems with the air/nitrogen control components required to operate the air-operated PORV.

With this background, it appears that the current surveillance requirements in the Westinghouse Standard Technical Specifications for the PORVs and their block valves are reasonable in that compliance with the Boiler and Pressure Vessel Code of the American Society of $\mathrm{Me}$ chanical Engineers (ASME Code) will check set point and leakage while the other Technical Specifications requirements will verify operability of the control system. Note that the Standard Technical Specifications do not specifically require a surveillance of the air/nitrogen emergency backup system (such as accumulator pressure). The STS do require that the emergency power supply for the PORVs and block valves shall be demonstrated operable every 18 months.

The NRC staff has adopted the position that the pressurizer power-operated relief valves (PORVs) should be included in the inservice testing (IST) program as Category $\mathrm{B}$ valves and tested to the requirements of Section XI of the ASME Code. However, since the PORVs have shown a high probability of sticking open and are not needed for overpressure protection during power operation, the NRC staff has concluded that routine exercising during power operation is "not practical" and therefore not required by IWV-3412(a).

The PORV function during reactor startup and shutdown is to protect the reactor vessel and coolant system from low-temperature overpressurization conditions and the staff has concluded that these valves should be exercised before initiation of system conditions for which vessel low-temperature overpressure protection is needed. (See Section 6.4 of this report.)

The following test schedule is required: 
(1) Full-stroke exercise should be performed at each cold shutdown or, as a minimum, once each refueling cycle.

(2) Stroke timing should be performed at each cold shutdown or, as a minimum, once each refueling cycle.

(3) Failsafe actuation testing should be performed at each cold shutdown.

(4) The PORV block valves should be included in the IST program and tested quarterly to provide protection against a small-break loss-of-coolant accident (LOCA) should a PORV fail open.

It should be noted that even this testing does not ensure operability. During the steam generator tube rupture event that occurred at Ginna Nuclear Power Plant in January 1982, the PORV was used to reduce RCS pressure. The PORV opened and closed successfully three times. On the fourth opening/closing cycle, the valve partially closed, then opened completely, and stuck. The block valve was successfully closed to terminate the RCS blowdown.

The most common reason for mechanical failure in PORVs, according to NUREG/CR-4692, appears to be the degradation of the seat/disc interface or other internal parts by high-pressure steam and/or water. Internal leaking was the most common failure mode. It therefore appears that preventive maintenance is important for these valves to assure that they do not degrade to the point where they fail to operate or seal.

\section{Findings}

- Operational use of PORVs is covered under resolution of Generic Issues (GIs)-70 (PORV Reliability) and -94 (Additional LTOP for LWRs).

- Not every plant with PORVs has PORV limiting conditions for operation (LCOs) and surveillance requirements in the Technical Specifications.

\section{Recommendation}

Direction concerning PORV and block valves surveillances will be provided in the resolution of GI-70 and GI-94.

\subsection{High Point Vent Surveillance Testing (PWR)}

The Westinghouse Standard Technical Specifications require each RCS vent and block valve to be demonstrated operable every 92 days by operating the valve through one complete cycle of full travel from the control room.

Westinghouse plants have a problem testing the block valve upstream of the vent valve. When the block valve is opened at pressure, a pressure surge opens the vent valve resulting in a release of reactor coolant. The discharge is routed to either the pressurizer relief tank, a containment ventilation system, or directly to the containment atmosphere.

A review of operating history (NPRDs and LERs) revealed only one serious event occurred while this surveillance was being performed. This was at the Shearon Harris Nuclear Power Plant on October 9, 1987; the RCS leakage Technical Specifications limit was exceeded and an Unusual Event was declared (see LER 87-058 and NPE-5). However, there have been numerous incidents of smaller discharges.

Some Technical Specifications do not require testing these valves while at power. The Catawba Technical Specifications only require this surveillance during cold shutdown or refueling, at least once every 18 months.

The NRC staff recommends that the licensees with Technical Specifications requiring 92-day surveillances of RCS vent valves evaluate the requirements that appear in the Catawba Technical Specifications and revise their Technical Specifications, if applicable.

This is an example of a design problem (the valve's tendency to open on a pressure surge) making a surveillance test difficult.

\section{Findings}

- Testing of RCS vent valves at pressure has the potential to cause a release of reactor coolant.

- Testing is required every 92 days by Westinghouse Standard Technical Specifications and some plantspecific Technical Specifications. Other plant Technical Specifications only require testing these valves at cold shutdown or refueling.

\section{Recommendation}

Licensees to evaluate applicability of Catawba Technical Specification Bases with respect to high point vent 
surveillance testing and revise the frequency of testing of RCS vent valves to cold shutdown or refueling if appropriate.

\subsection{Low-Temperature Overpressure Protection (PWR)}

The Standard Technical Specifications recognize two methods of protecting a reactor vessel against lowtemperature overpressurization.* These are:

(1) Two power-operated relief valves (PORVs) with a lift setting of less than or equal to $[450]^{* *}$ psig, or

(2) The reactor coolant system (RCS) depressurized with an RCS vent of greater than or equal to [ ]** square inches.

In addition, some Technical Specifications allow the RHR system relief valves to be used to protect the reactor vessel against a low-temperature overpressurization. The Standard Technical Specifications require:

(1) Performance of an analog channel operational test on the PORV actuation channel, but excluding valve operation, within 31 days prior to entering a condition in which the PORV is required operable and at least once per 31 days thereafter when the PORV is required operable;

(2) Performance of a channel calibration on the PORV actuation channel at least once per 18 months; and

(3) Verifying the PORV isolation valve is open at least once per 72 hours when the PORV is being used for overpressure protection.

The NRC staff recommends:

(1) That licensees consider verifying that the PORV is not isolated at least once per shift when the PORVs are used for low-temperature overpressure protection.

(2) That licensees consider the benefit of providing continuous positive indication that the low-temperature overpressure protection system is armed and operable.

Recommendation 1 is more consistent with the degree of conservatism used in other sections of the Standard Technical Specifications for overpressure protection. For instance, the surveillance requirement for the RCS vents,

\footnotetext{
* Low-temperature overpressure protection is required in Mode 4 when the temperature of any RCS cold leg is less than or equal to $[275]^{\circ} \mathrm{F}^{* *}$, and in Mode 5 and Mode 6 with the reactor vessel head on.

** Plant-specific values are used.
}

when used for overpressure protection is that they shall be verified to be open at least once every 12 hours except when the vent pathway is provided with a valve that is locked, sealed, or otherwise secured in the open position. Then these valves shall be verified open at least once every 31 days.

Also, in the emergency core cooling system (ECCS) section of the Standard Technical Specifications, it is required that all charging pumps and safety injection pumps, except the required operable pumps (centrifugal charging pump and RHR pump), shall be demonstrated inoperable by verifying that the motor circuit breakers are secured in the open position at least once every 12 hours whenever the temperature of one or more of the RCS cold legs is less than or equal to $[275]^{\circ} \mathrm{F}$.*

An event at Millstone Nuclear Power Station, Unit 3 on January 19, 1988, illustrates the need for frequent surveillance of the low-temperature overpressure protection system and the need for positive continuous indication that the low-temperature overpressure protection system is operable.

The Millstone 3 Technical Specifications required at least one of the following for low-temperature overpressure protection when in Mode 3 with the temperature of any RCS cold leg less than or equal to $350^{\circ} \mathrm{F}$ or when in Modes 4, 5, and 6 with the reactor vessel head on.

(1) Two-residual heat removal suction relief valves each with a set point of $450 \mathrm{psig}$, or

(2) Two power-operated relief valves with lift settings which do not exceed the limit established in Technical Specification figures of pressure set point as a function of temperature, or

(3) The reactor coolant system depressurized with an RCS vent of 5.4 square inches or more.

On January 15, 1988, Millstone 3 was in Mode 5 in watersolid operation at $350 \mathrm{psia}$ and $125^{\circ} \mathrm{F}$. Two trains of RHR were in operation. The cold overpressure protection system (which uses the PORVs with a low-pressure set point) had been erroneously deactivated in November when the solid-state protection system had been removed from service at the beginning of the outage, but the licensee had not detected this condition.

On January 16, 1988, the A train of RHR was removed from service for maintenance. This put the licensee in an 8-hour action statement due to the non-operability of the cold overpressure protection system and only one train of RHR (and consequently one relief valve) in operation. However, the operator assumed that the PORVs were still operable as low-temperature overpressure protection. There was no positive indication that the low-

"A plant-specific value would be used. 
temperature overpressure protection system was not operable.

Subsequently, a maintenance activity on January 19 caused inadvertent closure of the suction valve for the remaining operable RHR train, train $B$. The reactor coolant system was in solid condition with both charging pumps and letdown in operation. The letdown path was through the B train RHR pump.

LER 88-005 describes the event as follows:

At 10:55 the RHR low flow alarm was received at the Main Control Board. The operators noted that the RHR suction valve was going closed and stopped the operating RHR pump. The reactor operator reviewed the condition of the plant and noted that pressure was rising rapidly due to the charging system operating on a solid plant. Within two minutes, the operator manually isolated charging and increased letdown through the chemical and volume control system. The pressure increase immediately stopped and turned. Within 15 minutes the transient stabilized with reactor coolant pressure below 310 psia.

The peak pressure was $535 \mathrm{psig}$, which was above the Technical Specifications limit of 500 psig. Had a more effective and more frequent surveillance of the status of the cold overpressure protection system been required, the Millstone 3 operators should have noticed that the system was not operable. The Millstone 3 licensee has corrected procedures to assure better surveillance of the low-temperature overpressure protection system before it is required.

\section{Findings}

- Low-temperature overpressure protection is important to safety.

- PORV isolation valves are to be verified open every 72 hours. This may not be often enough.

- Some PWRs have no positive continuous indication that the low-temperature overpressure protection system is operable.

\section{Recommendations}

- Licensees should consider verifying that PORV isolation valves are open at least once per shift.

- Licensees should consider the benefit of continuous positive indication that the low-temperature overpressure protection system is armed and operable. This indication should be available whenever the low-temperature overpressure protection system is required to be operable.

- Implement resolution of GI-70 (PORV Reliability) and GI-94 (Additional LTOP for LWRs).

\subsection{Specific Activity of the Reactor Coolant - 100/E (PWR, BWR)}

The Technical Specifications surveillance requirements for specific activity of the reactor coolant vary significantly among different plant Technical Specifications.

The Technical Specifications for both PWRs and BWRs require that the specific activity (microcuries per gram) be determined periodically by measuring two quantities: dose equivalent iodine-131 and the quantity $100 / \overline{\mathrm{E}}$.

The design-basis accident which sets the limit for coolant activity in a PWR is the steam generator tube rupture. The limit on dose equivalent iodine-131 assures that radiation dose to the thyroid will be within the limit of 30 rem.

$\bar{E}$ is precisely defined in the "Definitions" section of the Technical Specifications. It is basically a weighted sample (by concentration) of the sum of the beta and gamma energies per disintegration of each radionuclide in the reactor coolant.

In calculating the effects of offsite dose, both the dose to the thyroid and to the whole body are considered. The dose to the thyroid is limited by the dose equivalent iodine-131 limit. The whole-body dose is limited by limiting the concentration of noble gases since the assumption is made that an individual at the site boundary is immersed in a cloud of released activity which is completely made up of noble gases. This limit on noble gases is $100 / \overline{\mathrm{E}}$.

The whole-body dose for the steam generator tube rupture accident is the dose resulting from immersion in the cloud of released activity. To insure that the public is adequately protected, the specific activity of the reactor coolant is limited to a value that will insure that the whole-body dose at the site boundary will not exceed 2.5 rem should a steam generator tube rupture accident occur.

The dose is calculated from the equation

$$
\text { Dose }=0.25 \overline{\mathrm{EAV}} \chi / \mathrm{Q}
$$

where 


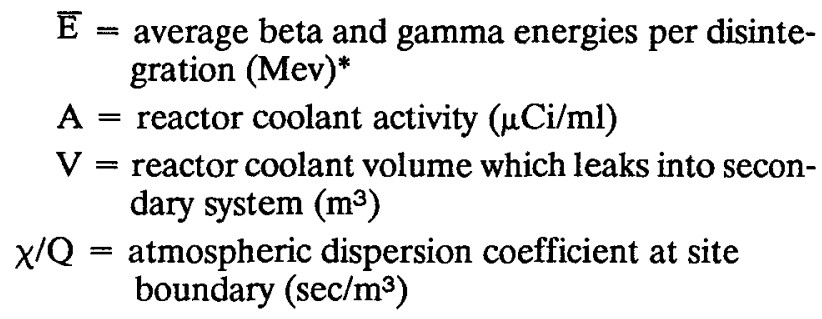

Using the 2.5-rem whole-body limit, and the plantspecific values for $V$ and $\chi / Q, A$ is given by

$$
\mathrm{A}=\frac{\text { Constant }}{\overline{\mathrm{E}}}
$$

For BWRs, the limiting accident in terms of offsite dose is the steamline break outside containment. The same equation is applicable; however, $\mathrm{V}$ is the total volume of reactor coolant released to the atmosphere.

Values for the constant vary considerably. A value of 100 is now used as a standard and the Bases section of Technical Specifications states that this value is conservative since it is based on a parametric evaluation of typical site conditions. It is not clear that this is true since some older Technical Specifications use values lower than 100 .

Practically, there are several difficulties with $\bar{E}$. The Technical Specifications require that it be determined every 6 months, but its value varies continually. Gross beta and gamma samples are required by some Technical Specifications to be taken every 72 hours as an indication of the total (primarily noble gas) radioactivity. In a PWR, the amount of noble gas in the system is, to some extent, a function of the letdown (cleanup) flow. In a BWR, noble gases are being continually released as offgas up the stack. Thus, in a BWR, there is no significant accumulation of noble gases.

The Technical Specifications surveillance requirements for specific coolant activity require that the I-131 value be obtained whenever there is a "problem" ( $>15 \%$ power change in one hour, offgas increase, etc.). This value can be obtained fairly quickly. Usually within 24 hours all of the radioactive iodines can be analyzed (usually involving an initial count and a 1-day decay count). To accurately obtain an $\bar{E}$ value or determine if the $100 / \bar{E}$ limit has been exceeded, the sample would need to be held for further decay counts. It could be a week before the value is known. This contradicts the statement in the Bases section of some Technical Specifications that "the surveillance requirements provide adequate assurance that ex-

\footnotetext{
" $\beta$ doesn't contribute to the whole-body dose, but is included here as an additional conservatism.
}

cessive activity levels in the reactor coolant will be detected in sufficient time to take corrective action." This is true for gross beta and gamma and dose equivalent $\mathrm{I}-131$. It is not true for $\overline{\mathrm{E}}$.

In addition to these problems, it appears that the industry does not have a clear idea of the purpose of $\bar{E}$. In some cases, chemists have stated that they have determined the gross activity in the primary coolant by boiling a sample to dryness and analyzing the residue. Boiling to dryness, of course, drives off the noble gases and such volatile materials as radioiodines. The residue is dissolved solids, primarily corrosion products such as cobalt -60 . In other cases, the coolant sample is degassed before measurement; there is then no noble gas left to measure.

The NRC staff recommends that industry (perhaps through the Electric Power Research Institute) derive a more meaningful measurement of noble gas activity. In the meantime, the NRC should assure that the 100/E limit is conservative for each plant and that it is being determined in a meaningful way.

\section{Findings}

- The quantity $100 / \bar{E}$ is a limit on the accumulation of noble gas activity.

- It is time consuming to determine the quantity.

- The industry does not appear to understand the quantity well.

- It is not clear that the quantity is conservative.

\section{Recommendations}

- The NRC should ask the industry (perhaps through the Electric Power Research Institute) to derive a more meaningful measurement of noble gas activity, possibly replacing the $100 / \bar{E}$ limit.

- The NRC should assure that the $100 / \overline{\mathrm{E}}$ limit is conservative for each plant and that it is being determined in a meaningful way.

\subsection{Pressurizer Heaters (PWR)}

The Standard Technical Specifications for a PWR require that the pressurizer heaters that are to be powered from an emergency power supply should be energized to measure circuit current at least once every 92 days. The purpose of this surveillance is to demonstrate that the capacity of the heaters has not degraded.

Most pressurizer heaters are in constant use, both the proportional and to some extent the backup heaters. Therefore, operators should be aware of problems that 
may arise with pressurizer heaters. In addition, pressurizer heaters are fairly reliable.

Therefore, 92 days appears to be too frequent and the staff recommends that this test be done once each refueling interval.

The Standard Technical Specifications also require that the pressurizer heaters should be demonstrated operable at least once every 18 months by manually transferring power from the normal to the emergency power supply and energizing the heaters. For some PWRs, the pressurizer heaters are connected to the emergency bus so that no transfer to emergency power is required. For those PWRs that have their emergency pressurizer heaters powered by an emergency bus during normal operation, this requirement should be deleted.

Some PWRs have dedicated safety-related heaters not used during normal operation. In these instances, the operator cannot be expected to have a grasp of the operational status of the dedicated safety-related heaters. In these instances, the 92-day test is appropriate.

\section{Findings}

- Pressurizer heaters are required to be tested every 92 days to assure adequate heater capacity.
- The operator should be aware of the status of both proportional and backup pressurizer heaters during normal operation.

- Some Technical Specifications require that the power supply be switched from normal to emergency power for testing every 18 months.

- Some PWRs have some pressurizer heaters permanently tied to a vital bus.

- Some PWRs have dedicated safety-related heaters.

\section{Recommendations}

- The capacity of pressurizer heaters should be tested once each refueling interval for those plants without dedicated safety-related heaters.

- The capacity of pressurizer heaters should be tested every 92 days for plants with dedicated safety-related heaters.

- For those PWRs that have some pressurized heaters permanently tied to a vital bus, no testing of switching between power supplies should be required.

- This surveillance requirement shall be changed on a plant-specific basis. 


\section{EMERGENCY CORE COOLING SYSTEM}

\subsection{Surveillance of Boron Concentration in the Accumulator/Safety Injection Tank/Core Flood Tank (PWR)}

In a letter sent to Duke Power Co. on September 30, 1986 (Hood, 1986), the staff approved a proposed Technical Specifications change to eliminate the verification of the boron concentration in an accumulator after a volume increase of $1 \%$ or more from normal makeup.

Normal makeup to an accumulator comes from the refueling water storage tank (RWST) which is also borated. No dilution can be caused by adding water from this source as long as the minimum concentration of boron in the RWST is greater than or equal to the minimum boron concentration in the accumulator.

\section{Finding}

Technical Specifications require that the boron concentration in the accumulators be sampled to verify that it is within its limits after an increase in volume of $1 \%$ or more from makeup.

\section{Recommendation}

It should not be necessary to verify boron concentration of accumulator inventory after a volume increase of $1 \%$ or more if the makeup water is from the RWST and the minimum concentration of boron in the RWST is greater than or equal to the minimum boron concentration in the accumulator, the recent RWST sample was within specifications, and the RWST has not been diluted.

\subsection{Verification That ECCS Lines Are Full of Water (Contain No Air) (PWR)}

The Standard Technical Specifications require that every 31 days the emergency core cooling system (ECCS) be verified to be full of water by venting the ECCS pump casings and accessible high points.

It appears from a review of operational data that air becomes entrained in the ECCS during shutdown as a result of drain and fill operations but that once the system has been placed in an operational condition there is no mechanism for the introduction of air. In fact, in a PWR there is an elevation head from the RWST on the ECCS lines. Therefore, following testing or maintenance, it is essential to check the system before declaring it operable.
At some plants, personnel who perform this check must wear protective clothing because of radiation from the ECCS. The proposed change would result in a decrease in the dose to plant workers. The amount of decrease was not determined in this study.

In a recent event (July 20,1988) at San Onofre Nuclear Generating Station, Unit 3, entrained air caused a water hammer in one train of the high-pressure safety injection (HPSI) piping. The plant was in Mode 5 undergoing an integrated leak rate test (ILRT) at the time with the containment pressurized. Several sump isolation valves were not fully closed, allowing air to enter the HPSI suction piping. The pump became air bound; however, one or more slugs of water traveled down the discharge piping before the pump was stopped. Normal practice at San Onofre following an ILRT is to vent all the piping and pumps so no pumps would be air bound and there would be no air entrained in the piping during normal operation.

NRC Information Notice 88-23, "Potential for Gas Binding of High-Pressure Safety Injection Pumps During a Loss-of-Coolant Accident," discusses an incident at Farley 1 in which hydrogen gas accumulated in the piping to an HPSI pump. Hydrogen is normally used for the cover gas in the volume control tank (VCT); thus, water flowing through the VCT is saturated with hydrogen while it is in the VCT. The dissolved hydrogen will come out of solution downstream of the VCT if the pressure at some point (i.e., elbows or ties) decreases to less than that at the VCT. The hydrogen gas will not readily go back into solution. The incident at Farley indicates the need to maintain this requirement to verify that the ECCS lines are free of air.

\section{Findings}

- Air in ECCS piping could cause a water hammer that could damage the piping, rendering the system or portions of the system incapable of performing its safety function.

- Verifying that there is no air in the ECCS every 31 days can result in a radiation dose to personnel.

- A review of operating data showed (as illustrated by the San Onofre event) that air entrainment water hammers in PWR ECCS piping occur during shutdown.

- The Farley incident has shown that air entrapment can occur during normal operation, due to $\mathrm{H}_{2}$ blanketing and saturation of the VCT.

\section{Recommendation}

Inspections should be conducted for entrapped air in ECCS lines before startup from any condition in which 
testing of the ECCS, performing an ILRT, or draining of any portion of the ECCS has occurred. The 31-day surveillances to detect entrained air in the ECCS should be retained.

\subsection{Verification of Proper Valve Lineups of ECCS and Containment Isolation Valves (PWR, BWR)}

Walkdown of the ECCS and containment isolation valves are required by the Technical Specifications every 31 days. Although there was some discussion among utility personnel about the radiation dose incurred in doing these surveillances, the overall opinion was that such walkdowns are desirable, and should be retained. The NRC staff concurs.

\section{Finding}

Walkdowns of containment isolation and ECCS valves are good checks that containment integrity and ECCS operability are maintained.

\section{Recommendation}

Retain the requirements for containment isolation valve and ECCS valve walkdowns to ensure correct valve position.

\subsection{Accumulator Water Level and Pressure Channel Surveillance Requirements (PWR)}

(1) Each accumulator water level and pressure channel is to be demonstrated operable every 31 days by performing an analog channel operational test as well as a channel calibration at least every 18 months.

It is noted that licensees perform channel checks of this instrumentation also, even though it is not stated as a requirement in the Technical Specifications. Licensees should examine their channel checks surveillance and operational experience to determine whether there is sufficient basis to justify the extension of the analog channel-operational test frequency.

(2) One of the action statements for the accumulator limiting condition for operation (LCO) states that with one cold-leg injection accumulator inoperable, except as a result of a closed isolation valve, the inoperable accumulator must be restored to operable status within 1 hour or the reactor must be in at least hot standby within the next 6 hours and the pressurizer pressure must be reduced to less than 1000 psig within the following 6 hours.

This action statement is extremely stringent since only one hour is available to fix a problem. This action statement affects the surveillances required on the accumulator water level and pressure channel in the following way. It was noted during discussions at one site visit that accumulator level instrumentation has experienced downward drift. Although it doesn't pose a problem to declare a channel inoperable as a consequence of a channel check (comparison of the readings from redundant level channels), there is a tendency to require a containment entry to recalibrate the transmitter that indicates low just for the insurance it provides if the other channel becomes inoperable. This is a consequence of the time limits of the action requirements that require a plant shutdown in one hour, which is not enough time to rectify a problem with one instrument. If the allowable outage time were greater with both level instrument channels inoperable, the containment would not be entered just to recalibrate one level transmitter that has experienced excessive drift.

A containment entry with only one instrument channel inoperable would result in an unnecessary exposure to radiation.

The combination of redundant level and pressure instrumentation may provide sufficient information so that it may not be worthwhile to always attempt to correct drift associated with one instrument if there were sufficient time to repair one in the event that a second one became inoperable. Because these instruments do not initiate a safety action, it is reasonable to extend the allowable outage time for them. The staff, therefore, recommends that an additional condition be established for the specific case, where "One accumulator is inoperable due to the inoperability of water level and pressure channels," in which the completion time to restore the accumulator to operable status will be 72 hours. While technically inoperable, the accumulator would be available to fulfill its safety function during this time and, thus, this change would have a negligible increase on risk.

\section{Findings}

- Analog channel operational tests on accumulator pressure and level channels are performed too frequently.

- The action statement associated with an inoperable accumulator is too stringent.

\section{Recommendations}

- Licensees to examine channel checks surveillance and operational history to determine if there is a 
basis for justifying the extension of frequency for analog channel operational tests for pressure and level channels.

- Add a condition to the ECCS accumulator LCO for the case where "One accumulator is inoperable due to the inoperability of water level and pressure channels," in which the completion time to restore the accumulator to operable status will be 72 hours.

\subsection{Visual Inspection of the Containment Sump (PWR)}

The Standard Technical Specifications require "a visual inspection which verifies that no loose debris (rags, trash, clothing, etc.) is present in the containment which could be transported to the containment sump and cause restriction of the pump suctions during LOCA conditions. This visual inspection is required to be performed for all areas affected within containment at the completion of each containment entry when containment integrity is established."

The NRC staff recommends that this inspection should be done at least once daily if the containment has been entered that day and when the final containment entry is made (similar to the technical specification on air locks for multiple entries). This would reduce exposure to people doing work in this area by limiting the time spent in the containment.

The recommendation would require that a record be kept of all areas visited during the multiple containment entries, but this should not be difficult.

This requirement would apply mostly to containment entries when at power, hot standby, or hot shutdown (because the requirement states "when containment integrity is established") so that the entries would most likely be made for working on a specific problem in only a few areas.

\section{Findings}

- Visual inspections of the containment assure that no loose debris will be transported to and clog the sump.

- Requiring inspections to be done at the completion of each containment entry results in a higher dose to people doing the inspections than necessary.

\section{Recommendation}

Inspect the containment at least once daily if the containment has been entered that day, and during the final entry to ensure that there is no loose debris that would clog the sump.

\subsection{Verification of Boron Concentration in the Boron Injection Tank (Westinghouse PWR)}

The boron injection tank (BIT) is downstream of the charging pumps and is used to provide highly concentrated $(13,000-16,000 \mathrm{ppm})$ boric acid to the core following a main steam line break accident. The boron concentration of this tank is to be verified typically every 7 days. The BIT has been removed (or made inoperable) at many Westinghouse PWRs. For those reactors that still use the BIT, verifying the boron concentration can result in incurring a significant radiological dose. The BIT is kept mixed by circulation of borated water between the BIT and the boric acid storage tanks in order to keep a uniform temperature to maintain boron solubility. One licensee recommended taking the sample at the boric acid storage tank rather than at the BIT to reduce the dose to personnel. Licensees should be permitted to do this if they can justify that the mixing is adequate to give a boron concentration in the boric acid storage tank which is representative of that in the BIT.

\section{Findings}

- The BIT contains highly borated water which is mixed constantly with the rest of the boric acid storage system to maintain a uniform temperature and boron concentration.

- Verifying the boron concentration of the BRT can result in a significant dose of radiation to plant personnel.

\section{Recommendation}

Measure concentration of boron in the boric acid storage tank rather than in the BIT if it can be justified that the concentrations are the same. 


\section{CONTAINMENT}

\subsection{Containment Spray System (PWR)}

Each containment spray system must be demonstrated operable at least once every 5 years by performing an air or smoke flow test through each spray header and verifying that each spray nozzle is unobstructed.

The qualitative risk analysis indicates that the system is important to risk, especially for those plants in which the containment spray system performs the dual functions of removing iodine and cooling the containment, since the heat removal function is redundant.

The NRC staff searched for problems involving the containment spray system that had been uncovered by means of this testing (NPE-1). Only three cases were found and in all three cases the problem involved a construction error. These are listed in Table 8.1. (This is not true of boiling water reactors [BWRs] that have had blocked containment spray lines. However, in a BWR, the containment spray system is not a safety-related system.)

This testing gives no quantitative data on flowrates exiting the nozzles. It only verifies that there is flow, which, from the operating data, does not appear to be a problem.

Therefore, the staff recommends that this test interval be extended to every 10 years.

\section{Findings}

- PWR containment spray nozzles are checked every 5 years to verify flow from the nozzles
- The test is qualitative. It does not measure the flowrate.

- The only reported problems with this test have been construction related.

\section{Recommendation}

The surveillance interval should be extended to 10 years.

\subsection{Containment Purge Supply and Exhaust Isolation Valves (PWR)}

The Technical Specifications require that each largediameter containment purge supply and exhaust isolation valve shall be tested quarterly to demonstrate that the leakage rate is less than $0.05 \mathrm{~L}_{\mathrm{a}}$ when pressurized to pressure $P_{a}$. When the unit is operating, there can be high radiation in the area where these valves are located and the testing then becomes an ALARA (as low as reasonably achievable) concern.

The issue of leak tightness of large-containment purge supply and exhaust isolation valves with resilient seals was raised by NRC Circular 77-11, "Containment Leakage Due to Seal Deterioration," dated September 6, 1977. This circular discussed the unsatisfactory performance of resilient seals on containment isolation valves (i.e., they did not pass required leak rate tests). The valves had seat materials of neoprene and ethylene propylene.

The causes of degradation (hardening and wear) of the seat material were identified as environmental conditions (humidity and temperature) and valve cycling.

Table 8.1 Containment spray nozzle problems at PWRs

$\begin{array}{lll}\text { Plant } & \text { Date } & \text { Problem discovered }\end{array}$

Rancho Seco

Turkey Point 4

August 1978

Farley $1 \quad$ January 1982
Painters, painting the reactor building, covered up nozzles of the reactor building spray system and did not subsequently remove tape from 16 of 199 nozzles. Only 4 had tape over spray openings.

While preparing for a spray nozzle test, the licensee discovered that the restricting orifices were not installed in the branch connections from the containment spray headers to the emergency filter spray system. Unit 3's orifices were verified in place.

Certain containment spray header nozzles were found to be oriented incorrectly or positioned on the header incorrectly. Also, two nozzles were not installed due to interference. Analysis showed that peak containment temperature would not have been affected. 
A generic issue (GI B-20, "Containment Leakage Due to Seal Deterioration") was established by the staff to study the problem and propose an appropriate testing frequency. It was recognized during the study of this issue that plant personnel must enter the containment because that is where the leak test connection is located. It was considered necessary to test passive (closed) purge lines for leaks because of the potential adverse effect of seasonal weather conditions on the integrity of the isolation valves.

The resolution of GI B-20 is reflected in the present Technical Specifications surveillance requirement. The staff study appears to have been comprehensive.

The study recognized the high dose rate received by workers doing this test.

Duke Power Co., on the Catawba docket, proposed deleting the requirement for surveillance on these valves and cited plant-specific data that showed that these valves had required neither maintenance nor repair (Tucker, 1986). The proposal also cited the high radiation dose ( 3000 person-mrem/test) and the high temperatures associated with this test as reasons for deleting this test.

The NRC staff replied by letter dated July 31, 1987 (Jabbour, 1987), that the test data presented were not sufficient and that an analysis performed by the staff indicated that a quarterly test frequency could produce as much as an-order-of-magnitude reduction in the probability of containment purge/vent system failure when compared to the current 10 CFR Part 50 Appendix J requirement for leak testing at every refueling outage.

Licensees may be able to show, on a plant-specific basis or as part of a group effort, that their seals do not degrade over a sufficiently long period of time to permit an extension of the surveillance interval.

The NRC staff recommends that its position be retained until further data or analyses are presented to justify a change.

\section{Findings}

- The surveillance on containment purge and exhaust isolation valves is in excess of 10 CFR Part 50 Appendix $\mathrm{J}$ requirements.

- This increase in surveillance testing results in anorder-of-magnitude reduction in probability of containment purge system failure.

- Workers performing this test receive a high dose of radiation.

\section{Recommendation}

This requirement should be retained.

\subsection{Ice Condenser Inlet Doors (PWR)}

According to the Standard Technical Specifications for ice condenser containments, ice condenser inlet doors must be:
Demonstrated operable during shutdown at least once per 3 months during the first year after the ice bed is initially fully loaded and at least once per 6 months thereafter by testing a sample of at least $25 \%$ of the doors and verify- ing that the torque required to open each door is less than a specified amount.

The purpose of this surveillance is to provide assurance that the lower inlet doors are capable of opening properly when required during a loss-of-coolant accident (LOCA) or other high energy line break so that the steam released in the lower containment compartment can enter the ice condenser and be condensed by the ice inside.

Because this testing cannot be performed at power, this specification requires a unit outage every 6 months to perform this surveillance.

Duke Power Co. proposed a change for McGuire Nuclear Station, Units 1 and 2 (Tucker, 1985) which would allow a maximum of 18 months between the tests for any one door. The proposed surveillance interval is as conservative as the current Standard Technical Specification surveillance interval on an individual door basis.

This change was justified because the McGuire inlet door design does not allow water condensation to freeze, a common cause of stuck doors.

The licensee also provided information concerning door reliability (Tucker, 1985). Since 1981 to the date of the application in 1985, there had been 416 individual door inspections at McGuire Unit 1 and since 1983 there had been 216 at McGuire Unit 2. In all of these tests, the doors met their acceptance criteria.

The NRC staff approved this proposed change in a letter (Hood, 1988).

Other utilities with an ice condenser containment may wish to consider this change if it can be justified on a plant-specific basis.

\section{Finding}

Duke Power Co. justified a surveillance interval for containment inlet door testing that eliminated the need for a shutdown. 


\section{Recommendation}

The Duke proposal may be used by other utilities if it can be justified on a plant-specific basis.

\subsection{Testing Suppression Chamber to Drywell Vacuum Breakers (BWR)}

BWR Technical Specifications require that at least once every 31 days each vacuum breaker between the suppression chamber and the drywell shall be tested by cycling each vacuum breaker through at least one complete cycle of full travel. The American Society of Mechanical Engineers Boiler and Pressure Vessel Code (ASME Code) requires this test to be performed quarterly.

This test is also required following any discharge of steam to the suppression chamber. The time for this test following the steam discharge varies among Technical Specifications (e.g., for Hatch Unit 2 the time is 2 hours, for LaSalle Units 1 and 2 the time is 12 hours). The NRC staff recommends that the time be established as 12 hours.

Vacuum breaker operating problems were surveyed briefly. From October 1978 through July 1988, a total of 167 reported failures of suppression chamber to drywell vacuum breakers were found. Some of these reported multiple vacuum breakers inoperable. In addition, a significant number were reported from only a few plants, indicating either design or preventive maintenance problems. In many cases, the vacuum breakers were inoperable only in the licensing sense because many of the failures were problems with position indication and set points out of tolerance. In some of these events, however, the vacuum breakers were actually inoperable because of mechanical binding, rust or foreign objects in air lines, or excessive leakage.

The NRC staff recommends retaining the monthly surveillance requirement because of the relatively high incidence of problems and because these vacuum breakers are so important to safety.

\section{Findings}

- Vacuum breakers have an important safety function.

- The Technical Specifications require a monthly surveillance; the ASME Code recommends quarterly surveillance.

- There have been a significant average number of failures per year.

- These failures seem to be concentrated at a few BWRs.

\section{Recommendations}

- The monthly surveillance test should be retained.

- The time each vacuum breaker shall be tested following any discharge of steam to the suppression chamber shall be changed to 12 hours.

\subsection{Hydrogen Recombiner (PWR, BWR)}

The hydrogen recombiner system removes the hydrogen and oxygen gases that accumulate in the containment atmosphere following a design-basis loss-of-coolant accident. It is not capable of removing the highest hydrogen concentrations that could be present after a severe accident.

The present Technical Specifications require testing the hydrogen recombiners at least once every six months by performing a functional test.

A search of LERs was performed to assess the reliability of hydrogen recombiners. Twelve failures of hydrogen recombiners were found over the time period from 1980 to June 1988. In most cases, only one train of the hydrogen recombiner system was inoperable. In one case in which both trains were inoperable, a backup hydrogen purge system was available. In two cases, the failure was fixed within two hours. Since the hydrogen recombiner is manually started many hours after a LOCA occurs, the system would have been operable when called upon.

The NRC staff recommends that, because of the redundancy and apparent high reliability, the surveillance test interval should be changed to once each refueling interval.

\section{Findings}

- A search of LERs found 12 failures of hydrogen recombiners between 1980 and the middle of 1988 .

- In each case, either a redundant hydrogen recombiner or a diverse system (hydrogen purge system) was available.

\section{Recommendation}

Change the surveillance test interval for hydrogen recombiner functional tests to once each refueling interval.

\subsection{Sodium Tetraborate Concentration in Ice Condenser Containment Ice}

The Technical Specifications for the ice bed of an ice condenser containment require a chemical analysis of the stored ice to assure a boron concentration of at least 1800 
ppm and a pH of 9.0 to 9.5 at $25^{\circ} \mathrm{C}$. This analysis is required at least every 9 months. This surveillance requirement could mean that someone would have to enter the containment to take the sample while the unit is at power which means that that person would receive a radiation dose. According to Duke Power Company chemists, meeting the boron concentration and $\mathrm{pH}$ requirements of this LCO has never been a problem.

The NRC staff therefore recommends that the frequency for performing this chemical analysis be changed to once each refueling interval.

\section{Findings}

- A chemical analysis of the ice in the ice bed of an ice condenser containment is required every 9 months.

- This requires a containment entry while at power.

- Samples have always been within the required limits on boron concentration and $\mathrm{pH}$.

\section{Recommendation}

Change the analysis interval to once each refueling interval. 


\section{PLANT SYSTEMS}

\subsection{Auxiliary Feedwater Pump and System Testing (PWR)}

The Standard Technical Specifications and most plant Technical Specifications require the monthly testing of auxiliary feedwater (AFW) pumps. The Boiler and Pressure Vessel Code of the American Society of Mechanical Engineers (ASME Code), Section XI, Paragraph IWP-3400, requires the testing of Class 1,2 , and 3 centrifugal pumps "normally every three months." AFW pumps are the only pressurized water reactor (PWR) pumps required by Technical Specifications to be tested more frequently than required by the ASME Code.

The Technical Specifications do not require the testing to be as thorough as required by the ASME Code. Table 9.1 compares inservice testing required by the ASME Code with that required by Technical Specifications.

Another difference in the testing is that, at some plants, one group may perform the monthly testing required by the Technical Specifications, and a different group will perform the ASME Code testing every third month.

In both types of tests, the AFW pump takes suction from the condensate storage tank and returns the water to the condensate storage tank through a recirculation line. In most plants, the recirculation line is sized between $5 \%$ and $15 \%$ of the best estimate point flow (NP-4264, Vol. 1). This size was derived from considering temperature rise in the pump. Pump manufacturers are now recommending that standby pumps be tested at a flow no less than $25 \%$ of the best efficiency point flow (NUREG/ CR-4597). This is based on "hydraulic instability" of the pump. This is a term for unsteady flow phenomena which can cause degradation of the pump and which become more pronounced as the pump operates further away from its best efficiency point.

Two studies have been done of the AFW system. Report NP-4264 is an Electric Power Research Institute (EPRI) study that used data from the time period early 1979 to late 1982. NUREG/CR-4597 is a study done for the NRC's Nuclear Plant Aging Research (NPAR) Program.

Both studies concluded that a significant cause of failures of AFW pumps is testing the pump by recirculating flow through a minimum flow line which is not adequately sized. Both studies deduced this from a review of licensee event report (LER) data and other data on the types of failures that occurred. This was reinforced by experience with feed pumps at fossil power plants; these are also horizontal multistage centrifugal pumps similar to AFW pumps.

Both reports recommend, among other things, that the size of the recirculation lines be increased. In many cases, this can be achieved by modifying the orifice in the recirculation line although, as the flow increases through the recirculation line, adequate flow to the steam generators must still be maintained. This could require a complicated interlock which would close valves on the recirculation line when an actual demand signal is present.

Although a change in recirculation flow from approximately $10 \%$ to approximately $25 \%$ is the best solution to this problem, a reduction in the frequency of testing of the AFW pumps from monthly to quarterly (the frequency specified in the ASME Code, Section XI), could be a reasonable step to reducing the rate of wear.

This problem should be put in perspective. Using the EPRI data, 236 LERs reporting failures of turbine-driven AFW pumps were found over the period from early 1979 through late 1982 . Of these, $163(69 \%)$ reported failures related to the turbine (a figure which NP-4264 [Vol. 1] states is roughly consistent with previous EPRI studies on the high-pressure coolant injection [HPCI] and reactor core isolation cooling [RCIC] systems in boiling water reactors [BWRs]) and $73(31 \%)$ were pump related. Of those that are pump related, $23 \%$ were failures of the "rotating element" as opposed to instrumentation and controls or valves. Thus, at the most, $23 \%$ of the failures

Table 9.1 Inservice testing required by Standard Technical Specifications and ASME Code

\begin{tabular}{ll}
\hline ASME Code & Standard Technical Specifications \\
\hline Inlet pressure & - \\
Differential pressure & - \\
Flow rate & Flow rate \\
Vibration amplitude & - \\
Lubricant level and pressure & - \\
Bearing temperature & - \\
- & Discharge pressure \\
\hline
\end{tabular}


could be reduced by decreasing the surveillance frequency for the turbine-driven AFW pumps.

For the motor-driven AFW pump, the "rotating element" accounted for 13 of $50(26 \%)$ reported failures (instrumentation and controls, as well as valves, were the other major contributors to failure of the motor-driven AFW pump). Thus, for the motor-driven AFW pump, at the most, $26 \%$ of the failures could be reduced by less frequent surveillance or by decreasing the flow resistance of the recirculation line.

Another consideration is that, according to the NRC report NUREG/CR-4597, $42 \%$ of the AFW pump failures were found during surveillance testing and $29 \%$ were found during operation (6\% were found during maintenance and, for $23 \%$, the method of detection was not stated). Thus, surveillance testing is important in detecting failures in the AFW system. However, surveillance testing also contributes to the problem. The availability of the AFW pump, while related to the conduct of surveillance testing, is not continuously linearly related to surveillance testing. That is, at some point an increase in surveillance testing (i.e., reducing the surveillance test interval) will not contribute to an increase in availability, and in fact could contribute to equipment unavailability. Analysis of AFW pump failures indicates that a monthly surveillance test interval (STI) may be contributing to AFW pump unavailability through failures and equipment degradation. The changing of the AFW pump STI to quarterly, on a staggered basis, is consistent with this analysis. Conducting the tests on a staggered basis will permit system testing monthly, while reducing AFW pump testing to quarterly, thereby maintaining a consistent degree of reliability. The recommended change in testing frequency to quarterly is also consistent with the requirements of the ASME Code.

\section{Findings}

- The ASME Code requires Class 2 pumps (such as AFW pumps) to be tested quarterly.

- Technical Specifications require testing such pumps monthly.

- AFW pump wear is caused by recirculating water during tests through a line that has a smaller diameter than presently recommended by pump manufacturers.

- A review of LERs shows that, at most, $23 \%$ of turbine-driven AFW pumps and $26 \%$ of the motordriven AFW pumps had failures due to the "rotating element" itself, as opposed to valves, controls, and so forth.

- $\quad 42 \%$ of pump failures were found during surveillance testing.
- $\quad \mathrm{AFW} / \mathrm{EFW}$ pump and valve surveillances have high risk impact per NUREG/CR-5200.

- The licensee burden is increased by monthly testing.

- AFW pump availability is increased by quarterly testing on a staggered basis.

\section{Recommendation}

Change frequency of testing AFW pumps to quarterly on a staggered test basis.

\subsection{Main Steam Line Isolation Valve (MSIV) Surveillance Testing}

\subsubsection{Pressurized Water Reactors}

The ASME Code, Section XI, Article IWV-3000 states that "valves shall be exercised to the position required to fulfill their function unless such operation is not practical during plant operation. If only limited operation is practical during plant operation the valve shall be part-stroke exercised during plant operation and full-stroke exercised during cold shutdown."

Since closing a main steam line isolation valve (MSIV) during operation would result in a plant trip, licensees do partial-stroke testing quarterly as specified by the ASME Code.

The purpose of this test is to demonstrate that an MSIV is capable of movement.

The test is being done in several different ways. The valve may be closed rapidly in response to a close signal while being tested. In this case, the valve closes until it is stopped by a limit switch at $10 \%$ closed (or less, depending on the distance that the valve disc can be placed into the steam line without fully closing because of the force of the steam flow).

Another method is to drain hydraulic fluid to reduce system pressure which in turn tends to close the valve. The operator must respond to the valve closure and secure the bleeding at the $10 \%$ closed level. If the operator overshoots this level or if the test equipment fails, the MSIV will close and the plant will trip. Likewise, if the limit switch fails, the valve will completely close, causing a trip.

The MSIVs were not designed to be tested by the latter testing method. The hydraulic fluid outlets were designed to be used for maintenance and not for periodic testing.

A review of operating experience with MSIVs (from information in NPE-4) shows many cases in which MSIVs could not be closed because of problems with the valves' actuators or mechanical binding of the valves (as opposed 
to control system problems). Some of these problems were found while the valves were being stroke tested. Most problems were found while the valves were being operated after maintenance or as part of other plant activities. Many of the problems seemed to arise from inadequate maintenance. The buildup of foreign material and packing that was too tight were common problems. Thus, it seems that surveillance testing is needed to find these failures.

On the other hand, this test is considered, by PWR operators, to have a high potential for reactor trip. Two recent trips as a result of MSIV testing occurred at Virgil C. Summer Nuclear Station on May 12, 1988 (LER 88-006) and at Waterford Generating Station, Unit 3 on December 11, 1987 (LER 87-028). Thus, a brief study shows that plants do trip during MSIV testing but that failures also occur that affect the ability of an MSIV to close.

The NRC staff's qualitative safety assessment showed that the present quarterly surveillance test interval is acceptable. However, a study of MSIV surveillance testing could be conducted to weigh the risks of testing versus the risks from failures not being discovered.

\section{Findings}

- Quarterly testing of MSIVs is required by the ASME Code.

- MSIV failures in which the valve would not close on demand have occurred.

- $\quad$ MSIV testing has a high potential for trips.

- A significant number of PWR MSIV failures appear to result from inadequate maintenance.

\section{Recommendation}

The vendor owners groups should consider the benefits of a study that would justify increasing the quarterly testing of MSIVs.

\subsubsection{Boiling Water Reactors}

The purpose of BWR main steam isolation valves is to prevent the discharge of primary coolant outside the containment following a pipe break in the main steam system. There are two MSIVs in series on each steam line. Since these valves must contain reactor coolant after an accident, minimizing leakage is an important consideration. MSIVs also provide a signal to the reactor protection system (RPS) to trip the reactor upon $10 \%$ closure to anticipate the pressure and neutron flux transients that will follow a full closure.
BWR MSIVs are required to be tested quarterly (ASME Code) by verifying full closure within a specified time interval (typically between 3 and 5 seconds).

Some of the problems found during testing of BWR MSIVs include:

- Failed relays and limit switches so that no signal is sent to (that division of) the RPS.

- Air supply contaminated with fine particles or oil which prevented the MSIV from closing.

- Seat leakage in excess of technical specification allowed values.

- Low hydraulic dashpot oil level resulted in fast closing times.

Reactor trips occur during BWR MSIV tests; however, because significant problems were discovered during testing of these valves, and because these valves are so important to safety, the NRC staff recommends that no change be made in the test frequency of BWR MSIVs.

\section{Findings}

- MSIVs are very important to reactor safety.

- Significant problems have been found during testing of BWR MSIVs.

\section{Recommendation}

The surveillance frequency of BWR MSIVs should not be changed.

\subsection{Control Room Emergency Ventilation System (PWR, BWR)}

As part of the verification of the operability of the control room emergency ventilation system, the Technical Specifications require that the control room temperature be verified to be under a specified value every 12 hours. Some typical values are given below:

$\begin{array}{ll}\text { Crystal River } & 120^{\circ} \mathrm{F} \\ \text { Catawba } 1 / 2 & 110^{\circ} \mathrm{F} \\ \text { San Onofre } 2 / 3 & 110^{\circ} \mathrm{F} \\ \text { LaSalle } 1 / 2 & \text { None specified } \\ \text { Hatch 2 } & 105^{\circ} \mathrm{F} \\ \text { North Anna } 1 / 2 & 120^{\circ} \mathrm{F} \\ \text { Vermont Yankee } & \text { None specified }\end{array}$

These values are derived, according to the Technical Specifications "Bases" section, to ensure that (1) the ambient air temperature does not exceed the allowable temperature for continuous duty rating for the equipment 
and instrumentation cooled by this system and (2) the control room will remain habitable for operations personnel during and following all credible accident conditions.

It is not clear that temperature limits this high accomplish these objectives. For one PWR, the following information was available to judge the conservatism in the Technical Specifications surveillance requirement for control room temperature.

The most conservative outdoor design temperature used by ASHRAE (American Society of Heating, Refrigeration and Air Conditioning Engineers) is the $0.1 \%$ level which is the highest temperature that occurs only $0.1 \%$ of the year or 9 hours. ASHRAE suggests this value "only for extremely conservative work." Using this temperature criterion at this site, the indoor ambient temperature would not exceed $104^{\circ} \mathrm{F}$. The technical specification limit is $120^{\circ} \mathrm{F}$ for this plant.

The control room temperature could exceed $111^{\circ} \mathrm{F}$ at this site for 1-1/2 hours per year but would always remain below $117^{\circ} \mathrm{F}$. The FSAR for the reactor states that the Class 1E electrical equipment would be capable of operating for only "short periods of time" at temperatures above $117^{\circ} \mathrm{F}$. From discussions with plant personnel dur- ing the NRC staff's site visits, it is not clear that non-Class $1 \mathrm{E}$ equipment would function at this temperature at all.

The NRC staff recommends that the surveillance requirement to record control room temperature every 12 hours be replaced with a more useful surveillance requirement or possibly deleted if a more effective limit cannot be established.

\section{Findings}

- The surveillance requirements for the control room emergency ventilation system contain a requirement that the control room temperature be verified every 12 hours to assure that it is less than a temperature limit typically in excess of $100^{\circ} \mathrm{F}$.

- This temperature limit is to ensure equipment operability and human habitability. It does not appear to be effective for either purpose.

\section{Recommendation}

Replace this requirement with a more useful surveillance or delete it if a more effective limit can not be established. 


\section{ELECTRIC POWER}

\subsection{Emergency Diesel Generator Surveillance Requirements (PWR, BWR)}

Corresponding to their importance to safety, emergency diesel generators (EDGs) have the most detailed Technical Specifications surveillance requirements of any piece of mechanical or electrical equipment in a nuclear power plant. Surveillance requirements for EDGs are currently based on Regulatory Guides 1.108 and 1.9.

The safety function of the diesel generators is to supply ac electrical power to plant safety systems whenever the preferred ac power supply is unavailable. Through surveillance requirements, the ability of the EDGs to meet their load and timing requirements is tested and the quality of the fuel and the availability of the fuel supply are monitored.

As part of the resolution of Unresolved Safety Issue (USI) A-44, "Station Blackout," the NRC staff has prepared Regulatory Guide (RG) 1.155 to provide guidance on EDG reliability levels. RG 1.155 also specifies that the reliable operation of onsite emergency ac power sources should be ensured by a program designed to maintain and monitor the reliability level of each power source over time to ensure that the selected reliability levels are being achieved.

Generic Safety Issue (GSI) B-56, "Diesel Reliability," was established to develop guidelines for an EDG reliability program. In addition to these efforts, the Office of Nuclear Regulatory Research (RES) is conducting the Nuclear Plant Aging Research (NPAR) Program, which is intended to resolve technical safety issues related to the aging degradation of equipment important to reactor safety. An important part of this program is the study of the aging of emergency diesel generators.

The results of these programs were reviewed as part of this study to determine how these programs will affect surveillance requirements for EDGs in the Technical Specifications.

The current performance requirements are stringent. The EDG must start on any of several signals (e.g., manual actuation, safety injection, or loss of normal power to an emergency bus), increase to rated speed in a short time (e.g., 10 seconds), and pick up its emergency load in blocks at programmed times (load sequencing). These times are relatively short and are set by the requirements of the large-break loss-of-coolant accident (LOCA).
Research done by NRC and the industry has shown that some of the assumptions in the analysis of the LOCA, required by 10 CFR 50.46 and Appendix $\mathrm{K}$ to $10 \mathrm{CFR}$ Part 50, are very conservative. In addition to the conservative nature of the regulations, other conservatisms have been included in the vendors' LOCA models. SECY-83-472 provides a method to eliminate those conservatisms not specifically required by the regulations.

Under the sponsorship of the Electric Power Research Institute (EPRI), calculations were performed, using the methods given in SECY-83-472, that show margin is available to the criteria of 10 CFR 50.46 that could be used to extend the EDG start and load times. Studies done for a typical four-loop Westinghouse PWR (NSAC-130) show that the diesel start and load time could be increased to 45 seconds from 10 seconds. The 45-second start time is limited by environmental qualification considerations of equipment in containment. The calculated peak cladding temperature was below $2200^{\circ} \mathrm{F}$.

A similar calculation for a typical BWR 4 showed that the diesel generator start and load time could increase to 118 seconds (NSAC-96), and still be within acceptable limits.

However, for the purpose of evaluating the effects of surveillance testing, start and load times should be addressed separately.

A fast start (i.e., start and acceleration to synchronous speed at full fuel rack position) has the potential to accelerate the degradation of the diesel generator if conducted without the benefit of a prelube period. However, prelubricating diesel generators is now common practice, and any remaining negative effects of fast starts are minimal. Nevertheless, fast starts can be eliminated on some diesel generators by changing the governor configuration, but only at the cost of reducing diesel generator reliability, by eliminating a redundant overspeed protection feature, that is, the backup mechanical governor. In this case, the gain associated with slow starts does not offset the loss of the backup overspeed protection.

Fast loading (i.e., zero to full load in 120 seconds or less) during surveillance testing is, on the other hand, the most significant cause of accelerated degradation of diesel generators. It can cause rapid piston ring and cylinder liner wear (up to 40 times greater than normal wear) and should be eliminated in favor of loading in accordance with the manufacturer's recommendations, except for the 18-month loss of offsite power (LOOP) test. Manufacturers' recommendations for diesel generator loading can be 30 minutes or more to reach full load.

In an actual emergency, loads will be sequenced onto a diesel generator in approximately 60 seconds. This 
constitutes fast loading of the diesel generator regardless of whether the sequencing started at 10 seconds or at either 45 or 118 seconds (as suggested by the studies referenced above) after the diesel generator starts. Hence, design changes for slower diesel generator starting and acceleration would not significantly reduce the degradation of diesel generators which is inherent with rapid loading that is necessary to meet safety analysis requirements.

The NRC staff recommends that all testing of the diesel generators, with the exception of the LOOP tests which are performed with and without an ESF signal once each refueling, be performed by gradual loading in accordance with the manufacturer's recommendations.

EDG tests were typically started with the EDG initially at ambient conditions with no prelubrication or warmup time. Generic Letter (GL) 84-15 changed this, stating that "[l]icensees are encouraged to submit changes to their Technical Specification[s] to accomplish a reduction in the number of [cold] fast starts." A typical technical specification was included in GL 84-15 which required a start from ambient conditions every 184 days rather than every month.

Some nonstandard Technical Specifications require that, with an inoperable EDG, not only the remaining operable diesel generator(s) must be tested at a higher frequency than normally required but, in addition, other emergency equipment such as the emergency core cooling system (ECCS), safety-related cooling water pumps (e.g., service water), and other power supplies also must be demonstrated operable. This testing must commence "immediately" upon discovering that a diesel generator is inoperable.

Some nonstandard Technical Specifications also require that if a train or subsystem of certain safety systems other than the diesel generators (for example, a low-head safety-injection pump of the ECCS) is declared inoperable, not only the other train of the particular system but also other equipment of the emergency core cooling systems and the diesel generators must be tested. Thus, a failed train in one safety system can cause a great deal of testing of apparently unrelated systems. This type of testing is called "alternate testing."

An example of this in matrix form is shown in Table 10.1 (from a letter from Vermont Yankee Nuclear Power Corp., July 15, 1988 [Capstick, 1988]) which is based on the Vermont Yankee Technical Specifications.
By a letter dated December 7, 1987 (Murphy, 1987), the licensee for Vermont Yankee submitted a request to revise this surveillance/alternate testing requirement. The NRC staff reviewed this proposed change to the Technical Specifications and requested a more quantitative analysis than had been originally supplied. In response to this request, the Vermont Yankee Nuclear Power Corp. submitted an analysis dated July 15, 1988 (Capstick, 1988), using reliability methods. The NRC staff is reviewing that submittal.

The analysis quantified the unavailabilities of the systems when required to perform their intended function upon demand, both with and without alternate testing. Two systems were chosen for detailed analysis: the core spray system and the diesel generators.

The pros and cons of testing were quantified, that is, (1) the decreased potential for an undetected failure due to the alternate testing and (2) the increased unavailability due to (a) the alternate testing and (b) repair of demand-related and test-related failures. Other disadvantages to alternate testing which were not quantified in this study are:

(1) reduced reliability due to equipment degradation from excessive testing

(2) potential for unnecessary shutdowns that result in plant transients and challenges to safety systems

(3) potential for plant transients initiated during surveillance tests

(4) diversion of operating personnel time and attention

(5) increased radiation exposure to operating personnel

The analysis showed that, for the core spray system, alternate testing (which is required daily by the Vermont Yankee Technical Specifications) produced unavailabilities at least a factor of 4 greater than monthly testing. For the diesel generators, this factor was about 3 .

Considering this analysis and similar conclusions in NUREG-1024, the staff recommends that alternate testing requirements be deleted from the Technical Specifications for all plants so that the failure of a train or subsystem of a safety-related system other than an emergency diesel generator would not require testing of the diesel generators or any other equipment. 
Table 10.1 Alternate testing requirements

\begin{tabular}{|c|c|c|c|c|c|c|c|c|c|c|c|c|c|}
\hline $\begin{array}{l}\text { Inoperable } \\
\text { subsystem }\end{array}$ & $\begin{array}{l}\text { Operation } \\
\text { inoperable } \\
\text { components } \\
\text { (days) }\end{array}$ & $\begin{array}{l}\text { Standby } \\
\text { liquid } \\
\text { control }\end{array}$ & $\begin{array}{l}\text { Core } \\
\text { spray }\end{array}$ & $\begin{array}{l}\text { LPCI } \\
\text { subsystem }\end{array}$ & $\begin{array}{l}\text { Diesel } \\
\text { generators }\end{array}$ & $\begin{array}{l}\text { Containment } \\
\text { cooling }\end{array}$ & $\begin{array}{l}\text { RHR } \\
\text { service } \\
\text { water }\end{array}$ & $\begin{array}{l}\text { Service } \\
\text { water }\end{array}$ & $\begin{array}{l}\text { Alternate } \\
\text { cooling } \\
\text { tower }\end{array}$ & ADS & RCIC & HPCI & $\begin{array}{l}\text { Standby } \\
\text { gas } \\
\text { treatment }\end{array}$ \\
\hline $\begin{array}{l}\text { Standby } \\
\text { liquid } \\
\text { control }\end{array}$ & 7 & I/D & & & & & & & & & & & \\
\hline Core spray & 7 & & I/D & I & I & & & & & & & & \\
\hline LPCI pump & 7 & & I & $\mathrm{I} / \mathrm{D}^{\mathrm{a}}$ & I & I & & & & & & & \\
\hline $\begin{array}{l}\text { LPCI } \\
\text { subsystem }\end{array}$ & 7 & & I/D & I/D & I/D & I/D & & & & & & & \\
\hline $\begin{array}{l}\text { Diesel } \\
\text { generators }\end{array}$ & 7 & & I/D & $\mathrm{I} / \mathrm{D}$ & I/D & $\mathrm{I} / \mathrm{D}$ & & & & & & & \\
\hline $\begin{array}{l}\text { Containment } \\
\text { cooling }\end{array}$ & 30 & & & & & I/D & & & & & & & \\
\hline $\begin{array}{l}\text { RHRSW } \\
\text { pump }\end{array}$ & 30 & & & & & & I/D & & & & & & \\
\hline $\begin{array}{l}\text { RHR service } \\
\text { water }\end{array}$ & 7 & & & & I/D & & I/D & & & & & & \\
\hline Service water & 15 & & & & & & & $\mathrm{I} / \mathrm{D}$ & I/D & & & & \\
\hline $\begin{array}{l}\text { Alternate } \\
\text { cooling } \\
\text { tower }\end{array}$ & 7 & & & I/D & & & I/D & $\mathrm{I} / \mathrm{D}$ & & & & & \\
\hline ADS & 7 & & & & & & & & & & & I & \\
\hline $\mathrm{RCIC}$ & 7 & & & & & & & & & & & I/D & \\
\hline $\mathrm{HPCI}$ & 7 & & I & I & & & & & & $I / D$ & I/D & & \\
\hline $\begin{array}{l}\text { Standby gas } \\
\text { treatment }\end{array}$ & 7 & & & & & & & & & & & & I/D \\
\hline UPS $^{b}$ & & & & & & & & & & & & & \\
\hline
\end{tabular}

Note: I-Immediate; D-Daily

a-Redundant component only
b-See LPCI subsystem, core spray, and diesel generator alternate testing requirements. 
The NRC staff recommends that the requirements to test the remaining diesel generator(s) when one diesel generator is inoperable due to any cause other than preplanned preventive maintenance or testing be limited to those situations where the cause for inoperability has not been conclusively demonstrated to preclude the potential for a common mode failure. However, when such testing is required, it should be performed within 8 hours of having determined that the diesel generator is inoperable.

The NPAR Program found that regulatory surveillance requirements are not the only contributor to EDG degradation. NUREG/CR-4590, Volume 1, identified four categories of stressors that contributed to emergency diesel generator aging: vibration, inferior quality of components, adverse environment, and human error.

The NPAR Program did not specify the fraction of problems found with emergency diesel generators which are due to testing. A study done for EPRI (NP-4264, Vol. 2) looked specifically at failures of emergency diesel generators that result from surveillance testing. The data for this study consist of LERs from January 1979 through early 1983, a period of just over 4 years. Note that this period preceded the issuance of Generic Letter 84-15 so that, hopefully, the situation now would be somewhat better. A total of 585 failures of 136 diesel generators were found. Of these 585 failures, $70(12 \%)$ were determined to be related to surveillance testing. The components that had the highest numbers of surveillance-test-related problems were: turbocharger, power assembly and bearings, starting system, cooling system, lube oil system, governor and exciter, and regulator. However, no specific failures were widespread enough to be considered generic. Generic failures with diesel generators have occurred in the past, but solutions to these problems are available and, in most cases, have been implemented.

Emergency diesel generator testing appears to be an area that would benefit from a reliability-based testing program (as discussed in Section 3.8 of this report). The NRC staff is evaluating reliability-centered concepts for the resolution of GI B-56 that may further reduce unnecessary testing. NUREG/CR-5078 describes an approach to a reliability-based testing program for emergency diesel generators. As part of this reliability-based approach, a detailed root-cause analysis procedure and a good preventive maintenance program (also reliability based) should be included. Detailed monitoring and trending are important to assure good performance.

Diesel generator surveillance requirements could also be improved in another area.

The Standard Technical Specifications contain a requirement to operate each emergency diesel generator for 24 hours. During the first 2 hours, the diesel is to operate with its 2-hour-rated load and for the last 22 hours it is to operate at its continuous-rated load. The Standard Technical Specifications require that, within 5 minutes after completing this 24-hour test, the emergency buses must be deenergized and loads shed with a subsequent fast start and full load acceptance.

Duke Power Co., by letter dated February 15, 1988, on the Catawba Units 1 and 2 dockets (Tucker, 1988) proposed to separate the 24-hour test from the 5-minute test. The NRC staff approved Duke's proposal in a letter to Duke dated July 28, 1988 (Jabbour, 1988).

The reason for requesting this change is that separating these two required tests gives plant operators added flexibility and prevents critical path complications during the outages.

Duke stated that it has been necessary to shut down the diesel generator faster than recommended by the diesel generator shutdown procedure in order to perform the hot restart test within 5 minutes of the 24-hour test run. Another problem with performing these tests in quick succession is their potential for causing critical path complications and delays during an outage. Engineered safety features (ESF) actuation testing is performed at the beginning of refueling outages. Block tagouts are delayed until completion of ESF testing. As a result of the testing sequence currently dictated by Technical Specifications, a minimum of $\mathbf{4 8}$ hours of critical path time is spent each refueling outage running the two diesel generators. By revising the surveillance requirements as requested, the two 24-hour runs could be completed later in the outage or at some other convenient time.

Duke proposed to substitute a diesel generator run at continuous-rated load for 1 hour or until the operating temperature had stabilized, followed within 5 minutes by a diesel engine start. To ensure that operating temperatures have stabilized, the NRC staff concludes that 2 hours is a more appropriate time limit.

The hot-restart test is performed to verify that the diesel generator does not have, in any way, impaired performance following operation at full load or equilibrium temperature.

Failure to restart when hot, or extended delay in restarting, is typically only experienced with small forced-aircooled diesel engines which, upon being tripped undergo a temperature rise transient. The large diesel generators are typically water cooled and do not experience any significant temperature rise transients during operation or after shutdown. In addition, diesel generators are normally maintained at hot standby conditions (heated cooling water and lubricating oil). 
The NRC staff, therefore recommends that other utilities be permitted to change their Technical Specifications to separate the 24-hour test and the hot-startup test if they propose doing so.

\section{Findings}

- EDGs are very important to safety.

- EDGs are tested too often because:

(1) Technical Specifications at some plants require testing if other safety-related equipment is inoperable.

(2) Technical Specifications at some plants require not just one start to verify operability but starts "immediately," or within 1 hour, and every 8 hours thereafter.

- Studies show that testing too frequently is counterproductive to safety in terms of equipment availability.

- Rapid loading is a major cause of diesel generator degradation.

- There is no safety reason for performing a startup of a diesel within 5 minutes of the 24-hour test run as is required by Technical Specifications.

\section{Recommendations}

- When an EDG itself is inoperable (not including a support system or independently testable component), the other EDG(s) should be tested only once (not every 8 hours) and within 8 hours unless the absence of any potential common-mode failure can be demonstrated.

- EDGs should be loaded in accordance with the vendor recommendations for all test purposes other than the refueling outage LOOP tests.

- The hot-start test following the 24-hour EDG test should be a simple EDG start test. If the hot-start test is not performed within the required 5 minutes following the 24-hour EDG test, it should not be necessary to repeat the 24-hour EDG test. The only requirement should be that the hot-start test is performed within 5 minutes of operating the diesel generator at its continuous rating for 2 hours or until operating temperatures have stabilized.

- Delete the requirement for alternative testing that requires testing of EDGs and other unrelated sys- tems not associated with an inoperable train or subsystem (other than an inoperable EDG).

\subsection{Battery Surveillance Requirements (PWR, BWR)}

Industry guidance for testing large lead storage batteries of the kind used in nuclear power plants is found in Standard 450-1980 of the Institute of Electrical and Electronics Engineers (IEEE). Regulatory Guide 1.129, Revision 1 (February 1978) endorses an earlier version of this standard (IEEE 450-1975). The Standard Technical Specifications follow this standard to some extent but are more conservative in some requirements and less conservative in others. Table 10.2 compares IEEE 450-1980 with the Westinghouse Standard Technical Specifications, Version $4 \mathrm{~A}$.

Note that IEEE 450-1980 requires more visual inspections of the condition of the batteries (e.g., cleanliness, evidence of corrosion, cracks and leakage of electrolyte) than the Westinghouse Standard Technical Specifications (STS). On the other hand, the Westinghouse STS are more conservative with respect to the frequency of measurements of battery charger output, pilot cell conditions, and total terminal battery voltage. (The Westinghouse STS require these every 7 days while IEEE $450-1980$ requires these surveillances only monthly.)

It is apparent from this comparison that the Westinghouse STS are most concerned with measurements of the operability of the batteries and not as concerned with mechanisms that degrade the batteries.

Perhaps the most significant surveillance not included in the Westinghouse STS is the surveillance for ambient room temperature. IEEE 450-1980 requires a monthly surveillance. The Westinghouse STS do not. The Westinghouse STS do require a quarterly surveillance of electrolyte temperature in a representative number of cells, but the requirement is that the temperature be greater than a minimum value, an operability requirement. There is no maximum temperature specified.

A limit on maximum ambient temperature would protect the batteries from degradation mechanisms.

NUREG/CR-4457, which studied the aging of Class 1E batteries for the NPAR Program, states that "thermal stresses, whether caused by internal sources. . or by the room temperature, are probably the most detrimental with respect to accelerating the aging of batteries." As an example, the report cites a major battery manufacturer as stating that an increase in ambient temperature from $77^{\circ} \mathrm{F}$ to $95^{\circ} \mathrm{F}$ reduces the life of the battery by $50 \%$. 
Table 10.2 Comparison of requirements of IEEE Standard 450-1980

with requirements of Westinghouse STS

\begin{tabular}{|c|c|c|}
\hline Requirement & $\begin{array}{l}\text { IEEE } \\
450-1980\end{array}$ & $\begin{array}{l}\text { Westinghouse } \\
\text { STS }\end{array}$ \\
\hline $\begin{array}{l}\text { 1. General appearance and cleanliness of battery } \\
\text { and battery area }\end{array}$ & $\mathbf{M}$ & - \\
\hline 2. Evidence of corrosion on terminals or connectors. & $\mathbf{M}$ & $\mathbf{Q}$ \\
\hline 3. Cracks in cells and leakage of electrolyte & $\mathbf{M}$ & - \\
\hline 4. Individual cell condition & $\mathbf{Y}$ & $\mathbf{R}$ \\
\hline 5. Tightness of bolted connections & $\mathbf{Y}$ & $\mathbf{R}$ \\
\hline 6. Integrity of battery rack & $\mathbf{Y}$ & $\mathbf{R}$ \\
\hline 7. Condition of ventilation equipment & $\mathbf{M}$ & - \\
\hline 9. Electrolyte levels, each cell & $\mathbf{M}$ & $\mathbf{Q}$ \\
\hline 10. Ambient temperature & $\mathbf{M}$ & - \\
\hline 11. Voltage, specific gravity, each cell & $\mathbf{Q}$ & $\mathbf{Q}$ \\
\hline 12. Electrolyte temperature, representative cells & $\mathrm{Q}$ & $\mathbf{Q}$ \\
\hline 13. Total terminal battery voltage & $\mathbf{Q}$ & Every 7 days \\
\hline 14. Pilot cell electrolyte level & See item 9 & Every 7 days \\
\hline 15. Float voltage & $\mathbf{M}$ & Every 7 days \\
\hline 16. Specific gravity & $\mathbf{M}$ & Every 7 days \\
\hline 17. Electrolyte temperature & $\mathbf{M}$ & - \\
\hline
\end{tabular}

Note: $M=$ monthly, $Q=$ quarterly, $Y=$ yearly, $R=$ not to exceed 18 months.

The NRC staff therefore recommends a study of the need for a maximum (and minimum) allowable ambient temperature for batteries.

There are other important phenomena discussed in NUREG/CR-4457 that are not covered by either the Standard Technical Specifications or IEEE 450-1980. These are the seismic vulnerability of the batteries and excessive harmonic fluctuations in the battery charger voltage, called ac "ripple."

According to NUREG/CR-4457, excessive harmonic fluctuations in voltage from the battery charger cause stresses at the battery plate similar to overcharging, accelerate corrosion, and produce excessive internal temperatures. The NRC Office of Nuclear Regulatory Research should continue to study these to determine if this situation is really a problem at nuclear power plants.

The seismic event is the design-basis event for the mechanical integrity of batteries. Seismic vulnerability is caused by physical degradation of the structure of the battery. There are no good tests to detect this aging, but
IEEE Standard 535-1986 requires that batteries that have been aged to their end-of-life service be given a pre-seismic capacity test, a capacity test during a simulated seismic test, and a post-seismic test. IEEE 535-1986 also requires seismic qualification of the battery rack. Therefore, batteries tested to IEEE 535-1986 should be acceptably qualified for seismic events, recognizing that this is not a Technical Specifications issue and seismic testing should not appear in the Technical Specifications.

The Standard Technical Specifications require several surveillances more often than called for by IEEE 450-1980. These are the electrolyte level, float voltage, specific gravity of the pilot cell (Category A items of Table 4.8.2), and the total terminal battery voltage. Several of the PWR licensees identified these as burdensome surveillance intervals. However, as shown in Table 10.3 (taken from NUREG/CR-4457), some of the most common causes of battery failure are associated with items covered by these surveillances. Note that the leading cause of battery inoperability is low specific gravity. Insufficient charge and low electrolyte levels are also significant causes of battery failure. 
Table 10.3 Battery failure events reported in LERs

\begin{tabular}{lcr}
\hline Failure cause & No. & $\%$ \\
\hline Low specific gravity & 67 & 27 \\
Personnel (operation, maintenance, testing) & 52 & 21 \\
Insufficient charge & 27 & 11 \\
Defective/weak cells & 22 & 9 \\
Low electrolyte solution level & 14 & 6 \\
Faulty connections & 13 & 5 \\
Defective procedures & 11 & 4 \\
Charger malfunction & 9 & 4 \\
Design, fabrication, construction & 8 & 3 \\
High electrolyte solution level & 8 & 2 \\
Unknown causes & 5 & 2 \\
Corrosion & 4 & 2 \\
Short circuit & 4 & 1 \\
Normal wear/natural end of life & 3 & $<1$ \\
Extreme environment & 1 & 100 \\
$\quad$ Total & 248 & \\
& &
\end{tabular}

Source: NUREG/CR-4457.

Note also that testing (grouped together with operation and maintenance) is the second largest contributor to battery failures. However, these 7-day surveillances should not be significant contributors to testing failures.

In addition, one utility representative told the NRC staff during a site visit that in addition to the Technical Specifications requirement, it was company policy to do these checks every 7 days.

The NRC staff therefore recommends that the battery surveillance requirements remain as they are.

As noted earlier, many factors specified in IEEE 450-1980 are important for degradation of batteries that are not covered by Technical Specifications. This is probably appropriate, if the purpose of the Technical Specifications is limited to operability concerns. However, the staff recommends that these factors be included in any preventive maintenance program.

\section{Findings}

- Operability surveillances of batteries required by Technical Specifications are performed more often than the industry standard recommends.

- There is no Technical Specifications requirement for monitoring or controlling battery room temperature.

- Seismic qualification is an important consideration for Class $1 \mathrm{E}$ batteries and battery racks. All Class $1 \mathrm{E}$ batteries and battery racks should be qualified to IEEE Standard 535-1986. This is not a Technical Specifications issue.

- Alternating current (ac) ripple from battery chargers may be a degradation concern.

\section{Recommendation}

- The NRC should consider the above findings and determine whether any additional action is warranted. 


\section{REFUELING}

The staff identified no problems with surveillance testing regarding refueling in Technical Specifications. 


\section{SPECIAL TEST EXCEPTIONS}

\section{Suspending Shutdown Margin Requirements (PWR)}

\author{
Section 10 of the Standard Technical Specifications deals \\ with special test exceptions to other Technical Specifica- \\ tions requirements needed to perform tests to verify that \\ the reactor will be operated within its approved limits, for \\ example, low-power physics testing.
}

One of these test exceptions permits the shutdown margin requirements in Mode 2 (startup) to be suspended for certain low-power physics tests. The surveillance requirements state that each control rod not fully inserted shall be demonstrated capable of full insertion when tripped from at least the $50 \%$ withdrawn position within 24 hours prior to reducing the shutdown margin to less than the limits required in Mode 2.

In a letter to NRC (August 17, 1987), Florida Power and Light Co. proposed changing this time from 24 hours to 7 days (Woody, 1987). The staff approved the request in a letter dated October 28, 1987 (Tourigny, 1987).

Another Technical Specifications requirement also requires tripping the control rods but for a different purpose. In this case, the control rods are tripped in order to verify that control rod drop times are less than the value(s) assumed in the safety analyses. These tests are usually performed more than 24 hours before the control rod worth measurements are needed. Thus, in practice, the control rods are tripped at least twice following a refueling outage: once for the drop time measurements and once prior to the time that the shutdown margin limit is suspended.

This change would permit only one such test of the control rods. The change is permissible for several reasons.
First, Florida Power and Light Co. showed, using data from the St. Lucie plants (Units 1 and 2), that the probability of a stuck control rod was not significantly increased by this change. Second, there would be no changes to core geometry between the time that the control rods are tripped for the drop time measurements and the time that the shutdown margin limit would be suspended (up to 7 days) because the vessel head and all vessel internals would be in their final position and secured.

Although plant-specific data were used in part to justify this change, the operation of the St. Lucie units with respect to this testing would be representative of the operation of other pressurized water reactors (PWRs). Therefore, if it is assured that rod drop timing tests will be performed within 7 days, with no changes made that would affect the capability of the control rods to trip within this time, the verification of rod insertion prior to suspending shutdown margin should not be required for other PWRs.

\section{Findings}

- During low-power physics testing in PWRs, two rod drop tests are required.

- Only one test is required as long as there is adequate assurance that there will be no changes to the core or control rods after the first test.

\section{Recommendation}

All PWR licensees may select the Florida Power and Light Co. proposal to eliminate one rod drop test if they satisfy the condition of performing a rod drop test no more than 7 days before reducing shutdown margin. If a rod drop test has been performed within this time, another test is not necessary. 


\section{RADIOACTIVE EFFLUENTS}

\section{Waste Gas Storage Tanks (PWR)}

Waste gas storage tanks collect the radioactive noble gases and airborne halogens to reduce the anticipated annual releases and personnel exposure in restricted and unrestricted areas in order to meet "as low as reasonably achievable" (ALARA) guidelines.

The Technical Specifications contain a limit on the curies of noble gases that are allowed to be stored in the gas storage tanks and require that the quantity of material in the tanks be determined to be less than this limit at least once every 24 hours when radioactive materials are being added to the tank. Measuring the contents of this tank exposes the chemists to high radioactivity.

The "Bases" section of the Standard Technical Specifications states that the Technical Specifications limit placed on the number of curies (Ci) permitted in the waste gas tank ensures that the resulting total body exposure to an individual at the nearest exclusion area boundary will not exceed $0.5 \mathrm{rem}$, which is consistent with the Standard Review Plan (NUREG-0800) guidance for calculating the consequences of the failure of a waste gas tank.

It was pointed out by both staff and licensee personnel that the Technical Specifications limit placed on the allowed curies in the waste gas tank is considerably above the value that would occur, even if the reactor were operating at the Technical Specifications specific coolant activity limit, $1 \mu \mathrm{Ci} / \mathrm{cc}$. The San Onofre licensee did a calculation to demonstrate this (Katz, 1988).

San Onofre Nuclear Generating Station, Unit 3 experienced fuel failures during its first cycle. Data were tabulated for the period when highest primary coolant activities were experienced. When the Unit 3 primary coolant dose- equivalent I- 131 averaged $0.48 \mu \mathrm{Ci} / \mathrm{gram}$, the maximum activity measured in the inservice waste gas storage tank was $36 \mu \mathrm{Ci} / c c$. Using this relationship, a primary dose equivalent I-131 of $1.0 \mu \mathrm{Ci} / \mathrm{gram}$ would result in a maximum waste gas storage tank activity of $75 \mu \mathrm{Ci} / \mathrm{cc}$. Assuming Units 2 and 3 were operating with primary coolant I-131 dose equivalents of $1.0 \mu \mathrm{Ci} / g r a m$ (the Technical Specifications limit), a maximum storage tank activity of $150 \mu \mathrm{Ci} / \mathrm{cc}$ can be calculated. A storage tank with $150 \mu \mathrm{Ci} / \mathrm{cc}$ of noble gas at 300 psig would contain $60,000 \mathrm{Ci}$. This is far below the Technical Specifications limit of 134,000 Ci for San Onofre.

Thus, iodine concentration in the coolant will rarely reach the Technical Specifications limit, if at all, at operating reactors. However, Xe-133 activity can accumulate and approach Technical Specifications limits during degas operations prior to shutdown for refueling. Therefore, the surveillance requirement should be changed to state that the quantity of radioactive material contained in each waste gas decay tank shall be determined to be within the limit at least once every 7 days whenever radioactive materials are added to the tank, and at least once every 24 hours during primary coolant system degassing operations.

\section{Findings}

- The total number of curies of radioactive gas in the waste gas tank will only approach the Technical Specifications limit during degas operations.

- Personnel receive high doses of radioactivity in measuring the number of curies in the waste gas tank.

\section{Recommendation}

The surveillance requirement for the limit on the number of curies in the waste gas tank should be changed to: "The quality of radioactive material contained in each waste gas decay tank shall be determined to be within the limit at least once every 7 days whenever radioactive materials are added to the tank, and at least once every 24 hours during primary coolant system degassing operations." 


\section{CONCLUSIONS}

This study examined individual surveillance requirements in Technical Specifications and assessed their effectiveness in ensuring reactor safety. In addition, as the study progressed, several more general conclusions were reached. These have been discussed individually in Section 3, "General Findings," but they will be reiterated here.

First, there are a lot of surveillance requirements. Thousands of tests are done in a cycle. It is necessary to test equipment to ensure that it is operable or to discover that it isn't functioning so that it can be restored to operable status. However, performing more tests than are necessary, or performing ineffective tests, obviously does not accomplish anything and can be harmful to people (radiation dose) or equipment (wear).

The utilities should be given as much latitude as possible in scheduling surveillance tests. Few tests have timing requirements so critical that an extension would not be acceptable.

Scheduling the thousands of required surveillance tests while maximizing availability of equipment, minimizing the operations that may cause scrams, and ensuring that at least one train of emergency equipment always remains operable is at times difficult. More thought should be given to which tests have surveillance schedules that are critical and which tests do not.

Utilities should be given an opportunity to point out unnecessary types of tests at their facilities and to eliminate them.

Incorporating the concept of reliability into the Technical Specifications would be useful in eliminating excessive testing and in identifying which components or systems need the most surveillance.

Preventive maintenance is very important in reducing the number of failures. Operability testing does not reduce the number of failures, it only discovers failures that have occurred. Operability testing reduces the time period associated with inoperability, and increases availability. Preventive maintenance, however, should also be reliability based to assure that resources are allocated where they are needed most.

Part of the reason that surveillance tests are difficult to perform is the layout of the plant and the design of equipment in the plant. Although this is hard to fix in an operating reactor, adequate planning should be required for the advanced light water reactors (or other reactors) currently being considered to facilitate surveillance testing.
It should also be kept in mind that surveillance testing required by Technical Specifications is not a major cause of reactor trips (such required testing contributes to approximately $20 \%$ of the total for a mix of new and mature plants); nor is the testing a major contributor to radiation dose (approximately $20 \%$ of the total radiation dose can be attributed to such testing).

The amount of equipment wear or number of failures is more difficult to assess, but several studies of key safetyrelated equipment have not identified testing as a major cause of failure, although, as with the other categories (trips and radiation dose), it is significant.

\section{General Recommendations}

Before presenting the detailed "line item" recommendations of this report (see Table 14.1), the more general recommendations are given.

(1) A study should be done of the feasibility of using reliability-based Technical Specifications on one or several systems. A lead plant should be selected and the licensee of that plant should select, with the agreement of the staff, the systems that would be candidates for reliability-based Technical Specifications.

(2) The current industry effort on advanced reactor designs should include a study of how all required surveillance testing will be performed in order to (a) minimize the possibility of a transient caused by testing, (b) minimize the burden on plant personnel who will have to perform these tests, and (c) minimize the radiation exposure received by people in performing the required testing.

(3) The NRC should study the issue of containment entries at power to assess the risk to containment integrity from these entries and the effect on the people who enter containment with the reactor at power.

(4) Section 4.0.2 of the Technical Specifications, which allows the extension of a surveillance test interval, should be made applicable to Section 4.0 .5 concerning ASME Code testing in those Technical Specifications which presently do not allow Section 4.0.2 to be applied.

The implementation of the recommendations of this study should reduce reactor transients, radiation dose to personnel from testing, and wear on equipment. This study, however, should be considered as only the beginning to a more enlightened approach by both NRC and the nuclear industry to assuring that equipment important to reactor safety is effectively and safely tested. 
Table 14.1 Summary of recommended changes to surveillance requirements

\begin{tabular}{ll}
\hline Section & \\
of this & TS surveillance requirement \\
report & [applicable criteria*]
\end{tabular}

\section{REACTIVITY CONTROL SYSTEMS}

4.1

MTC testing at $300 \mathrm{ppm}$ (PWR). [B]

\subsubsection{Control rod movement testing every 31 days (PWR). [B,T] 4.2.2 Control rod movement tests every 7 days (BWR).
$[\mathrm{B}, \mathrm{T}]$}

4.2.2 If a BWR control rod is immovable because of friction or mechanical interference, the other control rods should be tested every 24 hours.

4.3 Standby liquid control system explosive valve testing performed every 18 months (BWR). [B]

4.3 Standby liquid control system pump test monthly (BWR). [B]

4.4 Closure time testing of SDV vent and drain valves. Verification that valves will close in $\mathbf{3 0}$ seconds (BWR). [B]

4.5 Reactor trip test to verify operability of SDV vent and drain valves. Required once every 18 months (BWR). [B,T]

\section{Recommended change}

VEPCO proposal may be used to assess whether testing is required at $60 \mathrm{ppm}$ if criterion is not met at $300 \mathrm{ppm}$. Plantspecific analysis is required.

Change STI to quarterly.

BWR Owners Group should study the feasibility of extending the surveillance interval. If it is feasible from an engineering viewpoint, the NRC staff should examine the study findings and allow the extension if found acceptable.

Change the frequency to "within 24 hours and every 7 days thereafter."

Change STI to once each refueling interval for fuel cycles up to 24 months' duration.

Change STI to quarterly.

Closure time may be extended if justified by plant-specific analysis. (Approved for Hatch Nuclear Plant, Units 1 and 2.)

Delete requirement for a scram check of SDV vent and drain valve operability at a $50 \%$ rod density or less.

Require an evaluation of SDV system response after each scram to verify that no abnormalities exist prior to plant restart.

Require vent and drain valve operability testing during a scram from shutdown conditions.

Change STI from monthly to quarterly.
5.1 Nuclear instrumentation surveillance (PWR). [B,T] Channel functional tests required monthly.

See footnote at end of table. 
Table 14.1 (Continued)

Section

of this

report

TS surveillance requirement

[applicable criteria*]

\section{INSTRUMENTATION (Continued)}

5.2

Slave relay testing (PWR, BWR). [B,T]

5.3

Test intervals for RPS and ESFAS (PWR, BWR). $[\mathrm{B}, \mathrm{T}]$

5.4 Combustible gas control surveillance for systems with sensor inside containment (PWR, BWR). [B]

5.5 Reactor trip breaker testing (PWR). [T]

5.6 Power range instrument calibration done to an uncertainty of $2 \%$ between nuclear instrumentation and heat balance for steady-state and transient conditions (PWR). [B]

5.7 CEA calculator surveillance (CE CPC PWR). $[\mathrm{B}, \mathrm{T}]$

5.8 Incore detector surveillance done weekly and 24 hours prior to use on CE plants and 7 days prior to use for $B \& W$ plants (CE and B\&W PWRs). [B]

5.9 Response time testing of isolation actuation instrumentation (PWR, BWR). [B,T]

5.10 Present calibration interval for SRMs and IRMs is quarterly for rod withdrawal block instrumentation but refueling in RPS instrumentation table (BWR). [B]

5.11 Calibration of recirculation flow transmitters (BWR). [B]
Change quarterly requirements to a staggered test basis over a cycle with tests most likely to cause trip done at refueling outage.

Test 3-channel systems on 4-channel schedule by not testing one of the 3 channels during a 4-channel surveillance interval.

Change analog channel functional testing to quarterly and calibration to once each refueling interval. Presently done monthly and quarterly, respectively.

The vendor owner groups should consider whether more recent operating experience would justify a change in the test interval for reactor trip and bypass breakers. Licensees should pursue implementing an increase in the allowable outage time for testing reactor trip and bypass breakers as addressed in the vendor topical reports for extending surveillance intervals.

The owners groups should consider allowing $5 \%$ uncertainty and if appropriate make a recommendation to NRC.

Change channel functional test from monthly to quarterly.

Change CE surveillance requirement to $B \& W$ surveillance requirement.

Delete for all signals that currently include EDG start time.

Change STI to once each refueling interval for calibration of rod withdrawal block function for IRMs and SRMs.

No TS change recommended. 
Table 14.1 (Continued)

\begin{tabular}{ll}
$\begin{array}{l}\text { Section } \\
\text { of this } \\
\text { report }\end{array}$ & $\begin{array}{l}\text { TS surveillance requirement } \\
\text { [applicable criteria*] }\end{array}$ \\
\hline & INSTRUMENTATION (Continued) \\
5.12 & Autoclosure interlock (ACI) removal (PWR, BWR).
\end{tabular}

5.13 Turbine overspeed protection (PWR, BWR). [B,T]

5.14 Radiation monitoring instrumentation (PWR, BWR). [B,T.W]

5.15 Radioactive gas effluent monitor calibration standard (PWR, BWR). [B]

5.16 IRM and APRM channel functional tests required

\section{REACTOR COOLANT SYSTEM}

6.1 Leak test RCS isolation valves if in cold shutdown for more than 72 hours if not leak tested in last 9 months (PWR). [B]

6.2 Test PORVs and block valves (PWR).

6.3 High point vent valve tests required every 92 days (PWR). [B,T]

6.4 There is no requirement for positive indication that the low-temperature overpressure protection system is armed (PWR)

6.5

$100 / \bar{E}$ as a measure of specific coolant activity (PWR, BWR). [B]
Recommended change

The NRC staff approved a generic proposal by the Westinghouse Owners Group (WCAP-11736-A) to delete the ACI. Other owners groups should determine if the risk of core melt is higher or lower if the ACI is deleted. GI-99 resolution supports deletion of ACI.

Change all turbine valve testing to quarterly if turbine vendor agrees.

(1) Change analog channel operational test to quarterly from every 31 days. (2) The vendor owners groups should study whether further reductions in radiation monitor surveillance testing are possible.

No TS change recommended.

BWR Owners Group should determine if it is feasible to increase surveillance test interval from 7 days for IRMs and APRMs.

Change 72 hours to 7 days.

No TS change recommended. To be addressed by resolution of GI-70 and GI-94.

Review applicability of Catawba TS and revise test frequency to cold shutdown or refueling, if appropriate.

Licensee to consider the benefit of providing continuous positive indication that the low-temperature overpressure protection system is armed and operable.

Implement resolution of GI-70 and GI-94.

A more meaningful measure of noble gas accumulation should be derived by industry. 
Table 14.1 (Continued)

Section

of this

report

TS surveillance requirement

[applicable criteria*]

\section{REACTOR COOLANT SYSTEM (Continued)}

6.6

Test capacity of pressurizer heaters every 92 days (PWR). [B]

6.6 Demonstrate emergency power supply to pressurizer heaters is operable (done every 18 months) (PWR). [B]

\section{EMERGENCY CORE COOLING SYSTEM}

7.1 Verify boron concentration in accumulator after makeup and every 31 days (PWR). [B]

At least every 31 days, check for air in ECCS (PWR). [B]

Verify proper valve lineup every 31 days for ECCS and containment isolation valves (PWR, BWR). [B,R]

$7.4 \quad$ (1) Do analog channel operational test on accumulator level and pressure instrumentation (PWR). [B]

(2) Action statement on an inoperable accumulator requires shutdown of the reactor if not fixed in 1 hour (PWR). [B]

7.5 Check areas entered in containment for loose debris after each entry (PWR). [R]

Verify boron concentration of BIT (W PWR). [R]

\section{CONTAINMENT (PWR)}

\section{Dry, Ice Condenser, Subatmospheric}

8.1 Test containment spray nozzles for obstructions every 5 years (PWR). [B]

8.2 Test 42-inch containment purge supply and exhaust isolation valves for leaks (PWR). [R]
Change frequency to once each refueling interval for those plants without dedicated safety-related heater.

Retain for those plants in which heaters are not permanently connected to a vital bus. Otherwise delete.

Change to delete boron concentration check if makeup from normal source (RWST) that had latest test in specifications and the minimum RWST boron concentration is greater than the minimum accumulator boron concentration.

No TS change recommended.

No TS change recommended.

Licensee to examine channel checks surveillance and operational history to establish the basis for satisfying frequency of testing extension.

Add condition to action statement to require shutdown of the reactor if the accumulator water level and pressure channels are not made operable within 72 hours.

Change to at least once daily when entries are made and on last entry when successive entries are made.

Check BIT boron concentration by measuring concentration in boric acid storage tank.

Extend to 10 years.

No TS change recommended. 
Table 14.1 (Continued)

Section

of this

report

TS surveillance requirement

[applicable criteria*]
Recommended change

\section{CONTAINMENT (PWR) (Continued)}

Dry, Ice Condenser, Subatmospheric (Continued)

8.3 Verify operability of ice condenser doors every 3 months (PWR). [B,T]

$8.4 \quad$ (1) Vacuum breakers from suppression pool to drywell tested monthly. ASME Code requirement is quarterly (BWR). [B]

(2) Vacuum breaker testing (suppression chamber to drywell) following any steam discharge (BWR). [B]

8.5 Hydrogen recombiner tested at least once every 6 months (PWR, BWR). [B]

8.6 Chemical analysis of concentration of sodium tetraborate and $\mathrm{pH}$ of ice every 9 months (PWR, BWR). [B,R]

\section{PLANT SYSTEMS}

9.1 AFW pump surveillance test (PWR). $[\mathrm{B}, \mathrm{W}]$

9.2.1 MSIV partial stroke testing quarterly per 4.0.5 (PWR). [T]

9.2.2 MSIV partial stroke testing quarterly per 4.0.5 (BWR). [T]

9.3 Verify every 12 hours that control room temperature is less than specified value (typically greater than $\left.100^{\circ} \mathrm{F}\right)(\mathrm{PWR}, \mathrm{BWR})$. [B]

\section{ELECTRIC POWER}

10.1 Emergency Diesel Generator Surveillance Requirements (PWR, BWR).

When one train or subsystem (other than an EDG) is inoperable, test the other train and other unrelated systems including the diesel generators. [B,W]

If an offsite power source becomes inoperable, test diesels that have not been tested within previous 24 hours. [B,W]
Change frequently to once each refueling interval for all doors rather than $25 \%$ each quarter.

No TS change recommended; retain monthly requirements.

Change to 12 hours for plants with less time than that.

Change STI to once each refueling interval.

Change the analysis interval to once each refueling interval.

Change frequency of testing AFW pumps to quarterly on a staggered test basis.

More study required.

No TS change recommended.

Delete or revise requirement.

Delete alternative testing requirements.

Delete this requirement. 
Table 14.1 (Continued)

Section

of this

report

TS surveillance requirement

[applicable criteria*]

\section{ELECTRIC POWER (Continued)}

10.1 Emergency Diesel Generator Surveillance

Requirements (Continued)

Action statement calls for starting an EDG. [B,W]

Verify that the EDG is loaded to greater than or equal to [continuous rating] $\mathrm{kW}$ in less than or equal to [60] seconds for monthly or accelerated testing based upon prior failures.[B,W]

After performing 24-hour EDG test, start EDG on loss of offsite power/SI signal within 5 minutes. [B]

10.2

Battery (PWR, BWR)

Battery room temperature-no present requirement.

AC ripple degrades batteries. There is no LCO in the Technical Specifications. [W]

\section{REFUELING}

None identified.

\section{SPECIAL TEST EXCEPTIONS (PWR)}

12

Each full-length control rod not fully inserted shall be demonstrated trippable from at least $50 \%$ withdrawn within 24 hours prior to reducing shutdown margin.

[B]
Recommended change
Start only once within 8 hours unless the absence of any common mode failure has been demonstrated as the cause of the EDG inoperability.

Change the loading requirement to be in accordance with the manufacturer's recommendation.

Replace the EDG start on loss of offsite power/safety injection signal with the monthly EDG start surveillance requirement. Add or modify the existing footnote so that the 24-hour test need not be repeated if the hotrestart test is not completed within 5 minutes provided it is performed within 5 minutes of operating the EDG at its continuous load rating for 2 hours or until operating temperatures have stabilized.

More study required.

More study required.

Change 24 hours to 7 days. If a rod drop test has been performed within this time, another test is not necessary.

See footnote at end of table. 
14 Conclusions

Table 14.1 (Continued)

\begin{tabular}{lll}
\hline $\begin{array}{l}\text { Section } \\
\text { of this } \\
\text { report }\end{array}$ & $\begin{array}{l}\text { TS surveillance requirement } \\
\text { [applicable criteria*] }\end{array}$ & Recommended change \\
\hline RADIOACTIVE EFFLUENTS (PWR) & \\
\hline 13 & $\begin{array}{l}\text { Number of curies in waste gas tank must be monitored } \\
\text { every } 24 \text { hours when additions are being made. [B,R] }\end{array}$ & $\begin{array}{l}\text { The quantity of radioactive material } \\
\text { contained in each waste gas decay tank shall } \\
\text { be determined to be within the limit at least } \\
\text { once every } 7 \text { days whenever radioactive } \\
\text { materials are added to the tank, and at least } \\
\text { once every 24 hours during primary coolant } \\
\text { system degassing operations. }\end{array}$ \\
\hline
\end{tabular}

*The four applicable criteria used in this study are: $B=$ licensee burden in terms of time; $T=$ plant transient; $W=$ unnecessary wear; and $R=$ radiation exposure to personnel. 


\section{BIBLIOGRAPHY}

AEOD/C503 U.S. Nuclear Regulatory Commission, Office for the Analysis and Evaluation of Operational Data, H. O. Ornstein, "Decay Heat Removal Problems at U.S. Pressurized Water Reactors," AEOD/C503, December 1985.

BAW-10167 Babcock \& Wilcox Co., "Justification for Increasing the Reactor Trip System On-Line Text Intervals," Volume 1, BAW-10167, May 1986.

Capstick, $1988 \quad$ Letter from R. W. Capstick, Vermont Yankee Nuclear Power Corp., to NRC, "Vermont Yankee Response to USNRC Request for Additional Information-Surveillance Testing of ECCS and SLC Equipment," July 15, 1988.

CEN-327 Combustion Engineering Owners Group, "RPS/ESFAS Extended Test Interval Evaluation," CEN327, May 1986.

Chilk, 1988 Memorandum from S. J. Chilk, Office of the Secretary, to V. Stello, EDO, "Staff Requirements-Briefing on Technical Specification Revisions" (June 20, 1988 meeting), July $6,1988$.

Circular 77-11 U.S. Nuclear Regulatory Commission, "Containment Leakage Due to Seal Deterioration," Circular 77-11, September 6, 1977.

Crocker, 1987 Letter from L. P. Crocker, NRC, to J. P. O'Reilly, Georgia Power Co., "Issuance of Amendment Nos. 136 and 75 to Facility Operating Licenses DPR-57 and NPF-5-Edwin I. Hatch Nuclear Plant, Units 1 and 2," May 13, 1987.

Engle, 1984 Letter from L. B. Engle, NRC, to W. L. Stewart, VEPCO, "Turbine Overspeed Protection System Surveillance Intervals," April 16, 1984.

Engle, $1986 \quad$ Letter from L. B. Engle, NRC, to W. L. Stewart, VEPCO, "End of Cycle Moderator Temperature Co- efficient Limit Measurements," September 8, 1986.
GL 84-5

GL 84-15

GSER, 1980

Hood, 1986

Hood, 1988

IN $88-23$

IN $89-42$

Jabbour, 1987
U.S. Nuclear Regulatory Commission, "Change to NUREG-1021 Licensing Examiner Standards," Generic Letter 84-5, April 2, 1974.

U.S. Nuclear Regulatory Commission, "Proposed Staff Actions to Improve and Maintain Diesel Generator Reliability," Generic Letter 84-15, July $2,1984$.

U.S. Nuclear Regulatory Commission, "BWR Scram Discharge Volume System," Generic Safety Evaluation Report, December 1, 1980.

Letter from D. Hood, NRC, to H. B. Tucker, Duke Power Co., "Issuance of Amendment No. 64 to Facility Operating License NPF-9 and Amendment No. 45 to Facility Operating License NPF-17McGuire Nuclear Station, Units 1 and 2," September 30, 1986.

Letter from D. Hood, NRC, to H. B. Tucker, Duke Power Co., "Issuance Notice of Amendment No. 83 to Facility Operating $\mathrm{Li}$ cense NPF-9 and Amendment No. 64 to Facility Operating License NPF-17-McGuire Nuclear Station, Units 1 and 2 (TAC Nos. 59239/59240)," May 11, 1988.

U.S. Nuclear Regulatory Commission, "Potential for Gas Binding of High-Pressure Safety Injection Pumps During a Loss-of-CoolantAccident," Information Notice 88-23, May 12, 1988.

U.S. Nuclear Regulatory Commission, "Failure of Rosemount Models 1153 and 1154 Transmitters," Information Notice 89-42, April 21, 1989.

Letter from K. N. Jabbour, NRC, to H. B. Tucker, Duke Power Co., "Deletion of Technical Specification Surveillance Requirement 
Jabbour, $1988 \quad$ Letter from K. N. Jabbour, NRC, to H. B. Tucker, Duke Power Co., "Issuance of Amendment No. 51 to Facility Operating License NPF-35 and Amendment No. 44 to Facility Operating Licensee NPF-52Catawba Nuclear Station, Units 1 and 2 (TACS 67765/67766)," July 28, 1988.

Kane, 1987 Memorandum from W. F. Kane, NRC Region I, to S. A. Varga, NRC, "Licensing Action Review for Susquehanna Steam Electric Station Units 1 and 2, Technical Specification Change Regarding Scram Discharge Volume System Surveillance Requirements," August 31, 1987.

Katz, $1988 \quad$ Letter from B. Katz, Southern California Edison, to E. Butcher, NRC, "Waste Gas Storage Tank Activity Limit," August 26, 1988.

LER 87-058 Shearon Harris, Docket No. 50-400, LER 87-058, Rev. 1.

LER 88-005 Millstone 3, Docket No. 50-423, LER 88-005.

LER 88-006 Millstone 3, Docket No. 50-423, LER 88-006.

MDE 1031184 General Electric Co., "Edwin I. Hatch Units 1 and 2 Relaxation of Scram Discharge Volume Vent and Drain Valve Closure Times," MDE 103 1184, Rev. 1, December 1984.

Murley, 1988

Murphy, 1987
Letter from T. E. Murley, NRC, to W. S. Wilgus, Chairman, B\&W Owners Group, May 9, 1988.

Letter from W. P. Murphy, Vermont Yankee Nuclear Power Corp., to T. E. Murley, NRC, "Surveillance Testing of ECCS and SLC Equipment," Supplement 1 to Proposed Change No. 85, December 7 , 1987.
NEDC-30851

NEDC-30851P

(Suppl. 1)

NEDC-30851

(Suppl. 2)

NEDC-30936

NEDC-31677P-A

NP-4264, Vol. 1

NP-4264, Vol. 2

NP-5924

NPE-1
General Electric Co., "Technical Specification Improvement Analysis for BWR Reactor Protection System," NEDC-30851, May 1985.

General Electric Co., "Technical Specification Improvement Analysis for BWR Control Rod Block Instrumentation," NEDC-30851P (Supplement 1), June 1986.

General Electric Co., "Technical Specification Improvement Analysis for BWR Isolation Instrumentation Common to RPS and ECCS Instrumentation," NEDC-30851 (Supplement 2), July 1986.

General Electric Co., "BWR Owners' Group Technical Specification Improvement Methodology With Demonstration for BWR ECCS Actuation Instrumentation," NEDC-30936, June 1987.

General Electric Co., "Technical Specification Improvement Analysis for BWR Isolation Actuation Instrumentation," NEDC-31667P-A, July 1990.

Electric Power Research Institute, Failures Related to Surveillance Testing of Standby Equipment, Volume 1: "Emergency Pumps," LPRI NP-4264, Mollers Engineering Corporation, October 1985.

Electric Power Research Institute, Failures Related to Surveillance Testing of Standby Equipment, Volume 2: "Diesel Generators," LPRI NP-4264, September 1985.

Electric Power Research Institute, "Surveillance Monitoring and Diagnostic Techniques to Improve Diesel Generator Reliability," Final Report NP-5924, July 1988.

Nuclear Power Experience; Volume PWR-2; Book-3, "Experiences"; VII-Safety Systems, Section B-"Containment Pressure Suppression," pp. 1-51 (January 1973-July 1988); S. M. Stoller Corp., Boulder, Colorado. 
NPE-2

NPE-3

NPE-4

NPE-5

NRC, 1987

NSAC-96

NSAC-130

NUREG-0713

NUREG-0800
Nuclear Power Experience; Volume PWR-2; Book-2, "Experiences"; VI-Turbine Cycle Systems, Section A-"Turbine," pp. 1-38 (January 1973-July 1988); S. M. Stoller Corp., Boulder, Colorado.

Nuclear Power Experience; Volume PWR-2; Book-1, "Experiences"; IV-Control Rods and Drives, Section A-"Control Rods," pp. 1-14 (January 1973-July 1988); S. M. Stoller Corp., Boulder, Colorado.

Nuclear Power Experience; Volume PWR-2; Book-2, "Experiences"; VI-Turbine Cycle Systems, Section D-“Steam," pp. 1-153 (January 1973-July 1988); S. M. Stoller Corp., Boulder, Colorado.

Nuclear Power Experience; Volume PWR-2; Book-1, "Experiences"; V-Reactor Coolant System, Section C- "Relief and Safety Valves," pp. 42-43 (January 1973-July 1988); S. M. Stoller Corp., Boulder, Colorado.

U.S. Nuclear Regulatory Commission, "Interim Policy Statement on TS Improvements," 52 FR 3788, February 6, 1987.

Nuclear Safety Analysis Center, "Effect of Diesel Start Time on BWR/6 Peak Cladding Temperature: Licensing Basis Sensitivity Calculations," NSAC-96, General Electric Co., January 1986.

Nuclear Safety Analysis Center, "The Effect of Diesel Start Time Delay on Westinghouse PWRs," EPRI-NSAC-130, Electric Power Research Institute, Palo Alto, CA, 1988.

U.S. Nuclear Regulatory Commission, "Occupational Radiation Exposure at Commercial Nuclear Power Reactors and Other Facilities, 1985," Eighteenth Annual Report, NUREG-0713, Volume 7, April 1988.

U.S. Nuclear Regulatory Commission, "Standard Review Plan for the
Review of Safety Analysis Reports for Nuclear Power Plants," LWR Edition, NUREG-0800, July 1981.

NUREG-0839 U.S. Nuclear Regulatory Commission, "A Survey by Senior NRC Management To Obtain Viewpoints on the Safety Impact of Regulatory Activities From Representative Utilities Operating and Constructing Nuclear Power Plants," August 1981.

NUREG-1024 U.S. Nuclear Regulatory Commission, "Technical SpecificationsEnhancing the Safety Impact," NUREG-1024, November 1983.

NUREG-1144 U.S. Nuclear Regulatory Commission, "Nuclear Plant Aging Research (NPAR) Program," NUREG-1144 (Revision 1), September 1987.

NUREG/CR-1341 U.S. Nuclear Regulatory Commission, "Regulatory Analysis for the Resolution of Generic Issue 115: Enhancement of the Reliability of the Westinghouse Solid State Protection System," April 1989.

NUREG/CR-3883 U.S. Nuclear Regulatory Commission, "Analysis of Japanese-U.S. Nuclear Power Plant Maintenance," NUREG/CR-3883, Battelle Pacific Northwest Laboratory, June 1985.

NUREG/CR-4335 U.S. Nuclear Regulatory Commission, "Potential Benefits Obtained by Requiring Safety-Grade Cold Shutdown Systems," NUREG/ CR-4335, Sandia National Laboratories, July 1985 .

NUREG/CR-4457 U.S. Nuclear Regulatory Commission, "Aging of Class 1E Batteries in Safety Systems of Nuclear Power Plants," NUREG/CR-4457, EG\&G Idaho, Inc., July 1987.

NUREG/CR-4590 U.S. Nuclear Regulatory Commission, "Aging of Nuclear Station Diesel Generators: Evaluation of Operating and Expert Experience, Phase 1 Study," Vol. 1, NUREG/ CR-4590, Pacific Northwest Laboratory, August 1987. 
NUREG/CR-4597 U.S. Nuclear Regulatory Commission, "Aging and Service Wear of Auxiliary Feedwater Pumps for PWR Nuclear Power Plants," Vol. 1, "Operating Experience and Failure Identification," NUREG/ CR-4597, Oak Ridge National Laboratory, July 1986.

NUREG/CR-4692 U.S. Nuclear Regulatory Commission, "Operating Experience Review of Failures of Power Operated Relief Valves and Block Valves in Nuclear Power Plants," NUREG/ CR-4692, Oak Ridge National Laboratory, October 1987.

NUREG/CR-4715 U.S. Nuclear Regulatory Commission, "An Aging Assessment of Relays and Circuit Breakers and Systems Interactions," NUREG/ CR-4715, Franklin Research Center, June 1987.

NUREG/CR-4999 U.S. Nuclear Regulatory Commission, "Estimation of Risk Reduction From Improved PORV Reliability in PWRs," March 1988.

NUREG/CR-5078 U.S. Nuclear Regulatory Commission, "A Reliability Program for Emergency Diesel Generators at Nuclear Power Plants Program Structure," Vol. 1, NUREG/ CR-5078, Science Applications International, Inc., April 1988.

NUREG/CR-5158 U.S. Nuclear Regulatory Commission, "Worldwide Activities on the Reduction of Occupational Exposure at Nuclear Power Plants," Brookhaven National Laboratory, June 1988.

NUREG/CR-5186 U.S. Nuclear Regulatory Commission, "Low Temperature Overpressure Systems Evaluation for Pressurized Water Reactors," July 1988.

NUREG/CR-5197 U.S. Nuclear Regulatory Commission, "Evaluation of Generic Issue 115: Enhancement of the Reliability of Westinghouse Solid State Protection System," January 1989.
NUREG/CR-5200 U.S. Nuclear Regulatory Commission, "Evaluation of Risks Associated With AOT and STI Requirements at the ANO-1 Nuclear Power Plant," NUREG/CR-5200, Brookhaven National Laboratory, August 1988.

SAIC-90/1394

Science Applications International Corporation, "The Effects of Proposed Changes in the New Standard Technical Specifications on Nuclear Power Plant Risk," SAIC-90/1394, June 28, 1991.

SECY-83-472 U.S. Nuclear Regulatory Commission, "Emergency Core Cooling System Analysis Methods," SECY83-472, November 17, 1983.

SECY-86-310 U.S. Nuclear Regulatory Commission, "Proposed Technical Specifications Policy Statement," SECY86-310, October 21, 1986.

SECY-87-314 U.S. Nuclear Regulatory Commission, "Staff Requirements Interim Policy Statement on Maintenance of Nuclear Power Plants and Requirements From Status Briefing on January 7, 1988," SECY87-314, February 25, 1988.

Shiffer, 1987a

Letter from J. Shiffer, PG\&E, to NRC, "Removal of RHR System Autoclosure Interlock Function," August 4, 1987.

Shiffer, 1987b Letter from J.D. Shiffer, PG\&E, to Document Control Desk, NRC, "Emergency Technical Specification Change to Technical Specification 4.3.4.1.2a and $b$. 'Turbine Overspeed Protection'," November $8,1987$.

Split report

See Murley, 1988.

Stewart, 1986 Letter from W. L. Stewart, VEPCO, to H. R. Denton, NRC, "Virginia Electric and Power Company North Anna Power Station Units No. 1 and 2 Proposed Technical Specifications Changes," January $3,1986$. 
Tourigny, 1987

Trammell, 1987

Tucker, 1985

Tucker, 1986

Tucker, 1988

WCAP-10271
Letter from E. G. Tourigny, NRC, to C. O. Woody, Florida Power and Light Co., "Issuance of Amendments (TAC Nos. 66014 and 66015)," October 28, 1987.

Letter from C. M. Trammell, NRC, to J. D. Shiffer, PG\&E, "Issuance of Amendment (TAC No. 66541)," November 18, 1987.

Letter from H. B. Tucker, Duke Power Co., to E. G. Adensam, NRC, "Technical Specification Amendment for Containment Ice Condenser," July 12, 1985.

Letter from H. B. Tucker, Duke Power Co., to H. R. Denton, NRC, "Technical Specification Amendment, November 17, 1986.

Letter from H. B. Tucker, Duke Power Co., to NRC, "Diesel Generator Surveillance 4.8.1.1.2g.7," February 15, 1988.

Westinghouse Electric Corp., "Evaluation of Surveillance Frequencies and Out-of-Service Times for the Reactor Protection Instrumentation System," WCAP-10271, January 1983.
WCAP-10271

(Suppl. 1)

WCAP-10271

(Suppl. 2)

WCAP-11736

Woody, 1987
Westinghouse Electric Corp., "Evaluation of Surveillance Frequencies and Out-of-Service Times for the Reactor Protection Instrumentation System," WCAP-10271 (Supplement 1), July 1983.

Westinghouse Electric Corp., "Evaluation of Surveillance Frequencies and Out-of-Service Times for the Engineered Safety Features Actuation System," WCAP-10271 (Supplement 2), Revision 1, March 1987.

Westinghouse Electric Corp., "Probabilistic Evaluation of Reduction in Turbine Valve, Test Frequency," WCAP-11525, June 1987.

Westinghouse Electric Corp., "RHR System Auto Closure Interlock Removal Report for the Westinghouse Owners Group," WCAP-11736, February 1988.

Letter from C. O. Woody, Florida Power and Light Co., to Document Control Desk, NRC, "Special Test Exceptions Shutdown Margin," August 17, 1987. 



\section{APPENDIX}

\section{ROUTINE INSPECTIONS (SURVEILLANCE TESTING) AT JAPANESE POWER PLANTS*}

"Source: NUREG/CR-3833. 
Appendix

Table 1 PWR surveillance tests under normal operation

\begin{tabular}{lll}
\hline Items and test & Frequency & Description \\
\hline $\begin{array}{l}\text { Diesel Generator } \\
\text { - Manual starting }\end{array}$ & Once/month & $\begin{array}{l}\text { Start and manually load the diesel generator } \\
\text { from the central control room to obtain } \\
\text { operating data, including measurement of time } \\
\text { to come up to speed. }\end{array}$ \\
Control Rod Drive Mechanism & Twice/month & $\begin{array}{l}15-20 \text { step insertion and pull-out for all banks } \\
\text { (except control group banks) used in reactor } \\
\text { control. }\end{array}$
\end{tabular}

Safety Injection System

- Manual starting of high-pressure Once/month

Checking of pump operation manually starting injection pump

- Operation of motor-operated Once/month valve

Residual Heat Removal System

Once/month from control room.

Checking of valve operation by manually opening/closing from the control room.

Checking of pump operation by manually starting from the control room.

Containment Spray System

- Manual starting of pump

Once/month

Checking of pump operation by manually starting from the control room.

- Operation of motor-operated Once/month valve

Checking of valve operation by manually opening/closing from the control room.

Heating and Ventilation System

- Manual starting of ventilation fan Once/month for containment vessel

- Manual starting of emergency Once/month

Checking of fan operation by manually starting from the control room.

filter fan for the control room

Checking of fan and damper operation by manually starting from the control room. 
Table 2 BWR surveillance conducted during normal operation

\section{Items and test}

Diesel Generator

- Manual starting

Once/month

Once/week

Control Rod Drive System

- One-notch test

Once/week

Reactor Protection System

- Functional test of average power range

Once/week

Once/month

- Manual scram test

Once/month

Once/month

Once/month

Once/week

- Volume and temperature of poison

Reactor Core Spray System

- Manual starting of pump

Once/month

- Manual operation of motor valve

Once/month

Once/month

\section{Description}

Start and manually load the diesel generator from the control room to obtain operating data including measurement of time to come up to speed.

Withdraw and insert all the control rods by one notch.

Confirm the function of average power range monitor with signals of malfunction and high neutron flux.

Push the manual scram button on one side in the main control room and confirm the scram signal of the channel on the same side.

Start the system manually and confirm the normal movement of auto valves and the normal function of the system.

Confirm the normal movement of the pump and the normal function of the system.

Sample and confirm density in the prescribed range.

Confirm volume and temperature of poison in the prescribed range.

Start the pump manually from the main control room and confirm normal function of the pump.

Open and close the motor valve manually from the main control room and confirm normal movement of the valve.

Start the pump manually from the main control room and confirm normal function of the pump. 
Table 2 (Continued)

Items and test
Reactor Auxiliary Cooling Water System
- Manual starting of pump

Once/month

High-Pressure Coolant Injection System

- Manual starting of pump

Once/month

- Manual operation of motor valve

Once/month

Once/week

Once/3 months
Description

Start the pump manually from the main control room and confirm normal function of the pump.

Start the pump manually from the main control room and confirm normal function of the pump.

Open and close motor valve manually from the control room and confirm normal involvement of the valve.

Close MSIV manually to $90 \%$ opened position and confirm normal movement of the valve.

Close MSIV manually at $<60 \%$ power and measure its full stroke time. 


\begin{tabular}{|c|c|}
\hline $\begin{array}{l}\text { U.S. NUCLEAR REGULATORY COMMISSION } \\
\text { BIBLIOGRAPHIC DATA SHEET } \\
\text { (See instructions on the reverse) }\end{array}$ & $\begin{array}{l}\text { 1. REPORT NUMBER } \\
\text { (Assigned by NRC, Add Vol.' } \\
\text { Supp., Rev., and Addendum 'Num- } \\
\text { bers, if any.) } \\
\text { NUREG-1366 }\end{array}$ \\
\hline \multicolumn{2}{|l|}{ 2. TITLE AND SUBTITLE } \\
\hline \multirow[t]{2}{*}{ Improvements to Technical Specifications Surveillance Requirements } & \begin{tabular}{c|c} 
MONTH & YEAR \\
December & 1992
\end{tabular} \\
\hline & $\begin{array}{l}\text { 4. FIN OR GRANT NUMBER } \\
\text { N/A }\end{array}$ \\
\hline \multirow[t]{2}{*}{ R. Lobel, T. R. Tjader } & $\begin{array}{l}\text { 6. TYPE OF REPORT } \\
\text { Final Topical }\end{array}$ \\
\hline & $\begin{array}{l}\text { 7. PERIOD COVERED (Inclusive Dates) } \\
\text { N/A }\end{array}$ \\
\hline
\end{tabular}

Division of Operational Events Assessment

Office of Nuclear Reactor Regulation

U.S. Nuclear Regulatory Commission

Washington, DC 20555

9. SPONSORING ORGANIZATION - NAME AND ADDRESS (If NRC, type "Same as above"; if contractor, provide NRC Division, Office or Region, U.S. Nuclear Regulatory Commission, and mailing address.)

Same as above

10. SUPPLEMENTARY NOTES

Report Completion Date: May 1992

11. ABSTRACT (200 words or less)

In August 1983 an NRC task group was formed to investigate problems with surveillance testing required by Technical Specifications, and to recommend approaches to effect improvements. NUREG-1024 ("Technical Specifications-Enhancing Safety Impact") resulted, and it contained recommendations to review the basis for test frequencies; to ensure that the tests promote safety and do not degrade equipment; and to review surveillance tests so that they do not unnecessarily burden personnel.

The Technical Specifications Improvement Program (TSIP) was established in December 1984 to provide the framework for rewriting and improving the Technical Specifications. As an element of the TSIP, all Technical Specifications surveillance requirements were comprehensively examined as recommended in NUREG-1024. The results of that effort are presented in this report. The study found that while some testing at power is essential, safety can be improved, equipment degradation decreased, and unnecessary personnel burden relaxed by reducing the amount of testing at power.

12. KEY WORDS/DESCRIPTORS (List words or phrases that will assist researchers in locating the report.)

Reactor Plant Technical Specifications

Surveillance Tests Safety Enhancement

\begin{tabular}{l} 
13. AVALABILITY STATEMENT \\
Unlimited \\
\hline 14. SECURITY CLASSIFICATION \\
(This Page) \\
Unclassified \\
\hline (This Report) \\
Unclassified \\
\hline 15. NUMBER OF PAGES \\
\hline 16. PRICE \\
\hline
\end{tabular}

